Portland State University

PDXScholar

Fall 1-1-2012

\title{
Oral Health Knowledge, Attitudes, and Behaviors: Investigation of an Educational Intervention Strategy with At-Risk Females
}

Susan Romano Rustvold

Portland State University

Follow this and additional works at: https://pdxscholar.library.pdx.edu/open_access_etds

Part of the Dental Public Health and Education Commons, Substance Abuse and Addiction Commons, and the Women's Health Commons

Let us know how access to this document benefits you.

\section{Recommended Citation}

Rustvold, Susan Romano, "Oral Health Knowledge, Attitudes, and Behaviors: Investigation of an Educational Intervention Strategy with At-Risk Females" (2012). Dissertations and Theses. Paper 612. https://doi.org/10.15760/etd.612

This Dissertation is brought to you for free and open access. It has been accepted for inclusion in Dissertations and Theses by an authorized administrator of PDXScholar. Please contact us if we can make this document more accessible: pdxscholar@pdx.edu. 
Oral Health Knowledge, Attitudes, and Behaviors: Investigation of an Educational Intervention Strategy with At-Risk Females

by

Susan Romano Rustvold

A dissertation submitted in partial fulfillment of the requirements for the degree of

\title{
Doctor of Education
}

in

Educational Leadership: Postsecondary Education

\author{
Dissertation Committee: \\ Christine Cress, Chair \\ Janine Allen \\ Karen Haley \\ Andrew P. Job \\ Leslie G. McBride
}

Portland State University

2012 
(C) 2012 Susan Romano Rustvold 


\begin{abstract}
A self-perpetuating cycle of poor health literacy and poor oral health knowledge and behavior affects approximately 90 million people in the United States, most especially those from low-income groups and other at-risk populations such as those with addiction. Poor oral health can result from lack of access to regular preventive dental appointments, lack of access to restorative care when dental diseases are treatable, and low oral health knowledge that leads to poor oral health self-care behaviors. In addition, patients' dental anxiety can impede care, because highly anxious people often avoid dental appointments. To address these issues, this inquiry examined oral health knowledge, attitudes toward oral health, and levels of dental anxiety among women in two residential chemical dependency treatment programs. Participants engaged in oral health intervention sessions to determine possible efficacy of the educational intervention. Results indicate positive outcomes in increases in oral health knowledge and behavior. The frequency of high-to-severe dental anxiety is much higher in this sample than in the general population. Implications are discussed, including use of economically efficient small-group oral health education training.
\end{abstract}




\section{Table of Contents}

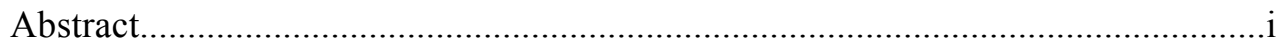

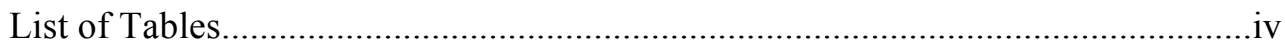

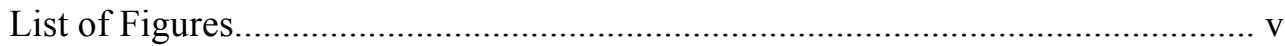

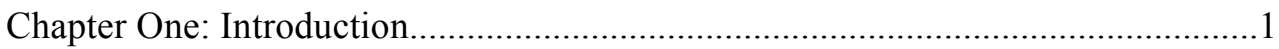

Overview of the Problem.................................................................................... 1

Interrelated Issues of Literacy, Health Literacy, and Oral Health Knowledge:

Why Do Oral Health Literacy and Oral Health Matter?.........................................

General Literacy and Health Literacy ..................................................... 3

Cultural Capital and Health Literacy ....................................................... 5

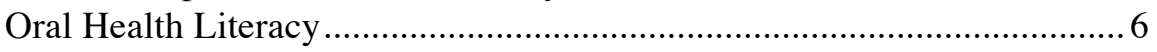

Dental Anxiety As It Relates to Oral Health Literacy.................................... 9

Purposes and Significance of the study.........................................................11

Chapter Two: Conceptual Framework and Literature Review............................. 14

Introduction: Adaptive Challenges in Oral Health .......................................... 14

Teaching and Learning: Relational Systems ................................................ 16

Individual Learner as an Open System: The Student ................................. 16

Doctor and Patient as Learning System .................................................... 17

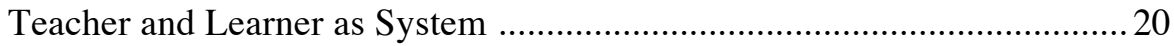

Gender and Culturally Responsive Learning.................................................. 24

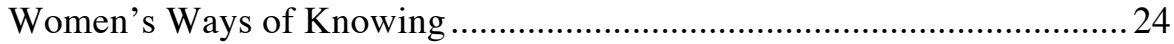

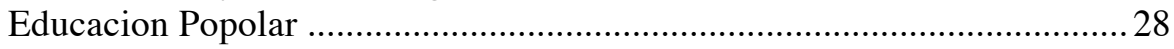

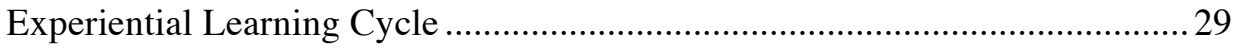

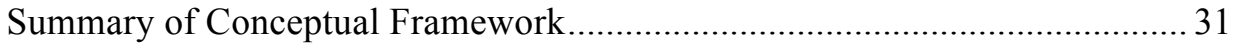

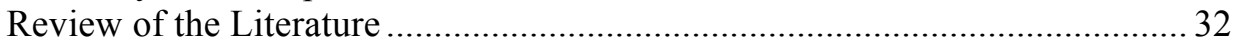

Oral Health Literacy and At-Risk Women ................................................ 32

Dental Anxiety as a Complicating Factor to Dental

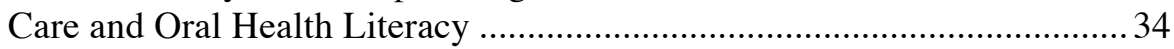

Health Beliefs: Challenging Beliefs to Improve Health Behaviors ............ 36

Models of Health Beliefs and Health Behaviors .......................................... 38

Small Group Medical Appointments ...................................................... 43

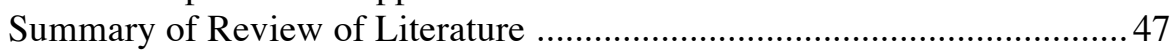

Chapter Three: Research Design and Methodology.............................................49

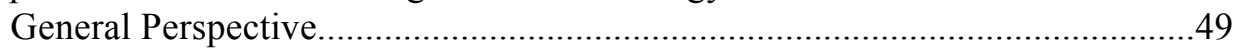

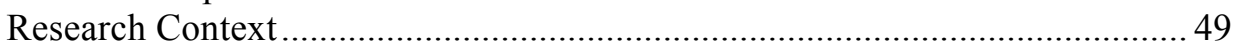

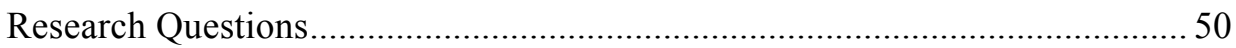

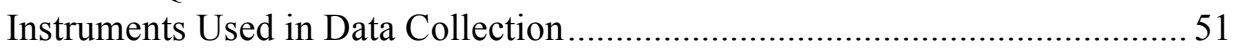

Research Question 1: Assessing Dental Anxiety ...................................... 51

Research Question 2: Measuring Oral Health Knowledge .......................... 54

Research Question 3: Measuring Attitudes Toward Oral Health ................ 57

Research Question 4: Further Dialogue Among Study Participants........... 60

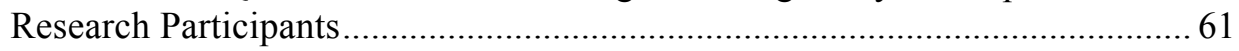

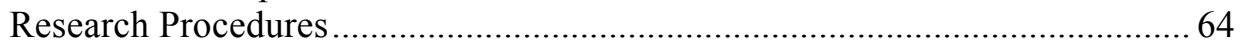




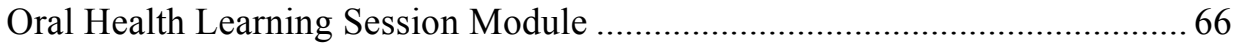

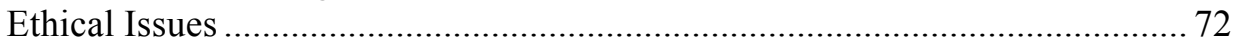

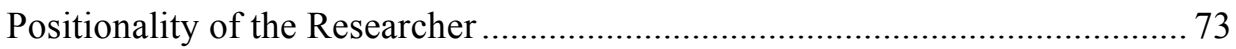

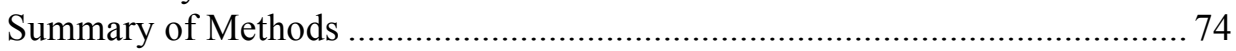

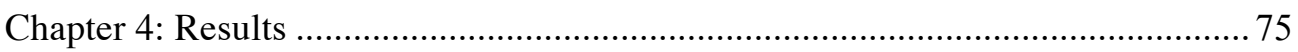

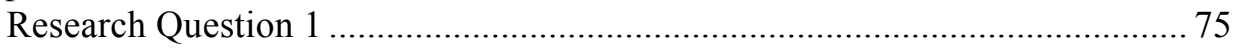

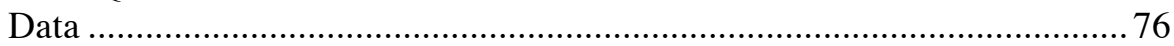

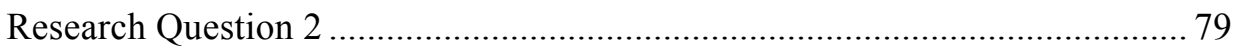

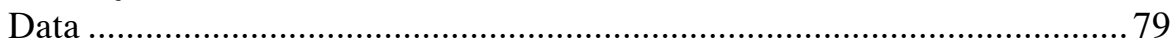

ROHKI Comparison of Mean Cumulative Scores ……….......................... 82

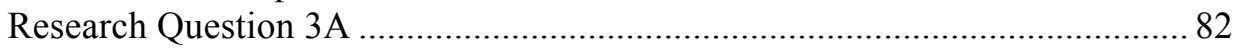

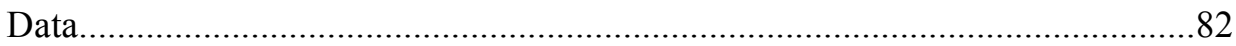

OHAQ Comparison of Mean Cumulative Scores, items 1-14 …............... 86

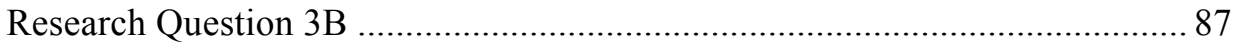

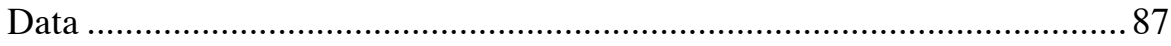

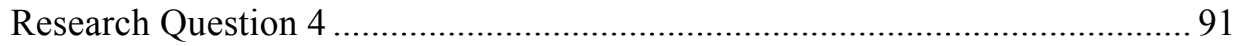

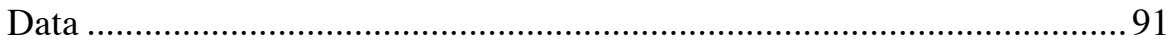

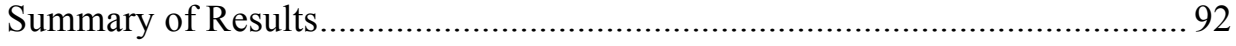

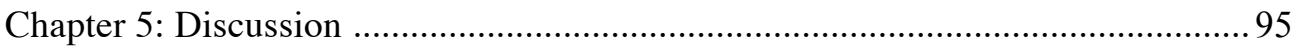

Dental Anxiety as a Significant Contributing Factor ...................................... 95

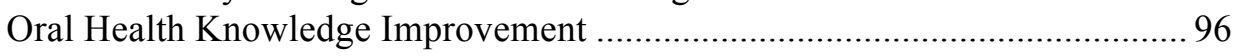

Improvement in Oral Health Attitudes and Behaviors ................................... 100

Lasting Benefits of Oral Health Education ..................................................... 102

Efficacy of Small Group Health Appointments and Oral Health Education. 103

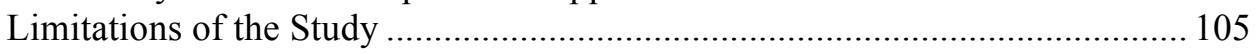

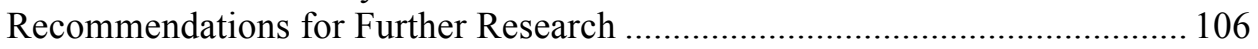

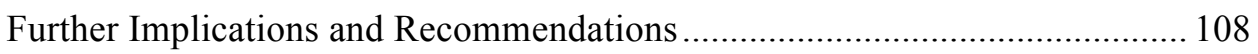

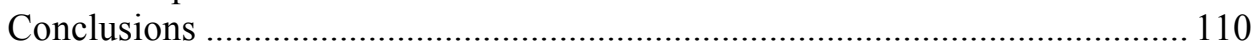

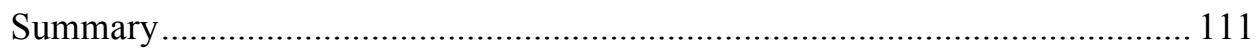

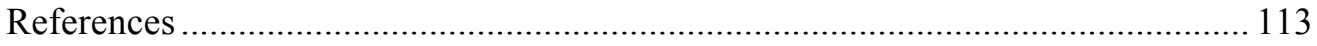

Appendices

Appendix A: Modified Dental Anxiety Scale (MDAS) .................................. 121

Appendix B: Rustvold Oral Health Knowledge Inventory (ROHKI) ............... 122

Appendix C: Oral Health Attitudes Questionnaire (OHAQ)........................... 124

Appendix D: Oral Health Learning Session Module....................................... 126

Appendix E: Informed Consent .................................................................. 138 


\section{List of Tables}

1. Comparison of Control- and Relationship-Based Personal Philosophies .. 19

2. Comparison of Teacher-Centered and Learner-Centered Models ..............22

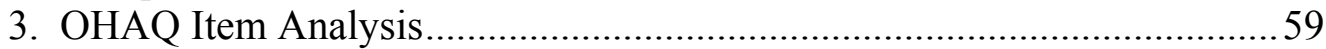

4. Demographic Characteristics of Participants ..........................................6 63

5. MDAS Category Frequency Distribution ............................................. 76

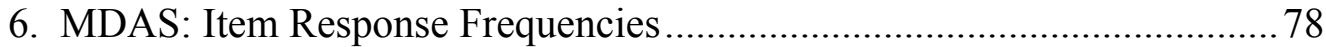

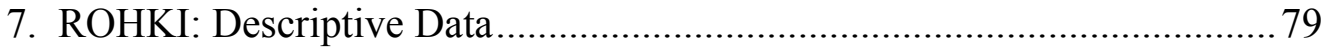

8. ROHKI Item 3: Does fluoride in toothpaste make any difference to the health of your teeth? .............................................................. 80

9. ROHKI Item 6: If you want to enjoy a sugary treat, when is the most "tooth-friendly" time to eat it? .............................................................. 81

10. ROHKI Item 8: Frequencies of Responses: Research studies have shown a link between periodontal (gum) disease and which of the following?

11. Comparison of Mean Cumulative ROHKI Scores ................................. 82

12. Oral Health Attitudes Questionnaire: Frequencies, Items 1-14 ................83

13. OHAQ Item 15: How often do you brush your teeth?........................... 87

14. OHAQ Item 16: How often do you clean between your teeth (by dental floss, tooth pick or inter-dental brush)? ............................................ 89

15. OHAQ Item 17: How often do you visit a dentist ..................................89

16. OHAQ Item 18: I plan to visit the dentist ............................................ 90

17. OHAQ Item 19: Do you smoke cigarettes or use another form of tobacco?

18. OHAQ Item 20: Have you ever used alcohol or other drugs to calm you to help you go to a dental appointment

19. OHAQ Item 21: Much learning occurs outside the classroom.

Please indicate which statement best fits your experience 


\section{List of Figures}

Figure 1. Theory of Planned Behavior

Figure 2. MDAS Anxiety Category Frequency Distribution........................ 77

Figure 3. OHAQ Item 15: How often do you brush your teeth? .....................88 
Chapter One: Introduction

\section{Overview of the Problem}

There is an almost invisible epidemic in the United States of dismal oral health that has implications for both individuals and society. While tooth decay rates are declining overall in the United States and more people are maintaining their teeth for a lifetime, low-income Americans have decay rates of twice those of the average American (Berry, 2005; Empey \& Bradley, 2007). Poor oral health increases the progression of lifethreatening systemic disease for individuals (Kim et al., 2007). Poor oral health results in increased public and private health care costs due to increased urgent care appointments and increased morbidity. Poor oral health results from several factors, including lack of access to regular preventive dental appointments, lack of access to restorative care when dental diseases are treatable, low general health literacy, and inadequate knowledge of principles of oral health (American Dental Association, 2010).

\section{Interrelated Issues of Literacy, Health Literacy, and Oral Health Knowledge: Why Do Oral Health Literacy and Oral Health Matter?}

Oral health is a mirror for general health and well-being, says former U.S.

Surgeon General Dr. Richard Carmona in the U.S. Surgeon General's first report on oral health (NIDCR, 2000). Oral health means more than healthy teeth; in addition, the health of the periodontium — the bone and soft tissues supporting the teeth—is integral to general health (NIDCR, 2000; Harris \& Garcia-Godoy, 2004). It is not possible to be healthy without oral health.

Threats to oral health include dental decay and diseases of the tissues surrounding the teeth, the periodontium (Latin for "that which is around the teeth"). The periodontal 
tissues include gingiva (gums), fibers that attach teeth to bone (periodontal ligament), and the alveolar bone.

Periodontal diseases are a continuum of chronic and progressive conditions that begin as bacterial and immune-system-mediated inflammation of the gingiva (gingivitis) and may spread to the periodontal ligament and alveolar bone (periodontitis), with resulting destruction of the bone that supports teeth (Harris \& Garcia-Godoy, 2004). The chronic inflammation yields systemic effects, in part due to C-reactive protein, which is one factor present in tissue and blood in both periodontal diseases and systemic disorders. Periodontal diseases have been shown to be a cofactor or contributing factor to systemic conditions including diabetes mellitus, coronary artery disease, and arteriosclerosis (Kim et al., 2007). Periodontal diseases in pregnant women also have been implicated in the incidence of preterm low-birth-weight babies (Wayne, Trajtenberg, \& Hyman, 2001). Thus, poor oral health poses significant and potentially severe threats to general morbidity and life-threatening illnesses. The effects of oral diseases are cumulative; the mouth does not heal decay or periodontal diseases without professional hands-on intervention. Because poor oral health decreases systemic health, it affects job and school performance and, hence, the economic well-being of the individual, community, and nation (DePaola, 1998).

To keep one's mouth in good health requires maintaining a balance among the normal bacteria of the mouth, regularly removing toxins produced by these bacteria, providing appropriate nutrients to build health in all body systems, avoiding comestibles that detract from health rather than enhancing health (such as sugar-sweetened 
carbonated beverages), and avoiding pollutants to the system such as tobacco and its combustion byproducts. The oral hygiene practices of tooth brushing and flossing are a form of cultivation necessary for health.

There are concerns at the national level about our ability to fund health care for all Americans. The failure of individuals to prevent oral diseases affects both the individual's "ecology," or homeostasis, and the ability of the health care system to provide treatment for these individuals who are at increased risk for serious systemic diseases. The economic sustainability of our national system of health services is jeopardized by a great number of people lacking a health promotion perspective.

One can ask, "Is this individual's health status sustainable given his degree of periodontal disease?" The answer is "no" for individuals with poor oral health who are

likely to need more extensive and expensive dental restorative treatment as well as more systemic health interventions to treat persistent diseases that are preventable or can be mitigated by improved periodontal health.

\section{General Literacy and Health Literacy}

Functional health literacy - the ability to read and comprehend prescription bottles, appointment slips, and the other essential health-related materials required to successfully function as a patient-constitutes a subset of general literacy. Health literacy encompasses other skills such as writing, listening, numeracy, oral communication, and the ability to navigate the health system (Horowitz \& Kleinman, 2008). An individual's functional health literacy may be significantly lower than the individual's general literacy, because functional literacy is context specific (NCES, 2003). Low literacy and, 
thus, low health literacy affect an estimated 90 million people in the United States, including 42 million American adults who can't read at all and 50 million American adults who are unable to read at a level that is expected of a fourth- or fifth-grader (Bertness \& Holt, 2004; Keenan, 2004). Low literacy is associated with several adverse health outcomes, including low health knowledge, increased incidence of chronic illness, and less than optimal use of preventive health services (Weiss et al., 2004). People with low general literacy who live in poverty exhibit characteristics of a culture of oral communication and are not likely to seek information via written materials such as brochures (Beegle, 2003). Literature indicates that socioeconomic classes differ in the type of health beliefs held and that lower socioeconomic classes are not as prone to practice the sorts of health promotion behaviors embraced by members of the middle and upper classes (Beegle, 2003; Rosenstock, 1974).

Health literacy is shown to correlate with overall literacy and with high school completion, the rates of which are lower among those living in poverty and among incarcerated persons (NCES, 2003). Carmona has stated that the incarcerated population is in dynamic equilibrium with the welfare population; thus statistics available regarding prison populations can be seen as representative of the lower socioeconomic levels in general (Institute of Medicine, 2000). While in the general population the rate of high school noncompletion averaged approximately 25 percent (NCES, 2012), fully $79 \%$ of prison inmates in Oregon have not completed high school (Duin, 2004). Basic literacy is necessary for the development of adequate general health literacy.

Low health literacy costs the U.S. health care system between $\$ 58$ billion and $\$ 73$ 
billion each year (Bertness \& Holt, 2004). People with low health literacy incur increased use of emergency health services for issues that could be prevented, resulting in tremendous strain on the U.S. health system (Freudenberg, 2002).

\section{Cultural Capital and Health Literacy}

The concept of cultural capital has recently been expanded to include attitudes toward health and interactions with the health care system. Culture-related factors such as normative beliefs, knowledge, and behaviors interact with economic and social factors in the structuring of people's health chances and choices (Beegle, 2003). People with low socioeconomic status and underrepresented ethnic groups, such as Native American Indians, African Americans, and Hispanics, have the highest incidence of caries (tooth decay) and are more likely to have poor access to dental care (U.S. Department of Health and Human Services, 2000). Failure to acknowledge and analyze the values, norms, and paradigmatic assumptions that determine an individual's or a group's responses to environmental change allows perpetuation of organizational inequalities and inequities pertaining to gender, race, class, and sexuality (Brookfield, 1995; Creedon, 1993). It is not possible to change health behaviors or have health information be adopted unless the system of assumptions that constitutes an individual's health beliefs is challenged and revolutionized.

It is not a simple endeavor for an individual to take action on health promotion behaviors. Information is not enough. Health promotion behaviors require a sense of selfefficacy and health beliefs including an appreciation of cultivation, care, and consequences rather than chance. 
If the individual is ignorant of health principles and health promotion concepts and lacks critical thinking skills, he or she is unlikely to adopt health behaviors. Thus, information alone is insufficient to change health literacy and health behaviors. Beliefs and values must be identified and challenged. Providing increased access to care without at the same time identifying and challenging beliefs and values will not immediately transform those with low health literacy into proactive practitioners of health promotion behaviors. As Engstrom and Tinto (2008) noted with respect to student retention in higher education, "access without support is not meaningful opportunity" (p. 21). In a parallel manner, improving health literacy and health behaviors will require the support consisting of sustained structured intervention to identify, challenge, and change health beliefs. Glick (2009) comments that what appears to policy makers to be an issue of access to care (i.e., geographic distribution of health providers), is perhaps from the patient perspective a utilization issue - that is, lack of attendance at dental appointments due to lack of funds, transportation, or time off work. In addition, based on my work with incarcerated women and low-income people seen in the Medical Teams International (MTI) free mobile dental clinics, I speculate that high levels of dental anxiety and low levels or oral health knowledge exist in this population.

\section{Oral Health Literacy}

As health literacy is seen within the umbrella of general literacy, oral health literacy is a subset of general health literacy. Health literacy represents an ecological orientation to health and health behaviors - sustainability on the personal level. This is a broad approach that considers patterns as well as details, the relationships among "forest" 
and "trees," and relationships among actions and consequences.

Health literacy in dentistry is "the degree to which individuals have the capacity to obtain, process, and understand basic health information and services needed to make appropriate oral health decisions" (Horowitz \& Kleinman, 2008, p. 334). Because my interest in this study does not involve issues of access to services, I consider here a subset of health literacy in dentistry — that is, oral health knowledge. Oral health knowledge includes an understanding of the combined effects of normal oral bacteria; fermentable carbohydrates in the diet; daily personal oral health care practices (including brushing and flossing); the effects of tobacco, alcohol, and other drugs on oral health; and the importance of regular consultation with dentists and dental hygienists to maintain health and to find and address pathology in its early stages, when it is most treatable (Friedlander, Marder, Pisegna, \& Yagiela, 2003).

Oral health is seen from a health perspective as a balance between destructive factors such as sugar-rich diet, tobacco use, and poor oral hygiene versus protective factors including good oral hygiene and the application of fluoride, whether in toothpaste, rinses or varnishes, or in community drinking water (Sgan-Cohen \& Mann, 2007).

As a dental professional, I have encountered a wide discrepancy between the health beliefs of health care providers and the health beliefs among the populations living in poverty, including the homeless, many prison inmates, and people in chemical substance abuse recovery programs. My sense from conversations with these populations, many of whose families of origin are from lower socioeconomic groups, is that many believe that decay "just inevitably happens" and that oral health is the result of access to 
lots of fillings. Dentists' perspective, in contrast, is that oral health arises from the daily choices and disciplines of nutrition and oral hygiene and other habits. It is not possible for the public health system in the United States or in any area of the world to keep up with treatment of the decay rate in populations that do not take basic care of their own teeth (Treadwell \& Formicola, 2005). The populations most likely to have poor access to oral health care tend to be the same as those with low health literacy: underrepresented minorities, the working poor, and lower socioeconomic groups (DePaola, 1998). Yet even when access is improved, as in the Oregon Health Plan dental coverage for children, unless the parent has a health belief system that includes the importance of preventive health services, the pattern of access only in situations requiring urgent care continues (Treadwell \& Formicola, 2005). Urgent care appointments for treatment of acute oral pain do not tend to allow the dialogue that might foster improved oral health literacy and improved oral health behaviors.

Lack of oral health literacy manifests itself in grossly poor oral health. Incarcerated people provide a convenient group in which to study trends thought to exist in the lower socioeconomic groups in general (NIDCR, 2000). In a study of incarcerated women ages 18 to 64 , almost half of their tooth surfaces showed signs of decay, and more than 65 percent of the women exhibited clinical signs of destructive periodontal disease (Office of Women's Health Research, 1999). Another study found the prevalence of severely decayed teeth 14 times greater in incarcerated women than in the general population (Jones, McCann, \& Nugent, 2002). The level of oral disease present in 
incarcerated women reflects more than simply a lack of access to treatment prior to incarceration. It represents inadequate oral health literacy.

There is a self-perpetuating cycle from generation to generation of poor general literacy, poor health literacy, and poor oral health literacy. Those people caught in the cycle incur increased use of health services for issues that could be prevented, resulting in tremendous strain on the U.S. health system (Freudenberg, 2002; NIDCR, 2000).

Oral health and oral health education can and must be improved in order to establish individuals' preventive dental care patterns (Patton, Strauss, McKaig, Porter, \& Eron, 2003). Because women are primary caretakers of children, implementing dental education among women living in poverty has the potential to affect not only women themselves but also their children and communities at large (Bertness \& Holt, 2004). However, constraints on progress in the realm of oral health literacy with this population include the assumptions and methods of traditional dental treatment access, whether in private dental offices or public health clinics; personal and public health finance; individuals' health beliefs; and severe dental anxiety (Martino, 2011).

\section{Dental Anxiety as It Relates to Oral Health Literacy}

Articles in the dental literature generally attribute dental anxiety to such factors as traumatic dental experiences, especially in childhood, negative family attitudes toward dentistry (which has been associated with lower socioeconomic background), traumatic facial injuries, and fear of disapproval by the dentist (Ayers, 2005). Recent articles have begun to look at the contribution of histories of physical and/or sexual abuse on the development of dental anxiety (Friedlander, Friedlander, \& Marder, 2004; Gibson- 
Howell, 1996; Hays \& Stanley, 1997; Settineri, Tati, \& Fanara, 2005; Stalker, Russell, Teram, \& Schacter, 2005; Walker, Milgrom, Weinstein, Getz, \& Richardson, 1996). Estimates range from $15 \%$ to $25 \%$ of the general U.S. population who experience a high level of anxiety with respect to dental appointments and dental treatment (Abrahamsson, Berggren, Hakeberg, \& Carlsson, 2001; Corah, 1988; Ronis, 1994; Todd \& Lader, 1991). In addition to keeping the person away from regular preventive care and delaying treatment of dental problems (Abrahamsson et al., 2001), this anxiety interferes with the development of oral health knowledge - the very knowledge of effective daily oral hygiene, nutrition, and other factors that can minimize the progression dental diseases, promote oral and systemic health, and prevent the need for traumatic emergency dental appointments.

People who are highly anxious in the dental setting are more difficult for dentists to treat (Moore \& Brodsgaard, 2001). It is estimated that providing care requires $20 \%$ more time for highly anxious patients than for treating nonanxious people (Filewich, Jackson, \& Shore, 1981).

A further complication of unmanaged dental anxiety is the potential for triggering relapse in chemical dependency recovery, as anxious patients may use their substances to medicate their pain, bolster their courage, or calm themselves to visit the dentist when it becomes imperative that they access care (Bolton, Cox, Clara, \& Sareen, 2006; Bullock, 1999; Crossley, 1996; Jones, Knutson, \& Haines, 2003; Sainsbury, 1999). People with histories of physical or sexual abuse, in addition to likely having high levels of dental anxiety, are likely to abuse chemical substances (Dube et al., 2003). Thus, identifying and 
addressing dental anxiety must become an important component of chemical dependency treatment.

As a dental health professional and educator, I have developed compelling interest in intervening in this cycle of poor oral health, inadequate access to care, low oral health literacy, and dental anxiety. I believe that improving oral health knowledge, one component of oral health literacy, is the key to intervening in this cycle. But where do we start to change the system of attitudes, beliefs, and the limited knowledge that perpetuate low oral health literacy and poor oral health? Lecturing, admonishing, informing, and shaming are not effective. Unfortunately, these are the methods dentists and dental hygienists often employ to "motivate" their patients. If patients are so anxious as to avoid the dental office in the first place, they are not likely to be exposed to the elements of optimum self-care and to professional health promotion measures such as regular examinations and $\mathrm{x}$-rays, dental hygiene services, and restoring teeth when the decay is manageable (Abrahamsson et al., 2001).

\section{Purposes and Significance of the Study}

The purposes of this field-based study were to document the existing levels of dental anxiety, oral health knowledge, and attitudes toward oral health among a convenience sample of women in two residential chemical dependency treatment programs and to measure the effect of an educational intervention on measures of oral health knowledge and attitudes toward oral health.

The research questions posed are as follows:

1. Is the level of dental anxiety different from that observed in the general population? 
2. Does the oral health learning session have a measurable effect on the participants' oral health knowledge?

3. (a) Does participation in the oral health learning session have a measurable effect on the participants' self-reported beliefs and attitudes toward dental health and self-care?

(b) Are there measurable changes in self-reported oral health-related behaviors following the oral health learning session?

4. Is there discussion about oral health topics among the study population following the oral health learning session?

A profile of this study population was provided through administration of three self-completed written quantitative survey instruments: (a) Modified Dental Anxiety scale (MDAS), (b) Oral Health Attitudes Questionnaire (OHAQ), and (c) Rustvold Oral Health Knowledge Inventory (ROHKI).

These chemical dependency treatment programs are for low-income women, and thus the participants can be seen as generally representative of low-income populations with limited health care access and increased risk for multiple health problems (NIDCR, 2000).

The dependent variables were defined generally as oral health knowledge and self-reported oral health behaviors, beliefs, and attitudes toward oral health. An oral health educational intervention was presented and evaluated with the goal of informing processes in dental education and public health organizations to formally address these barriers to oral health literacy. The dental literature has presented the need for improving oral health literacy, with committees convening at the national level to investigate and make recommendations for improving oral health literacy (Horowitz \& Kleinman, 2008). More specifically, the development and testing of behavioral and social interventions to 
promote oral health is part of the National Institute of Dental and Craniofacial Research (NIDCR) strategic plan (NIDCR, 2009).

The dental literature currently acknowledges the complexity of the process of improving oral health knowledge, which involves social and behavioral factors such as family and cultural history, beliefs, motivations, and attitudes in addition to lack of information (Martino, 2011). The dental literature thus far does not address a factor essential for reaching the populations most in need of intervention in oral health knowledge and improvement of health behaviors: For the most part, the members of lowincome groups thought to have the lowest levels of oral health literacy are oriented more toward oral information than written information (Beegle, 2003). In addition, these individuals are not likely to appear regularly in private dental practices, so other arenas for reaching the population need to be developed (Logan, 2011). Thus, this study is a first step in potentially creating a new learner-centered dental health intervention model based on the conceptual and research studies and further informed by this inquiry.

The remainder of this dissertation will examine research and theoretical literature and detail methodological strategies designed to address research questions. A full presentation of the findings will be made, followed by discussion of the implications of the findings. 
Chapter Two: Conceptual Framework and Literature Review

\section{Introduction: Adaptive Challenges in Oral Health}

Poor oral health results in part from inadequate knowledge of principles of oral health (American Dental Association, 2010). To halt the pattern of high decay rates and costly hospital emergency room urgent care appointments associated with low income and poor oral health, methods must be established to reach low-income people both physically - that is, in locations where they are likely to congregate - and intellectually, incorporating methods other than written materials (Beegle, 2003; Empey \& Bradley, 2007).

To succeed in encouraging people to take action, dentists must recognize there are differences between technical problems and adaptive challenges. Ronald Heifetz differentiates between technical and adaptive challenges in the context of business and education, as cited in Parks (2005). Technical problems can be solved with established knowledge and procedures: If you share the information or give the roadmap, the action can be taken. Adaptive challenges, on the other hand, require innovation, new learning, and adoption of new patterns of behavior.

Information by itself is not sufficient to bring about change in behavior if this behavior requires that the individual go beyond familiar patterns, beliefs, and understanding. Adaptive challenges frequently comprise multiple systems of beliefs, knowledge, motivation, and behavior that do not lend themselves easily to technical analysis. Heifetz describes these complex adaptive challenges as "swamp issues" due to their complexity, murkiness, and difficulty to navigate (Parks, 2005). 
The dental profession in general has treated oral health literacy as a technical problem, coming from the stance that if we can learn better how to communicate with patients, then oral health disparities will lessen (DePaola, 1998). "You're leaving plaque by the gumline; you need to angle your brush more toward the gumline.” Then dentists grumble that patients do not follow through.

Oral hygiene instruction is only the tip of the iceberg of oral health literacy. For oral hygiene instruction to be successful in improving oral hygiene practices, the recipient of this instruction must already have an orientation toward health promotion behaviors. This orientation is undergirded by a health stance of internal locus of control; understanding of the oral environment and the rationale for cleaning teeth; and motivation to practice the tooth brushing, flossing, and other activities recommended (Harris \& Garcia-Godoy, 2004).

Substantive adaptive changes in oral health behaviors - in health behaviors in general-require an approach that considers the complex adaptive challenges of literacy, health beliefs, dental anxiety, access to care, and other factors. Adaptive changes in health behaviors require the individual to examine and challenge existing familiar understanding, beliefs, and patterns of behavior. These challenges require the transformation of deeply held assumptions and long-standing habits (Parks, 2005). Robertson (1996) summarizes the work of several education theorists describing teaching as an educational helping relationship that promotes transformative learning. In this educational helping relationship, educators facilitate learning rather than disseminating knowledge. 
When I taught dental students, I suggested from my experience that reasons people avoid dental appointments fell into four main groups: (a) finances, (b) fear or dental anxiety based on previous bad experience, (c) an attitude of "if it ain't broke, don't fix it, and (d)) the space-time continuum (time away from work, transportation, childcare, and other complicating factors). An American Dental Association survey (American Dental Association, 2008) lists the first three of these factors - finances, fear, and a reactive approach-each constituting $25 \%$ to $35 \%$ of responses. The fourth is evidenced by the continuing need for school-based emergency dental clinics even though all children in Oregon have access to medical and dental insurance coverage. To attend a regular dental clinic, parents would have to take time from work to accompany their children. If the parents lack a perspective of health promotion and prevention of disease, then they are not likely to take their children unless there is an emergency, and in too many cases, not even then — hence the need for the school-based emergency clinics (Empey \& Bradley, 2007). These four rationales combine in a cycle that keep their adherents from accessing care proactively and from learning oral health literacy from dentists and dental hygienists.

\section{Teaching and Learning: Relational Systems}

\section{Individual Learner as an Open System: The Student}

Each adult exists in a multisystem environment: self, family, workplace, community, and beyond (Moisey, 1984). The constructivist view of knowledge sees each adult learner interacting with this multisystem environment, taking in information by integrating it and using it (Airasian \& Walsh, 1997). The learner's worldview is 
continually enlarged to incorporate the new; this is a form of system self-organization. Each new challenge met is a kind of paradigm shift, which is not a smooth, comfortable process. New concepts bring cognitive dissonance-a gap between perceptions and expectations - that brings about a state of disequilibrium that can be confusing, frustrating, and disconcerting as well as exciting (Festinger, 1964). Learning and growth occur precisely in these necessary times of disequilibrium (Robertson, 1988; Wheatley, 1992). As the new component is incorporated into the learner's existing knowledge structure, coherence emerges, leading to a new stable state (Ennis, 1992).

\section{Doctor and Patient as Learning System}

The word "doctor" comes from the Latin doceo/doctum, which is "to teach." As dentistry in the United States has been transformed in the past 50 years to have a preventive focus, dentists are called upon to be teachers to their patients ever more explicitly than dentists in other cultures and times. Research in patient expectations and

desires for interaction with their dentists reveals that the interpersonal elements of caring and mentoring are foremost among patients' concerns (Stockinger-Moore, 1997). These include explanation of treatment, demonstrating respect for patients, fostering trust, and fostering patient acceptance and ownership of condition (Blomster, 1997; Holt \& McHugh, 1997). These interactions, which many of us take for granted, are a major contributor to oral health literacy. This relational model of learner-centered doctorpatient interaction will be explored more fully below.

In medicine in the United States in recent years, a shift has been advocated in conceptualization of the doctor-patient relational system. The past model has been an 
authoritarian, hierarchical control differential between doctor and patient. A partnership system is now fostered (Feldman \& Christensen, 1997). This change does not mean business as usual with a few tweaks to the practice, but represents radical changes in how patients are viewed, how knowledge is represented and obtained, how disease processes are characterized, and how prescriptions and recommendations are developed and communicated (Feldman \& Christensen, 1997). Because so many health conditions are of a chronic nature - that is, manageable but not curable — there must be an ongoing relationship and process between physician and patient. These radical changes and relationship model represent a systems approach to chronic disease management.

The control-hierarchy and relational-system models are compared in Table 1 below. The control philosophy has predominated for centuries. It represents a hierarchal, rather than systems, approach. The control philosophy leads to seeking a single cause and cure for a malady, realized by an astute observing physician, perhaps using objective laboratory data, yielding a prescription to be followed without question by the patient in order to achieve a cure. This model developed during centuries in which acute infectious illness was a major cause of death and thus physicians' major focus. As catastrophic infectious illnesses have become preventable or curable, long-term chronic illnesses have come to occupy more of the physician-patient relationship. These diseases and syndromes, including diabetes mellitus, hypertension, tooth decay, and periodontal disease, require effective management and compliance by the patient with recommended courses of treatment and self-care. Management of chronic illnesses requires a system of 
health beliefs and a sense of self-efficacy on the part of patients that support their taking steps toward wellness (Becker, 1974; Mann, Gruskin, Grodin, \& Annas, 1999).

Table 1

Comparison of Control- and Relationship-Based Personal Philosophies

\begin{tabular}{|l|l|l|}
\hline & \multicolumn{1}{|c|}{ Control } & \multicolumn{1}{|c|}{ Relationship (I-Thou) } \\
\hline Phenomenon of interest & Thing in itself & Thing in context \\
\hline Knowledge strategy & $\begin{array}{l}\text { Reductionist } \\
\text { knowledge; linear } \\
\text { causality }\end{array}$ & $\begin{array}{l}\text { Emergent knowledge; systems } \\
\text { thinking }\end{array}$ \\
\hline Clinician's stance & Detached observer & Participant observer \\
\hline $\begin{array}{l}\text { Information deemed } \\
\text { relevant }\end{array}$ & Objective data only & Subjective and objective data \\
\hline $\begin{array}{l}\text { Model for patient- } \\
\text { clinician relationship }\end{array}$ & Hierarchy & Partnership \\
\hline Focus of attention & Outcome-oriented & Process-oriented \\
\hline
\end{tabular}

(Feldman \& Christensen, 1997, p. 54)

The relational-system philosophy is a learner-centered model. In contrast to the control-hierarchical model, the relational-system approach considers the person within a systems context. The presenting malady is viewed also in context, with an examination of the various factors, situations, and environments that may contribute to it. The clinician and patient collaborate in dialogue to flesh out the contributors to and ramifications of the disorder from the patient's subjective perspective as well as from the objective laboratory and clinical findings, and to develop ways of addressing it. In dentistry, one manifestation of this shift is a movement away from a "see the decay and fill it" mode to a systematic exploration of the person's health beliefs, nutritional awareness and diet, salivary buffering capacity, access to dental care, participatory ways of enhancing patient compliance with home care recommendations, and moving beyond mere compliance to internalization of those practices (Holt \& McHugh, 1997). 
The relational changes between control- and relationship-based philosophies presented by Feldman and Christensen (1997) constitute examples of infrasystem change, of radical change in institutional and individual values and in paradigmatic assumptions. The older, control-based infrasystem protects patterns of dominance, such as considering patients as diagnoses rather than as individuals and dictating treatment protocols in an authoritarian, paternalistic manner. These patterns of dominance render difficult the change from a control to a relationship model, requiring infrasystem root change in both individual and organization. Both health care provider and patient need to adopt the relational model for it to be successful. While the changes have evolved in theory and in doctoral education and are evident in a number of clinicians' practices, the shift has not been universal. I maintain that the requisite changes among patients' beliefs and practices for self-care in a chronic health condition require health providers first to change their orientation from an authoritarian to a helping relationship and avoid lecturing and shaming, so that patients will be more likely to take ownership of their chronic health conditions. To be effective, health care providers and insurers must have practice policies that support patient education and motivation. These interconnected goals require a systems approach, relational leadership, and a relational provider-patient model, which we are beginning to witness (Horowitz \& Kleinman, 2008).

\section{Teacher and Learner as System}

In a parallel with medicine, there has been a shift in education away from a hierarchical model of teacher-as-expert dispensing knowledge to passive students, who take the knowledge in and recall it on exams without question. Learner-centered or 
teacher-learner-centered schools and classrooms, in contrast, focus on students' interactions with meaningful content and processes, with each other, and with the teacher, who serves as a facilitator and fellow learner (Freire, 1974). This is a systems approach, involving recognition of the complexity, interrelatedness, and dynamic nature of the teaching and learning relationships and of the process of learning. Learner-centered education is based on constructivist principles of active participation, building on prior knowledge and experience, collaboration, and dialogue. If a dentist admonishes a patient to floss daily but does not find out whether the patient understands the role of bacteria on the teeth in the progression of periodontal disease, or does not allow the patient to report that floss shredding on rough fillings makes the process unpleasant, the dentist has in all likelihood failed to foster behavior change in the patient. That dentist has perpetuated an ineffective, presumptuous, unidirectional communication model. In contrast, engaging the patient in dialogue with respect to rationale for and necessity of flossing and uncovering barriers to that activity provide a productive, relational-systems approach to the task.

Many regard constructivism as a metatheory in that it encompasses a number of cognitive and other theories of learning (Bruner, 1996). In the learner-centered constructivist model, learning is an active process in which learners construct new ideas or concepts based on their current knowledge, within the cultural and social contexts in which ideas occur, and with other influences that mediate understanding (Windschitl, 1999). Intellectual transformations, including changes in attitudes and thought processes, undergo metamorphoses, along with subject content being learned. 
Small-group medical appointments have been developed in recent years to allow health providers to interact with patients in a thoughtful, methodical dialogue outside the necessary time constraints of medical appointments (Noffsinger, 2001). These smallgroup appointments resemble a classroom format in that perhaps a dozen patients meet with a health professional to address a particular health condition. In such a learnercentered group setting an individual is more likely to develop an understanding of the interrelationships among health promotion behaviors (nutrition, exercise, oral hygiene practices, etc.) and her well-being than she previously was.

The learner-centered model is outlined in Table 2. The learner may become motivated to put the recommendations into practice as she develops confidence that she can be successful. These are profound developmental changes representing cognitive, attitudinal, and motivational metamorphoses.

The learner-centered model, which parallels the physician-patient relationship model in medicine outlined in Table 1, is compared with the teacher-centered model in Table 2 below.

Table 2

Comparison of Teacher-Centered and Learner-Centered Models

\begin{tabular}{|l|l|l|}
\hline & $\begin{array}{l}\text { Teacher-Centered; Objectivist } \\
\text { Externalism; Empiricism; } \\
\text { Scientific Realism (p. 85) }\end{array}$ & $\begin{array}{l}\text { Learner-Centered; Constructivist } \\
\text { Internalism; Interpretivism; } \\
\text { Conceptual Idealism }\end{array}$ \\
\hline
\end{tabular}




\begin{tabular}{|c|c|c|}
\hline $\begin{array}{l}\text { Phenomenon of } \\
\text { interest }\end{array}$ & $\begin{array}{l}\text { Subject matter: } \\
\text { Reality exists independent of our } \\
\text { awareness; inquiry seeks to discover } \\
\text { and describe aspects of reality. }\end{array}$ & $\begin{array}{l}\text { Subject matter in context: } \\
\text { "Inquiries participate, through their } \\
\text { interpretive nature, in the } \\
\text { continuing process of constructing } \\
\text { and reconstructing reality as } \\
\text { perceived at a given time and place } \\
\text { (context)" (p. } 76)\end{array}$ \\
\hline $\begin{array}{l}\text { Knowledge } \\
\text { strategy } \\
\text { (epistemology) }\end{array}$ & $\begin{array}{l}\text { Reductionist knowledge; linear } \\
\text { causality } \\
\text { Scientific method } \\
\text { Knowledge, comprehension, and } \\
\text { application of rules to solve } \\
\text { problems } \\
\text { Results are viewed and evaluated in } \\
\text { terms of proper procedures, } \\
\text { including statistical procedures and } \\
\text { analysis. }\end{array}$ & $\begin{array}{l}\text { Emergent, constructed knowledge; } \\
\text { systems thinking } \\
\text { Qualitative approaches; } \\
\text { phenomenologic } \\
\text { Meaning may be shared by a } \\
\text { community. }\end{array}$ \\
\hline $\begin{array}{l}\text { Researcher/ } \\
\text { Teacher } \\
\text { stance }\end{array}$ & $\begin{array}{l}\text { Detached, expert } \\
\text { Subject-object dualism (p. 86) }\end{array}$ & $\begin{array}{l}\text { Participant: "Knower and process } \\
\text { of knowing cannot be separated } \\
\text { from what is or what can be } \\
\text { known" (p. 88) }\end{array}$ \\
\hline $\begin{array}{l}\text { Information } \\
\text { deemed relevant }\end{array}$ & $\begin{array}{l}\text { Objective data; discipline- or } \\
\text { department-based } \\
\text { "Subjectivity" implies observations } \\
\text { distorted by the values of the } \\
\text { observer, or failure to maintain a } \\
\text { proper and necessary detachment. }\end{array}$ & $\begin{array}{l}\text { Subjective and objective data; } \\
\text { integrated disciplines } \\
\text { Coherence theory as an alternative } \\
\text { to correspondence or correlation; a } \\
\text { statement is judged true if it is } \\
\text { connected to and consistent with } \\
\text { other statements in the system or } \\
\text { schema. }\end{array}$ \\
\hline $\begin{array}{l}\text { Model for } \\
\text { teacher-learner } \\
\text { relationship }\end{array}$ & Hierarchy & Collaborative \\
\hline $\begin{array}{l}\text { Focus of } \\
\text { attention }\end{array}$ & Outcome-oriented (exams) & Process-oriented (mastery) \\
\hline
\end{tabular}

Table based on Smith (1989).

According to the information in Tables 1 and 2, an attempt to provide healthrelated information effectively_-first elucidating existing beliefs, attitudes, and behaviors, then building on them in a way that enhances patient autonomy and sense of efficacy—requires a setting in which teacher/doctor and learner are equals, cocreators of knowledge. Oral health literacy is not a technical problem that can be solved with fragmented bits of information transmitted unidirectionally by an authoritarian health 
care provider. Oral health literacy constitutes an adaptive challenge in which a dialogic orientation to teaching and learning allows ways of learning, thinking, and being that engage participants collaboratively (Parks, 2005). The small-group medical appointment format has not yet been reported in the dental literature. With the small-group learnercentered oral health intervention module that I have created, I hope to establish the effectiveness of this format for developing knowledge, understanding, motivation, and improved oral health practices in at-risk women who participate.

\section{Gender and Culturally Responsive Learning}

\section{Women's Ways of Knowing}

The developmental theory of women described by Belenky, Clinchy, Goldberger, and Tarule (1997) posits five developmental stances, that is, ways of knowing and interacting with the world. These positions are silence, received knowledge, subjective knowledge, procedural knowledge, and constructed knowledge. The earliest developmental phase, referred to as silence, is described as the position in which a woman lacks a voice of her own and attends to and obeys the voices of external authorities. Next is received knowledge, with attention to multiple voices of other people, receiving and reproducing knowledge but not creating or constructing her own knowledge. Subjective knowledge follows: a woman discredits written materials and the voices of others and trusts only her own firsthand experience, conceiving knowledge as personal, private, and intuitive. Procedural knowledge comprises connected knowing and separate knowing. Connected knowers believe truth is grounded in firsthand experience and relationship, while separate knowers rely on reason when developing meaning and 
exclude emotions. A woman in the stance of procedural knowledge is invested in learning and in the application of learning to inform new knowledge. In constructed knowledge, a woman acknowledges that knowledge is contextual. She sees herself as a creator of knowledge, integrating her own opinions and sense of self with reason and input from the outside world. She values both subjective and objective strategies for knowing.

In the research that led to the book Women's Ways of Knowing, the women in the first position, silence, were among the youngest and were the most deprived with respect to social connection, economics, and education. Belenky et al. (1997) attribute the development of reflective, abstract thought and critical thinking to the sharing of oral and written forms of language between two persons who both participate fully in the speaking and listening, reading and writing. The individuals share, expand, and reflect on each other's experiences. This allows the individuals to enter into the "social and intellectual life of their community" (Belenky et al., 1997, p. 26). For women in the position of silence, this interchange has yet to occur.

Women in the position of received knowledge, the second developmental stance, learn by listening, regarding words as central to the process of knowing. What they hear or interpret is concrete and dualistic: right/wrong, good/bad. Their experience is that there exists only one right answer to each question and that contrary views automatically are wrong. This is analogous to William Perry's (1968) perspective of dualism. Women in the position of received knowledge are hesitant to speak in groups, believing that truth comes from others. Through conversations with peers, they gradually come to believe these peers share exactly the same thoughts and experiences. These relationships provide 
women with the experiences of mutuality, equality, and reciprocity that facilitate the development of the belief in their own capacities for learning.

In the third developmental position, subjective knowing, the "fountain of truth simply has shifted locale" (Belenky et al., 1997, p. 54). The woman continues to view truth as binary, dichotomous in being either right or wrong, but now she discounts external authorities (and books), and truth resides within her. Belenky et al. (1997) comment that progression to this position is not a given, and when and if it occurs, it is important in the development of self-protection, self-assertion, and self-definition. While some earlier researchers have described this shift as a central task of adolescence, Belenky et al. found many of the women they interviewed moved to this perspective after age 40 . They report that subjective knowers represented almost half of the 135 women they interviewed. Education itself did not play a major role in the move into subjectivism for the majority of the women interviewed. Education and educators of their childhood and teen years had seemed alienating and irrelevant to the lives of many of these women, and it was in many cases a crisis of trust in male authority that served as a catalyst for change. Belenky et al. found a pervasive theme of childhood and adolescent sexual trauma among the women in the subjective knowing group. They report that $38 \%$ of women in schools and college and $65 \%$ of women contacted through the social agencies told the researchers they had been subject to incest, rape, or sexual seduction by a male in authority over them. The sexual abuse statistics for women contacted through social agencies are close to the estimates for incarcerated women (66\%) (Lewis, 2006; Zlotnick, 
1997 ) and for women with chemical dependencies, approximately $64 \%$ of whom have been subject to sexual trauma (Dube et al., 2003).

Regarding the fourth developmental position, Belenky et al. (1997) discuss two varieties of procedural knowledge: connected and separate knowing. They use "understanding" to identify connected knowing (i.e., a relational acquaintance with an idea or concept). They characterize separate knowing as "knowledge," referring to analytical evaluation. They posit that separate knowing is an adversarial form, such as that involved in playing "devil's advocate," or critical discourse. Expertise in separate knowing is likened to "playing the academic game" (Belenky et al., 1997, p. 107). Belenky et al. state that in both types of procedural knowledge the form rather than the content of knowledge is of central importance. Separate knowers apply formal instruction to develop a perspective, as in an academic discipline. Connected knowers learn through empathy. It may be that non-Western cultures, having a more collectivist than individualist orientation, privilege connected knowing (Iyengar, 2010). Both pathways lead to a capacity to see the world through a lens other than their knower's subjectivity.

In a group setting, connected knowers engage in collaborative explorations, which work best when members have a shared history and know each other well. (Belenky et al., 1997). Belenky et al. (1997) compare connected knowing with Noddings's "care," in that the effort to extend one's understanding into positions that are different from one's accustomed perspectives requires both relationship and thought, that is, "generous thinking" and "receptive rationality" (Noddings, 1984). Belenky et al. speculate that connected knowers, because they have more connection with topics they seek to 
understand, may make the transition to constructed knowledge more easily than separate knowers (1997).

Constructed knowledge, the fifth developmental position (Belenky et al., 1997), concerns the integration of knowledge felt intuitively with knowledge learned from others. Belenky et al. (1997) consider this position to point to the basic tenets of constructivist thought: "All knowledge is constructed, and the knower is an intimate part of the known" (p. 137).

Belenky et al. (1997) point toward the need for awareness of and respect for diversity in ways of knowing and acknowledgement of how culture and social power differentials affect beliefs and relationship with "authorities" such as health providers. At the same time, encounters with marginalized women can be structured to foster development toward constructed knowledge.

\section{Educacion Popolar}

Educacion popolar/popular education (education of, by, and for the people) developed in South America out of the literacy training programs of Brazilian educator Paulo Freire (Wiggins, 2010). Small groups of individuals discussed basic problems they were experiencing. As the causes of their problems became evident, the students analyzed and discussed what they could do together to change their situation. Freire used the term "concientización" for this process of action/reflection/action. The active and interactive methods employed in popular education provide ways to identify problems in a community, diagnose the causes, and develop plans to resolve the problems (Wiggins, 2010). This is analogous to Heifetz's adaptive challenges (Parks, 2005), which ideally 
lead to re-examination of the situation and its history and then to the generation of alternative solutions. Stake (1986), in a similar way, posits that changes in practice emerge from reactions to new experience- that the reflection and intuitive generation of possible avenues from which to choose contributes to the conviction that action is required. My experience working as a dentist with incarcerated women and women in residential chemical dependency treatment centers is that they are concerned about their own poor state of oral health and want a better level of health for their children. This topic lends itself to Freire's (1974) process of action/reflection/action.

Group methods in popular education include dinamicas (dynamic interactive exercises), brainstorming, participatory drama, simulation, and games. Burns (2008) advocates what she calls a "sustainability pedagogy," which emphasizes an experiential, participatory, and multidisciplinary approach to education that acknowledges systemic interrelationships and accentuates the need for personal and cultural transformation through critical reflection on dominant paradigms and unsustainable practices. From my perspective as a health care provider, the oral health beliefs and practices of the populations I have worked with constitute a challenge to health sustainability. Thus Burns's methods (2008), similar to those of Freire (1974), serve to empower the participants to take action for their health.

\section{Experiential Learning Cycle}

The action/reflection/action framework of popular education calls to mind Kolb's (1984) experiential learning cycle. Kolb proposes that learners engage in concrete experience, reflection, abstract conceptualization, and active experimentation in the 
process of learning. Individuals may have a preferred way of entering the cycle, but profound learning involves all the phases of the cycle (Kolb, 1984). I have endeavored to include all these phases in the structure of the oral health learner-centered intervention module.

Zull (2002) builds on the Kolb (1984) model in part by identifying areas of the brain that are engaged in the phases of the cycle and by spelling out in greater detail than Kolb the types of activities that encourage each phase. Zull (2002) points out that "what we already know" is concrete to us, the starting point for constructing new knowledge. Concrete experience engages the sensory cortex. Observing motion, making comparisons, and noting number and status position all are concrete experiences.

Zull (2002) points out that reflection is the search for connections needed to develop complexity. Reflection is enhanced by mental images and language, by fragments of sentences or words. Logs, journals, and brainstorming are venues for reflection. Reflection can occur during a lecture or presentation if the speaker points to connections and allows time for reflection. Zull characterizes reflection as a literal formation of neuronal connections within the brain. The format for the oral health learning module includes questions posed to generate ideas through brainstorming. Slides provide visual reinforcement of principles and allow time for reflection.

In abstraction we generate new ideas, which can occur during the processes of writing papers, analogies, or case studies or preparing a presentation. Zull (2002) comments that to make something meaningful, the emotions must be engaged, which activates a biochemically complex process involved in the plasticity of the brain. The 
amygdala and neurotransmitters trigger chemical changes that increase the numbers and responses of synapses, solidifying learning. Active experimentation brings the learning cycle full circle. Physical movement is needed to link our abstract mental notions with new concrete experience. Simulations, case studies, problem solving/homework, and small-group discussions all help provide the action that completes the biological wholeness of learning (Zull, 2002).

\section{Summary of Conceptual Framework}

Changing a person's health beliefs, knowledge, and health behaviors constitutes an adaptive challenge, not a technical problem. Adaptive changes require the individual to examine and challenge existing internal systems of familiar understanding, beliefs, and patterns of behavior. The technical part- the knowledge foundational for self-care—is a necessary component of motivation. However, the dental profession in general has treated oral health literacy as a strictly technical problem (i.e., a knowledge deficit), working from the premise that if we can improve our communication with patients, oral health disparities will lessen (DePaola, 1998). Oral health literacy is not a technical problem that can be solved with fragmented bits of information transmitted unidirectionally by an authoritarian health care provider.

Substantive changes in health behaviors require an approach that also considers the complex adaptive challenges of dental anxiety, general literacy, health beliefs, access, and other factors.

The relational-system philosophy is a learner-centered model in which teaching is conceived as an educational helping relationship (Robertson, 1996). In contrast to the 
control-hierarchical model, the relational-system approach considers the person within a systems context. Health providers must first change their orientation from authoritarian to helping relationship and avoid lecturing and shaming so that patients will be more likely to take ownership of their chronic health conditions.

Small-group appointments have demonstrated efficacy and effectiveness in the medical setting for enlisting and validating patients as their own caregivers (American Academy of Family Physicians, 1997). There is no literature yet on the use of smallgroup appointments with adults for enhancing oral health knowledge. The review of literature will first describe the issues of oral health literacy, dental anxiety, and health beliefs. The rationale for providing oral health knowledge in a small-group setting will then be established.

\section{Review of the Literature}

\section{Oral Health Literacy and At-Risk Women}

The combination of drug use with low general health literacy and the poor health behaviors that often accompany drug use yields disastrous results. Abuse of drugs such as methamphetamine, cocaine, tobacco, and opiates causes decreased saliva production and is often associated with high sugar intake, poor oral hygiene, and high incidence of caries (cavities) and periodontal disease (Curtis, 2003; Friedlander et al., 2003; Newman \& Bolton, 2003). Methamphetamine destroys teeth through a complex interaction among profoundly dry mouth, predilection for sugar-sweetened colas to slake thirst, lack of exposure to preventive dental care, and poor oral hygiene, in addition to the physical trauma to teeth caused by methamphetamine-induced clenching and grinding of teeth. 
The aim of oral hygiene practices (e.g., brushing and flossing) is to periodically disrupt the bacteria that exist naturally in the mouth so that large bacterial plaque colonies do not form. Some varieties of oral bacteria produce acid as a by-product of fermentation of sugars, and acid is the mechanism for tooth decay. Caffeinated soft drinks (which former methamphetamine users have told me they favored for the caffeine stimulation), besides containing high levels of sugars, are the most acidic of all soft drinks (Milne, 1989; Von Fraunhofer \& Rogers, 2004).

Adequate salivary flow is necessary to dilute and remove the acid produced by bacterial fermentation of dietary sugars. Many of the women I have encountered in drug rehabilitation groups come from a socioeconomic/educational group that lacks access to regular dental checkups, where oral hygiene practices are demonstrated and reinforced (DePaola, 1998). As a result, many believe they have done an adequate job of cleaning their teeth with a 15-second brushing of the "social six," the upper six anterior teeth that are visible in a smile.

Statistics are available regarding women in the correctional system; these statistics are thought to represent at-risk women in the community as well (Lewis, 2006; Zlotnick, 1997). Incarcerated women are typically young and poor and have limited formal education. Nationwide, fewer than $40 \%$ have a high school diploma or its equivalent. Results derived from a national sample showed that $48 \%$ of jailed women reported having been physically or sexually abused before admission. Studies conducted in urban jails have shown that rates of recent homelessness among incarcerated women are as high as $40 \%$ (Freudenberg, 2002). About $70 \%$ of incarcerated women are mothers 
of children younger than 18 years, and children are also victims of their mothers' incarceration due to disruptions in the family (Braithwaite, Treadwell, \& Arriola, 2005; Shimkus, 2004). Because more than 630,000 people enter or leave the prison system each year, many then entering the public health-system, it is imperative that incarcerated mothers understand the system of oral bacteria and hidden sugars in the diet and understand and practice effective dietary and oral hygiene interventions (Treadwell \& Formicola, 2005). In addition, parolees who have had drug-related offences are typically assigned to residential drug treatment following release. Thus, residential drug treatment facilities are an appropriate venue for an oral health literacy educational intervention. In effect, the prison population represents a concentration of lower socioeconomic population. Thus, any health impact achieved with the prison and/or postprison population may spread within the lower socioeconomic population when inmates are released and return to care for their families.

\section{Dental Anxiety as a Complicating Factor to Dental Care and Oral Health Literacy}

Dental anxiety is common among Americans, with about half experiencing at least moderate anxiety and $15 \%$ to $19 \%$ in the "severe" category (Corah, 1988; McCann, 1989; Ronis, 1994). People with low income access dental care primarily in emergency situations, when they are already in pain and fearful. This contributes to the fact that the prevalence of dental anxiety among low-income people is greater than that encountered in the general population (Jones et al., 2002).

In nearly all cases, dental anxiety stems from traumatic experiences, many in the dental setting, but also transferred from other traumatic life experience such physical and 
sexual abuse (Hays \& Stanley, 1997; Heines, 2005; Stalker et al., 2005). In the dental setting, inadequate local anesthesia, painful injections of local anesthetic, not being listened to, and being given no control over the experience contribute to severe anxiety (Ayers, 2005).

The parallels between situations of physical and sexual abuse and the dental environment are understandable. Patients who report high dental anxiety describe a sense of personal space infringement while in a prone and vulnerable position, unable to communicate orally while an authority figure (often male) with sharp metal instruments hovers above, potentially inflicting discomfort, expressing criticism of their level of oral hygiene.

Such intense anxiety has multiple negative consequences. Patients are more likely to miss appointments, and if they do show up, they are tense and difficult to treat, taking up to $20 \%$ more chair time (Filewich et al., 1981). They have negative attitudes about dentistry and convey these attitudes in and out of the dental office. Lack of regular dental appointments results in a lack of awareness of ways of promoting good oral health, which is an essential component of oral health literacy (Doerr, Lang, Nyquist, \& Ronis, 1998).

Highly anxious or phobic patients may self-medicate with marijuana, narcotics, or other substances to deal with their dental pain or with the appointment itself (Crossley, 1996). This leads to a vicious cycle given that current and recovering substance abusers are likely to have severe dental disease (Curtis, 2003; Newman \& Bolton, 2003). Persons in drug treatment or recovery who have a high level of dental anxiety are at risk of relapse in the level of drug recovery if they return to their drug of choice to medicate 
dental pain or dental anxiety (Crossley, 1996). This points to the need for addressing dental anxiety as part of chemical dependency treatment and recovery.

\section{Health Beliefs: Challenging Beliefs to Improve Health Behaviors}

Many people in lower socioeconomic groups believe that health status is a random phenomenon. They do not see a connection between their behaviors and their state of health - or lack thereof (Becker, 1974). This attitude comprises part of the individual's infrasystem beliefs and values and must be uncovered, challenged, and changed if sustainable changes in health behaviors are to be realized. The literature on oral health literacy does not address the complicating factor of patients' existing health beliefs.

As mentioned previously, links have been shown among periodontal disease and several serious chronic systemic health conditions (Wayne et al., 2001). It is thought that chronic inflammation may underlie the connection (Wayne et al., 2001; Kim et al., 2007). Incidences of periodontal disease, hypertension, and diabetes are higher in prison populations than in the general population, and many prison inmates are not compliant with health behavior recommendations including changes in diet and exercise, and are not compliant with taking medications as directed (Jaret, 2001). In addition, tobacco use is more prevalent among low-income populations (Mokdad et al., 2003; Sgan-Cohen \& Mann, 2007), which contributes to periodontal disease and oral cancer. Low socioeconomic status is a factor associated with both diabetes mellitus and obesity (Mokdad et al., 2003), and hypertension is associated with both diabetes and obesity. Remembering that research and statistics regarding the prison population can be seen as representative of the lower socioeconomic classes in general from a public health 
perspective, the incidence of these systemic health problems, also associated with periodontal disease, provides an important potential intervention point. Improving oral health knowledge and behaviors can reduce the severity of these systemic health issues and thus reduce the costs of treating them.

The management of dental diseases underwent a radical change in the 1960s for many Americans. The addition of fluoride to toothpastes and the advertising promotion by toothpaste manufacturers of the regular dental "checkup" led to a transition from treating the diseases by reactive repair and extractions to a preventive or health promotion focus: "Look Ma, no cavities!" This transition to prevention of decay/health promotion was missed, however, by a significant segment of Americans, many living in "generational poverty," who continue to suffer severe dental decay and lose teeth to periodontal breakdown (Beegle, 2003).

Cleaning the teeth is a health behavior familiar to many people, if only from toothpaste advertising on television, even if they have not had regular professional dental care. Thus, education for oral health literacy builds in part on prior knowledge. If effectiveness of tooth brushing and flossing can be improved, there is visible improvement in gingival health in as little as a week (Harris \& Garcia-Godoy, 2004). This provides tangible positive reinforcement to patients. Because periodontal health has implications for a number of systemic conditions, oral health knowledge may prove to be a good place to begin introducing general health behaviors.

As patients experience success with oral health care and an improved sense of self-efficacy, extrapolation to other health behaviors becomes more likely (Kneckt, 
Syrjaia, Laukkanen, \& Knuuttila, 1999). One implication of investment in an education program to enhance health literacy, oral health literacy, and oral health knowledge is the potential for improvement in participants' systemic conditions. In addition, improving patients' awareness of and motivation to practice health behaviors can help decrease the strain on healthcare resources.

The health system in the United States is moving toward a health maintenance and health promotion focus (Jaret, 2001). That is, rather than reacting to health conditions such as diabetes and hypertension, health care professionals encourage individuals to take active steps to prevent or manage these conditions. Health care providers have been called to radically change the system of helping patients manage chronic diseases such as hypertension and diabetes. Harrison (2004) concluded that the root of problems with health care quality lies in outmoded systems of distribution. There is a need to replace the traditional episodic treatment approach to chronic diseases with a total disease management approach that includes adequate counseling about self-care responsibilities. In cases of chronic disease, the episodic approach leads to higher morbidity, mortality, and costs. The public and many health professionals fail to recognize, however, that dental diseases — dental decay and periodontal diseases—are also chronic diseases that require systemic change in professional management and in helping patients manage their diseases. Both tooth decay and periodontal diseases are chronic infectious diseases caused by normal flora - the bacteria that normally reside in the mouth.

\section{Models of Health Beliefs and Health Behaviors}

A barrier to changing health behaviors and improving self-care lies in patients' 
health beliefs. Many of us in the healing professions in the 21 st century have beliefs that include the importance of self-care: attention to nutrition, exercise, and stress management and adherence to specific health care guidelines and recommendations when we do develop chronic diseases such as diabetes (Jaret, 2001). We might agree to some degree with these three statements from the Health Locus of Control scale (Wallston, Wallston, Kaplan, \& Maides, 1976):

- If I take care of myself, I can avoid illness.

- When I feel ill, it is often because I have not been getting the proper exercise or eating right.

- I am directly responsible for my health.

A person with this set of beliefs will take an interest in nutrition, oral hygiene, and simply washing hands. However, many low-income persons have not paid attention to health promotion behaviors (Hom, Lee, Divaris, Baker, \& Vann, 2012) and are perhaps more likely to have beliefs more along the lines of these statements, also from the Health Locus of Control scale:

- Good health is largely a matter of good fortune; people who never get sick are just plain lucky.

- Most people do not realize the extent to which their illnesses are controlled by accidental happenings; no matter what I do, if I am going to get sick, I will get sick.

- There are so many strange diseases around that you can never know how or when you might pick one up.

People with this second set of beliefs may not even be aware of health promotion behaviors or may consider them to be too much trouble or to be futile. In many cases low-income patients come from environments that make them vulnerable to poor health, addictions, low education, and low self-esteem (Toepell, 2003). Wolfe, Stewart, and 
Hartz (1991) found that the majority of factors that correlated with poor oral hygiene correlated with an external locus of control.

The theories that are considered in this research study are the health belief model (HBM) and the theory of planned behavior (TPB). The HBM is a psychological model designed to help explain and predict health behaviors. It was developed by social psychologists Hochbaum, Rosenstock, and Kegels in the 1950s (Rosenstock, 1974). The model was developed in response to the lack of participation in a U.S. Public Health Services free health screening program for tuberculosis. Since then, the HBM has been adapted to explore a variety of long- and short-term health behaviors.

The HBM explains health behavior from a social psychology perspective using the theories of value-expectancy and decision-making (Becker, 1974; Kronenfeld \& Glik, 1991; Maiman \& Becker, 1974). The model focuses on dimensions influencing an individual's control over a specific action and uses these same dimensions (or variables) to predict behavior. The original six constructs of the model include perceived susceptibility, perceived severity, perceived benefits, perceived barriers, cues to action, and demographics or psychological structures.

According to the HBM, a person will take a health-related action if that person (a) believes he or she is susceptible to a health problem, (b) feels that a negative health condition can be avoided, (c) has a positive expectation that by taking a recommended action he/she will avoid a negative health condition, and (d) believes that he or she can successfully take a recommended health action. These concepts constitute "readiness to act." This is related to the concept of self-efficacy, necessary for an individual to tackle 
the challenge of changing habitual unhealthy behaviors, such as being sedentary, smoking, overeating (Kneckt et al., 1999). Adopting the discipline of effective oral health self-care is another health behavior challenge. The HBM allows the researcher to assess whether the participants believe there is a potential oral health problem to which they are susceptible, whether they believe the problems of decay and periodontal diseases are avoidable, and whether they believe they can successfully take action to prevent or avoid the negative health processes of decay and periodontal diseases.

A barrier to changing health behaviors thus lies in patients' health beliefs and attitudes. Several authors have pointed out that health behavior change research does not typically lend itself to description by a single theory (Aro \& Absetz, 2009; Bartholomew \& Mullen, 2011; Logan, 2011). Bartholomew and Mullen (2011) point out that single theories typically predict only a small percentage of the variance in any health behavior and that the theories for description of the problem may differ from the theories for its solution. Therefore they recommend that the researcher select and use multiple theories to design, test, and report interventions (Bartholomew \& Mullen, 2011).

For this reason I also include the TPB, which looks more at the individual and, by assessing the intention to perform a behavior, yields a more fine-tuned picture of the probability that an action will be taken (Ajzen, 1991). The TPB asserts that intentions to perform behaviors of different kinds can be predicted with high accuracy from individuals' (a) attitudes toward the behavior, (b) subjective norms regarding the behavior, and (c) perceived behavioral control (Figure 1). These intentions, along with 
perceptions of behavioral control, account for considerable variance in actual behavior (Ajzen, 1991).

Figure 1

Theory of Planned Behavior

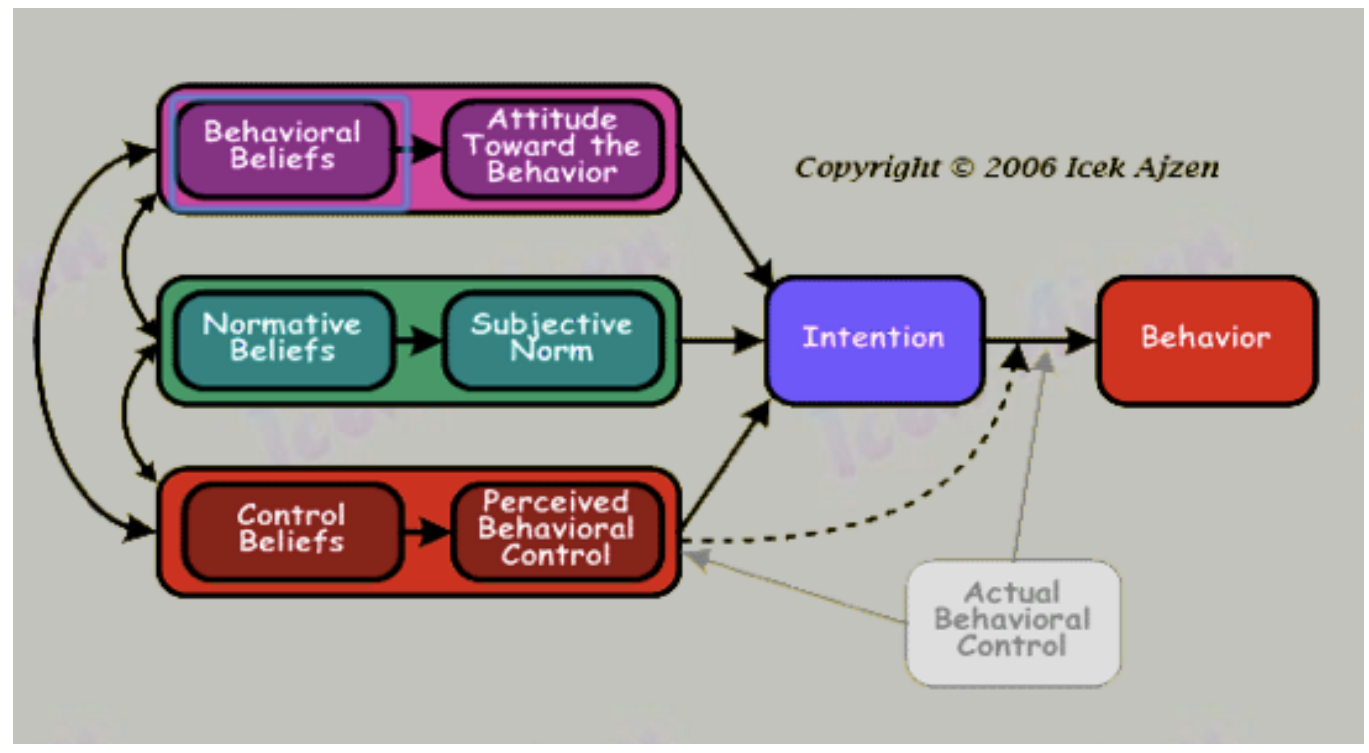

Used with permission (Ajzen, 2006).

A behavioral belief is an individual's subjective expectation that a behavior will produce a given result. Attitude toward the behavior is the individual's positive or negative valuation of the behavior. Behavioral beliefs are related to normative beliefs and control beliefs. Normative beliefs refer to an individual's perception of the behavioral expectations of important groups or individuals, such as family, friends, teachers, doctors, or supervisors. Normative beliefs, combined with the individual's motivation to comply (related to the attitude toward the behavior), determine the subjective norm. Control beliefs pertain to the perceived presence of factors that may facilitate or impede the performance of a behavior. Perceived behavioral control, then, is based on the control beliefs regarding facilitating or impeding factors. 
Intentions are assumed to capture the motivational factors that influence behavior. Intentions indicate readiness to perform a behavior: how hard individuals are willing to try, or how much effort they planning to exert, in order to perform a behavior. Intention is based on the attitude toward the behavior, the subjective norm, and perceived behavioral control (Ajzen, 1991). In general, the stronger the intention to engage in a behavior, the more likely the behavior is to occur. Behavior can be predicted by considering perceived behavioral control, to the extent that it is an accurate reflection of actual behavioral control, along with intention.

As applied to this study, considering the HBM and TPB, I would expect my independent variable, the oral health knowledge session, to influence or explain the dependent variables, which are oral health attitudes and oral health knowledge. In these health-related sessions, I endeavor to engage participants in considering their susceptibility to dental decay and periodontal diseases, to embrace the idea that these can be prevented or mitigated by individual action, and to encourage participants that they can be successful in their action. The HBM and TPB deal with a combination of attitudes, beliefs, and knowledge, a combination referred to as "behavioral capacity" (Bartholomew \& Mullen, 2011). The literature supports the idea that measuring this capacity is a good indicator of intention and behavior change (Ajzen, 1991, 2006).

Substantive changes in health behaviors require an approach that also considers the complex adaptive challenges of dental anxiety, general literacy, health beliefs, access, and other factors.

\section{Small-Group Medical Appointments}


The single-patient individual medical appointment system developed over a century ago, when most visits to physicians were for acute situations such as injuries and infections (Noffsinger, 2001). Over time, as the treatments for acute situations have improved and life expectancy has increased, the preponderance of medical interactions have come to deal with chronic illnesses and syndromes, issues that require lifestyle changes such as nutrition, exercise, and stress management, rather than immediate medical intervention. It is rare to be able to provide discussion of managing complicated medical situations in a 15-minute medical appointment or while simultaneously providing dental or dental hygiene treatment. The current paradigm of individual office visits alone is economically insufficient for enhancing patients' understanding of their health situation, acceptance of responsibility for self-care, and development of skill in self-care (Cunningham \& Blaser, 2004). Yet this information and understanding are critical for patients to make the change to proactive self-care behaviors.

For some patients, brochures may fill the gap in health knowledge. However, the use of written materials such as brochures is based on several assumptions: (a) a health belief system that embraces health promotion, (b) adequate motivation to read and follow recommendations, and (c) a level of literacy adequate for comprehension. These are questionable assumptions with respect to patients who lack high school completion and may present a "learned helplessness" approach to health (or lack of health) (Seligman, 1992). Rather, it is necessary to engage people in such a way as to foster quantum changes in beliefs and to provide mentoring in the processes of change.

Many people who live in poverty exhibit characteristics of oral culture. They 
interact and learn person-to-person, in conversation, rather than by reading information. Oral culture is characterized as relationship-based, spontaneous, and strongly associated with emotions (Beegle, 2003). Persons accustomed to oral culture will respond more favorably to a small-group dialogue setting than to brochures.

Group medical appointments are structured to provide an effective avenue for the constructivist principles of dialogue and active engagement for challenging health beliefs and for education for health literacy. Group visits permit education, dialogue, and team learning that cannot be accomplished in a brief office visit (Masley, Sokoloff, \& Hawes, 2000).

Group medical visits are designed to address a particular health condition in a supportive group setting. Group visit programs, also known as shared medical appointments or cluster visits, provide a level of patient education and follow-up that office visit schedules often do not allow (Cunningham \& Blaser, 2004; Lippman, 2000; Noffsinger, 2001). While the physician sees eight to 15 patients in the 60 - to 90 -minute visit, each patient spends 90 minutes with the doctor (Lippman, 2000). This is perceived as a positive experience on both sides (Noffsinger, 2001).

Group visits have been shown to (a) increase compliance with health behavior recommendations and taking medications, (b) improve patient satisfaction, (c) reduce health care expenses, and (d) challenge health beliefs and effect change in health behaviors so that patients are empowered to take responsibility for their health (Cunningham \& Blaser, 2004). Studies have shown that group appointment participants had a greater likelihood of practicing health promotion behaviors such as getting flu and 
pneumonia shots (Cunningham \& Blaser, 2004; Lippman, 2000; Masley et al., 2000; Noffsinger, 2001).

It is necessary to think beyond what is covered in typical office visits and to choose and share evidence-based screening and therapy targets with patients. Group visits will be most effective if they involve dialogue, not lecture. However, audiovisual materials and handouts enhance the effectiveness of presentations and foster the application of materials patients learn (Cunningham \& Blaser, 2004; Masley et al., 2000).

Studies have found that group appointment models decreased visits to the emergency room, reduced hospital admissions and the use of skilled nursing facilities, lowered referrals to specialists, and saved money (Cunningham \& Blaser, 2004; Lippman, 2000; Masley et al., 2000; Noffsinger, 2001). One expense that could be decreased with improved health literacy is related to the tendency of the poor to access hospital emergency rooms to treat oral infections (Freudenberg, 2002; U.S. Department of Health and Human Services, 2000). Dental-related emergency visits in Oregon increased by 31\% for Medicaid enrollees between 2008 and 2010. An emergency room visit costs approximately $\$ 1,000$ and does not address the root of the problem; patients are typically prescribed antibiotics and pain medicine at these visits. The costs to society are staggering (Tanner, 2012).

Medical problems that lend themselves to the group-visit format are those that are common, costly, and responsive to lifestyle changes. Some of the conditions that have been effectively addressed using group visits are asthma, congestive heart failure, coronary artery disease, depression, diabetes, gastro-esophageal reflux disease, irritable 
bowel syndrome, and obesity (Masley et al., 2000). Oral infections fit well into the list of problems that lend themselves to the small-group format: oral infections are prevalent in the United States, costly to treat, and responsive to lifestyle changes. The NIDCR estimates $92 \%$ of adults ages 20 to 64 have had dental decay; between $50 \%$ and $100 \%$ of adults have gingivitis, and between $8 \%$ and $9 \%$ have more severe periodontal disease (NIDCR, 2011).

Small group appointments have demonstrated efficacy and effectiveness in the medical setting for enlisting and validating patients as their own caregivers (American Academy of Family Physicians, 1997). There is no literature yet on the use of smallgroup appointments in dentistry for engaging adults in considering oral health.

\section{Summary of the Review of the Literature}

Fostering substantive adaptive changes in oral health behaviors requires considering the complex adaptive challenges of literacy, health beliefs, dental anxiety, access to care, and other factors. Adaptive changes in health behaviors require the individual to examine and challenge existing internal systems of understanding, beliefs, and patterns of behavior. The technical part— the knowledge foundational for self-careis a necessary component of motivation. However, the dental profession in general has treated oral health literacy as a strictly technical problem (i.e., a knowledge deficit), working from the premise that if we can improve our communication with patients, oral health disparities will lessen (DePaola, 1998). Oral health literacy is not a technical problem that can be solved with fragmented bits of information transmitted unidirectionally by an authoritarian health care provider. 
Documenting the existence and degree of knowledge and potentially related dental anxiety for this population is a necessary first step in addressing the need for refinement of the dental school preventive dentistry/health promotion curriculum and of communication practices among dental students, dental professionals, and the patients in their practices. Because dental diseases — dental decay and periodontal diseases — are chronic infectious diseases, systemic change in the approach dental professionals take is required to help patients manage their diseases. The small-group model for enhancing oral health knowledge and oral health literacy is one such change. Small-group learnercentered educational interventions will be more appropriate in public health clinics, group settings such as chemical dependency treatment and prisons, and among patients in the dental school setting than in private dental practice. In these settings, improving the knowledge of individuals can ultimately improve the knowledge and health practices of their families and community.

The following chapter outlines the research designed to assess the current knowledge, attitudes, and behaviors of the participants in the study as well as measure levels of dental anxiety. Following this is a description of the learner-centered Oral Health Learning Session Module (Appendix D). Incorporating the HBM and TPB, I examine the effect of the independent variable, the small group oral health knowledge intervention, on the dependent variables - oral health knowledge, attitudes, and behaviors. 
Chapter Three: Research Design and Methodology

This chapter reviews the descriptive and experimental research methods and data analysis used in the study.

\section{General Perspective}

This field-based experimental research embodies a quantitative perspective, assessing baseline status and changes following an educational intervention using selfcompleted written survey instruments. It is hoped that the information provided will inform health education and counseling for the broader population of women in treatment for chemical dependency.

\section{Research Context}

Lack of oral health knowledge contributes to poor oral hygiene and poor nutrition choices, which lead to poor oral health. I have in recent years provided oral health education in several residential chemical dependency treatment programs for women in the greater Portland area. This research project provided an opportunity to evaluate the effectiveness of the oral health education module with the goal of improving and expanding the oral health education program.

Both low oral health knowledge and dental anxiety are part of a cycle that contributes to poor oral health, and both factors constitute potential intervention points in the cycle. The present study examines specifically the potential effects of a one-hour oral health education intervention. Research has shown that reported behavior and behavioral intention can be altered and oral hygiene behavior can be improved in the short term by simple educative interventions (NHS Health Development Agency-UK, 1997). 
Dental anxiety is known to contribute to avoidance of dental appointments, and lack of regular preventive dental and dental hygiene appointments is likely to contribute to low levels of oral health knowledge and negative attitudes toward dentistry (Abrahamsson et al., 2001). Dental anxiety is beginning to be associated in the dental literature with chemical substance use; however, dental anxiety levels among women in chemical dependency treatment have not been reported. Information gained in the study regarding the levels of dental anxiety among the participants will be used to develop future strategies to address dental anxiety.

\section{Research Questions}

The research questions addressed by this study were introduced in Chapter 1 and are reviewed here. This field-based study has three goals: (a) to measure the levels of dental anxiety among women in chemical dependency treatment, (b) to examine the effect of a one-hour educational intervention on oral health knowledge, and (c) to assess the effect of a one-hour interactive learning module on oral health attitudes and behaviors.

The research questions are as follows. Among women in a chemical dependency recovery program:

1. Is the level of dental anxiety different from that observed in the general population?

2. Does the oral health learning session have a measurable effect on the participants' oral health knowledge?

3. (a) Does participation in the oral health learning session have a measurable effect on the participants' self-reported beliefs and attitudes toward dental health and self-care?

(b) Are there measurable changes in self-reported oral health-related behaviors following the oral health learning session? 
4. Is there discussion about oral health topics among the study population following the oral health learning session?

\section{Instruments Used in Data Collection}

Three instruments were administered as pretests at the first meeting with residents

of both Centers A and B. These are the MDAS (Appendix A), ROHKI (Appendix B), and OHAQ (Appendix C).

The ROHKI and OHAQ were administered a second time as posttests three weeks after the oral health learning session.

\section{Research Question 1: Assessing Dental Anxiety}

The first research question was the following: Is the level of dental anxiety different from that observed in the general population?

I used the following data collection strategy: Participants completed the MDAS, a five-question self-completed written quantitative survey designed to measure dental anxiety (Humphris, Morrison, \& Lindsay, 1995).

Models of human conditioning tell us that things learned in times of intense emotion are profoundly felt and difficult to unlearn without dealing with the visceral feelings (Davey, 1989). Managing phobia, which is by its nature a nonrational phenomenon, requires that it first be recognized. Anxious patients may mask their anxiety with a stoic facade.

Fortunately, a number of tools exist that can help dentists gauge their patients' anxiety. These include self-completed questionnaires such as MDAS, which can be completed in about a minute. The MDAS has been developed to better standardize the responses in the well-established four-item Dental Anxiety scale, revised (DAS-R) 
(Corah, 1988) and to add a fifth question regarding injections of local anesthetic (Humphris et al., 1995). The questions address various components of a typical dental appointment.

The five questions are:

1. If you went to your dentist for treatment tomorrow, how would you feel?

2. If you were sitting in the waiting room (waiting for treatment), how would you feel?

3. If you were about to have a tooth drilled, how would you feel?

4. If you were about to have your teeth scaled and polished, how would you feel?

5. If you were about to have a local anesthetic injection in your gum, above an upper back tooth, how would you feel?

Each question is answered on a 5-point Likert scale from "not anxious" (1) to "extremely anxious" (5). Thus the ratings totals for each of the five questions ranges from 1 to 5 . Summing the responses for the five questions for each individual yields scores ranging from 5 to 25 . Scores from 5 to 11 indicate little to low dental anxiety. Scores from 12 to 15 indicate moderate anxiety. Scores from 16 to 18 indicate a high level of dental anxiety, and scores from 19 to 25 indicate severe dental anxiety, sometimes referred to as "dental phobia."

Other instruments exist for assessing dental anxiety but are much longer and delve more specifically into the causes for the anxiety (Newton \& Buck, 2000). The MDAS has the advantages of high validity and brevity.

The MDAS was tested in four different settings. Humphris, Morrison, and Lindsay (1995), in a study of 800 participants in Ireland, Finland, and Dubai, found the mean MDAS score was 11.27, SD 5.07. The range of sample percentages scoring 19 or greater was from $3.0 \%$ to $19.5 \%$. Internal consistency coefficients (Cronbach alphas) 
ranged from 0.86 to 0.90 for the four samples. The overall reliability for the total sample was 0.89 . Validity of the MDAS was checked by investigating the relationship of dental anxiety ratings to self-reported dental attendance and individuals' rating of nervousness about visiting the dentist in general (Humphris, Freeman, Campbell, Tuuti, \& D'Souza, 2000).

Use of these standardized instruments not only quantifies the patients' anxiety but also opens the door to discussion about it. In some cases, that is all that is needed to temper patients' anxiety (Humphris, Clarke, \& Freeman, 2006). Humphris \& Hull (2007) report that opening the discussion of dental anxiety with written instruments also serves to normalize anxiety and validate the patient. Patients have told me they felt ashamed and inadequate because of their severe anxiety. They then felt less "abnormal" when they saw that dental anxiety is so widespread that these instruments exist to measure it.

For patients who suffer from the highest levels of anxiety/phobia, that is, a score of 16 to 25 on the MDAS (Humphris et al., 1995), the dental anxiety instruments and debriefing, relaxation training, and even antianxiety medications might not suffice to allow a patient to endure a dental appointment. In $2 \%$ to $3 \%$ of cases, the help of a mental health therapist is required. This is seen most often when the patient cannot or will not talk about the fear, is extremely difficult or hostile, has unmanaged panic attacks or an anxiety disorder, or has a history of physical or sexual abuse (Stalker et al., 2005). By using a dental anxiety instrument, which enables patients to articulate their fears, and by treating patients with respect and empathy, allowing a sense of control, we can 
facilitate their learning coping skills. Addressing dental anxiety by developing strategies to manage the anxiety is beyond the scope of the study.

\section{Research Question 2: Measuring Oral Health Knowledge}

The second question was the following: Does the oral health learning session have a measurable effect on the participants' oral health knowledge?

I used the following data collection strategy: The survey instrument used was the ROHKI, created for this project to assess knowledge of oral health concepts. The ROHKI is a 10-question multiple-choice self-completed written quantitative survey of the factors considered essential for oral health knowledge and basic oral self-care, based on the dental literature (ADA Center for Evidence-Based Dentistry; Harris \& Garcia-Godoy, 2004). The items comprising the ROHKI closely parallel the topics covered in the Oral Health Learning Session Module so that a posttest employing the ROHKI provides an accurate report of the effectiveness of the Oral Health Learning Session Module on improving oral health knowledge as measured by the instrument.

Oral health literacy involves knowledge about oral health as well as the ability to navigate the health care system. Because the current study does not deal with access to care per se, the researcher has focused on concepts pertaining directly to oral health and the effects of behaviors on oral health.

The goal is that a posttest employing the ROHKI provides an accurate report of the effectiveness of the Oral Health Learning Session Module on improving oral health knowledge as measured by the instrument. The topics addressed in the instrument and in the Oral Health Learning Session Module include the normal oral bacteria and sources of 
sugar that contribute to tooth decay; concepts of periodontal disease, including gingivitis;

the factors that contribute to and ways of preventing and treating periodontal diseases, including oral hygiene self-care; protective oral health habits; effects of oral health on systemic health; the effect of fluoride on the health of the teeth; and the effects of tobacco and other drugs on oral health. The questions are:

1. How does sugar contribute to tooth decay?

2. What is plaque?

3. Does fluoride in toothpaste make any difference to the health of your teeth?

4. What is the truth about flossing?

5. What is gingivitis?

6. If you do want to enjoy a sugary treat, when is the most "tooth-friendly" time to eat it?

7. What is the goal when we brush our teeth?

8. Research studies have shown a link between periodontal (gum) disease and which of the following?

9. What are the two most important dental health habits?

10. Which of the following statements is/are true about smoking cigarettes?

I have examined a website, http://writingtester.com, to determine reading level to ensure that the language used in this instrument is understandable at or below the sixthgrade reading level.

\section{Existing measures of oral health literacy and oral health knowledge. Oral}

health literacy is defined as "The degree to which individuals have the capacity to obtain, process and understand basic health information and services needed to make appropriate oral health decisions" (Institute of Medicine, 2000). Formal instruments for measuring oral health literacy have been developed only in the past five years.

Gong, Lee, Rozier, Pahel, Richman, \& Vann (2007) noted that, as yet, there existed no methods for assessing oral health literacy. The authors also noted that many written materials providing information on dental topics for patients are written beyond 
the twelfth-grade reading level. The Rapid Estimate of Adult Literacy in Dentistry-30 (REALD-30) was based on the REALM-30, a test of general health literacy (Davis, Long, \& Jackson, 1993). The REALD-30 instrument consists of a list of 30 words that the subject is to read aloud (Gong et al., 2007). Correct reading and pronunciation are assumed to indicate health or oral health literacy. My concern with the REALD-30 is that the words, which include periodontal, hypoplasia, malocclusion, caries, hyperemia, and apicoectomy, are not words necessary for knowledge of how to take care of one's oral health, and may not be familiar even to many college-educated people who have good oral health knowledge. Gong et al. found that a measure of oral health literacy provided information not generated by the REALM-30, supporting the need for a separate instrument.

The Test of Functional Health Literacy in Dentistry (TOFHLID) (Gong et al., 2007) is administered in an interview. The subject is initially presented with a list of 36 words, is told to read them aloud (as in the REALD-30), and is then asked to tell the interviewer what the words mean to the subject. Subsequently, the same words are used in sentences and the subject is asked to interpret the sentences. Thus the instrument evaluates reading ability, knowledge, and understanding. Cronbach's alpha for the overall TOFHLID score was 0.63 . The reading comprehension and numeracy sections produced alphas of 0.65 and 0.59 , respectively. (Gong et al., 2007). Its predictive validity is only partially established, and internal consistency just meets the threshold for acceptability.

Horowitz \& Kleinman (2008) comment that the REALD-30 and TOFHLID do not actually measure oral health literacy; rather, they approximate reading skills. Oral 
health literacy, while apparently having some differences from general health literacy, reflects similar individual abilities in reading and numeracy. Given the lack of effective measures of oral health knowledge, and the esoteric nature of the instruments that exist, I have developed the 10-question ROHKI, which surveys the factors considered essential for oral health knowledge and basic oral self-care, based on the dental literature (ADA Center for Evidence-Based Dentistry; Harris \& Garcia-Godoy, 2004).

\section{Research Question 3: Measuring Attitudes Toward Oral Health}

The third research question consisted of two parts. The first part was the following: (a) Does participation in the oral health learning session have a measurable effect on the participants' self-reported beliefs and attitudes toward dental health and selfcare care? The second part was the following: (b) Are there measurable changes in selfreported oral-health-related behaviors following the oral health learning session?

I used the following data collection strategy: Participants completed the OHAQ, a self-completed written quantitative survey instrument, prior to the oral health small group educational session. The instrument was administered a second time as a posttest three weeks after the educational intervention.

The OHAQ, created for this project, incorporates questions pertaining to the HBM and the TPB (Ajzen, 1991). Fourteen of its 20 items were distilled from the 28item Dental Coping Beliefs scale (Wolfe, Stewart, \& Hartz, 1991). The Dental Coping Beliefs scale builds on cognitive-behavioral psychology, including Julian Rotter's locus of control model (Wolfe et al., 1991) and Albert Bandura's self-efficacy model (Bandura, 1989; Kneckt et al., 1999; Kneckt, 2000). The remaining six questions in the OHAQ refer 
to oral health and health-related behavior and visits to dental offices (Harris \& GarciaGodoy, 2004).

Locus of control relates to the degree of control individuals believe they have over events in their lives (Wolfe et al., 1991). The self-efficacy model considers selfassessments of ability and expectancy toward action (Wolfe et al., 1991). These concepts are related to the self-efficacy construct of the health beliefs model (Becker, 1974), which in turn echoes the behavioral capacity and intention outlined in the TPB (Ajzen, 1991).

The Oral Health Learning Session Module addresses such beliefs as whether decay and periodontal diseases are inevitable or preventable and the importance of daily choices on oral health, which pertain to central elements in both the HBM and TPB. Items that I believe are of key importance were selected from the existing instruments, keeping in mind a goal of straightforwardness and brevity of the instrument, given the range of literacy among participants. In addition, the researcher did not want to overwhelm the participants with lengthy instruments.

The oral health attitudes items are:

1. I believe that only the dentist can prevent cavities.

2. I believe that if my parents have bad teeth, brushing and flossing will not help my teeth.

3. I believe that by brushing and flossing my teeth I am less susceptible to tooth decay.

4. I believe that tooth loss is a normal part of growing old.

5. I am likely to have gingivitis or gum disease in the next year or two.

6. I believe that I am responsible for preventing the loss of my teeth.

7. I believe that by flossing my teeth I can prevent gingivitis.

8. I believe dentures are less trouble than taking care of my natural teeth.

9. I believe I know how to brush my teeth correctly.

10. If my gums bleed when I floss this usually means that I am hurting my gums and I should stop flossing my teeth.

11. If I knew the facts about dental health I could help prevent the loss of my teeth.

12. I believe visiting the dentist is only necessary when I am experiencing pain. 
13. I am likely to have tooth decay in the next year or two.

14. If my gums bleed when I brush this usually means that I am brushing too hard and I should stop brushing my teeth.

15. How often do you brush your teeth?

16. How often do you clean your between your teeth (by dental floss, toothpick or interdental brush)?

17. How often do you visit a dentist?

18. When do you next plan to see the dentist?

19. Do you smoke cigarettes or use another form of tobacco?

20. Have you ever used alcohol or other drugs to calm you to help you go to a dental appointment?

The responses to the first 14 questions comprise a 4-point Likert scale ranging from "I agree completely" to "I disagree completely." Questions 15 through 19 have multiple-choice responses.

Items 1 through 12, with the exception of Item 10, measure locus of control

(Table 3). Items 1, 2, 8, 10, 12, and 14 indicate beliefs that constitute barriers to action.

Table 3

OHAQ Item Analysis

\begin{tabular}{|l|l|l|l|l|l|}
\hline & & $\begin{array}{l}\text { Locus of } \\
\text { Control }\end{array}$ & $\begin{array}{l}\text { Barrier } \\
\text { Beliefs }\end{array}$ & $\begin{array}{l}\text { Suscep- } \\
\text { tibility }\end{array}$ & $\begin{array}{l}\text { Self- } \\
\text { efficacy }\end{array}$ \\
\hline 1 & $\begin{array}{l}\text { I believe that only the dentist can } \\
\text { prevent cavities. }\end{array}$ & External & $\mathrm{X}$ & $\mathrm{X}$ & \\
\hline 2 & $\begin{array}{l}\text { I believe that if my parents have bad } \\
\text { teeth, brushing and flossing will not } \\
\text { help my teeth. }\end{array}$ & External & $\mathrm{X}$ & $\mathrm{X}$ & \\
\hline 3 & $\begin{array}{l}\text { I believe that by brushing and } \\
\text { flossing my teeth I am less } \\
\text { susceptible to tooth decay. }\end{array}$ & Internal & & $\mathrm{X}$ & $\mathrm{X}$ \\
\hline 4 & $\begin{array}{l}\text { I believe that tooth loss is a normal } \\
\text { part of growing old. }\end{array}$ & External & & $\mathrm{X}$ & \\
\hline 5 & $\begin{array}{l}\text { I am likely to have gingivitis or gum } \\
\text { disease in the next year or two. }\end{array}$ & External & & $\mathrm{X}$ & $\mathrm{X}$ \\
\hline 6 & $\begin{array}{l}\text { I believe that I am responsible for } \\
\text { preventing the loss of my teeth. }\end{array}$ & Internal & & $\mathrm{X}$ & $\mathrm{X}$ \\
\hline 7 & $\begin{array}{l}\text { I believe that by flossing my teeth I } \\
\text { can prevent gingivitis. }\end{array}$ & & & $\mathrm{X}$ & $\mathrm{X}$ \\
\hline 8 & $\begin{array}{l}\text { I believe dentures are less trouble } \\
\text { than taking care of my natural teeth. }\end{array}$ & External & $\mathrm{X}$ & & \\
\hline 9 & $\begin{array}{l}\text { I believe I know how to brush my } \\
\text { teeth correctly. }\end{array}$ & Internal & & $\mathrm{X}$ & $\mathrm{X}$ \\
\hline
\end{tabular}




\begin{tabular}{|c|c|c|c|c|}
\hline 10 & $\begin{array}{l}\text { If my gums bleed when I floss this } \\
\text { usually means that I am hurting my } \\
\text { gums and I should stop flossing my } \\
\text { teeth. }\end{array}$ & & $\mathrm{X}$ & $\mathrm{X}$ \\
\hline 11 & $\begin{array}{l}\text { If I knew the facts a out dental health } \\
\text { I could help prevent the loss of my } \\
\text { teeth. }\end{array}$ & Internal & & $\mathrm{X}$ \\
\hline 12 & $\begin{array}{l}\text { I believe visiting the dentist is only } \\
\text { necessary when I am experiencing } \\
\text { pain. }\end{array}$ & External & $X$ & \\
\hline 13 & $\begin{array}{l}\text { I am likely to have tooth decay in the } \\
\text { next year or two. }\end{array}$ & & & $X$ \\
\hline 14 & $\begin{array}{l}\text { If my gums bleed when I brush this } \\
\text { usually means that I am brushing too } \\
\text { hard and I should stop brushing my } \\
\text { teeth. }\end{array}$ & & $X$ & $X$ \\
\hline
\end{tabular}

Table based on Wolfe, Stewart, \& Hartz (1991).

Most of the items indicate awareness of susceptibility to dental diseases, with the exception of Items 7, 8 and 12. Self-efficacy, a component of behavioral capacity, is indicated by agreement with Statements 3, 6, 7, and 9. For these 14 items, drawn from the Dental Coping Beliefs scale (Wolfe, Stewart, \& Hartz, 1991), Cronbach's alpha is 0.76.

I have examined a website, http://writingtester.com, to determine reading level to ensure that the language used in this instrument is understandable at or below the sixthgrade reading level.

\section{Research Question 4: Further Dialogue Among Study Participants}

The fourth research question was the following: Is there discussion about oral health topics among the study population following the oral health learning session?

I used the following data collection strategy: Item 21 in the OHAQ addresses this question. Item 21 is present in the posttest version of the OHAQ.

Analysis of dental anxiety levels and existing oral health knowledge and attitudes variables will inform future educational interventions intended to expand oral health 
knowledge and improve coping skills for dental treatment in the population of women in chemical dependency treatment.

\section{Research Participants}

The research group was a convenience sample of women determined by participation in two residential chemical dependency treatment programs for women. Participation in the study was voluntary from among women engaged in the treatment programs. Participants were of varying ages, cognitive abilities, family configurations, education levels, and cultural and ethnic heritages. While participation in the chemical dependency treatment program is voluntary, consequences of not participating may be significant for some individuals (i.e., prosecution by the Department of Criminal Justice or jeopardizing the custody of their children).

A total of 51 participants in the two residential chemical dependency treatment centers for women completed three pretest instruments. The treatment programs require six months of residential attendance. Turnover in population at both centers is rapid, with new women being admitted or completing treatment each week, or deciding to leave without program completion, and there are daily absences due to medical or legal appointments or illness. In addition, attendance at the oral health class was optional for the 17 women in the final three months of treatment in Center B, and few of these women opted to attend the class. The study spanned five weeks, and thus consistency in participants was difficult to achieve.

Center A comprises 32 women, all mothers of young children, who have come to the attention of the Oregon State Department of Human Services Child Protection 
Services. Their drug use poses a threat to the well-being of their children. These women participate in a six-month residential chemical dependency treatment program as a condition of maintaining custody of their children. From July 2011 through June 2012 the Center A population included 25 (79\%) Caucasian, 2 (6\%) African American, 2 (6\%) Hispanic, 2 (6\%) Native American, and 1 (3\%) other ethnicity (Table 4). The age range is from 22 to 41. Education level of Center A was the following: approximately $80 \%$ have high school education through eighth to 10th grade; most of the remaining $20 \%$ have a General Equivalency Diploma (GED). At least 95\% of the women experienced childhood sexual abuse; the majority also were exposed to physical abuse and neglect and/or witnessed domestic violence (T. Hooper, personal communication, July 6, 2012).

Twenty-five of the residents of Center A completed pretest instruments. Twenty women attended the oral health learning session, and 16 completed posttest instruments.

Center B comprises 35 women who are in transition from incarceration in the Oregon Department of Corrections. Participation in a six-month chemical dependency treatment program is a condition of parole for these women. The health education component of Program B is aimed at those women who have been in residence between three weeks and three months of the six-month program, generally about half the total population of the center at any given time. The age range is from 23 to 51 . While $70 \%$ of Oregon prison inmates enter corrections lacking high school completion, achieving a GED is a goal for all prisoners who lack a high school diploma. Approximately $60 \%$ of residents of Center B enter with high school diplomas, GEDs, or some college, and the remaining residents are enrolled in GED coursework. During the period of this study, 
Center B population ethnicity included 26 (74\%) Caucasian, 7 (20\%) African American, and 2 (6\%) Native American. Almost all of the women experienced childhood sexual abuse, physical abuse, and/or neglect, and/or witnessed domestic violence (K. Perez, personal communication, May 10, 2012).

Compared with national statistics on incarcerated women, women in both Centers A and B have higher percentages of high school or GED completion and higher percentages of histories of interpersonal trauma. Fewer than $40 \%$ of female prisoners nationwide have high school diplomas or equivalents; $48 \%$ of jailed women report having been physically or sexually abused prior to incarceration (Lewis, 2006; Zlotnick, 1997).

Twenty-six of the women in Center B completed the pretest instruments. Eleven of the 16 women who attended the oral health session completed the posttest. The sample was confidential but not anonymous, as the scores on written instruments were associated between pretest and posttest for individuals.

Table 4

Demographic Characteristics of Participants

\begin{tabular}{|l|l|l|}
\hline & \multicolumn{1}{|c|}{ Center A } & \multicolumn{1}{|c|}{ Center B } \\
\hline Number of residents & 32 & 35 \\
\hline Ethnicity & & \\
\hline Caucasian & $25(79 \%)$ & $26(74 \%)$ \\
\hline African American & $2(6 \%)$ & $7(20 \%)$ \\
\hline Hispanic & $2(6 \%)$ & 0 \\
\hline Native American & $2(6 \%)$ & $2(6 \%)$ \\
\hline Other & $1(3 \%)$ & 0 \\
\hline Age range & $22-41$ & $23-51$ \\
\hline $\begin{array}{l}\text { Education: } 10^{\text {th }} \text { grade or } \\
\text { less }\end{array}$ & $25(79 \%)$ & $21(60 \%)$ \\
\hline $\begin{array}{l}\text { Education: GED or high } \\
\text { school completion }\end{array}$ & $7(21 \%)$ & $14(40 \%)$ \\
\hline
\end{tabular}




\section{Research Procedures}

The standardized instruments and the Oral Health Learning Session Module were presented to women participating in a regularly scheduled health class in their treatment centers. Question 1 in this field-based study, the measure of levels of dental anxiety among the participating women in chemical dependency treatment, is descriptive. Questions 2 and 3 in this study examined the frequencies of responses to the items in the instruments.

While Questions 2 and 3, which measure the short-term effect of the teaching module, involved a test-retest format, a true experimental methodology is difficult in the at-risk population setting (Stone, 2002). In fact, as individual behavior change is described as context-dependent, operating at multiple levels and ideally involving community and societal influences to promote sustainable change, behavior change does not lend itself to the gold standard of randomized controlled trials (Aro \& Absetz, 2009).

The women were asked to participate in the research study at a health education session in which the three survey instruments were presented as pretests. All attendees in the health class completed the MDAS, the ROHKI, and the OHAQ. While all women present at the class completed the instruments, only the data from those who agreed to participate in the study and completed the consent form (Appendix E) were submitted for analysis. Fifty-one participants, 25 from Center A and 26 from Center B, completed the pretest instruments.

The sample is confidential but not anonymous, as the scores on written instruments were associated between pretest and posttest for individuals. To ensure 
confidentiality, the name of each program participant was designated a random reference number. The list containing both names and numbers is kept in a password-protected computer file. Two 9x12-inch envelopes were addressed by name to each subject: one containing the pretest instruments, the other the posttest instruments. The random reference numbers were written on each of the instruments. The pretest envelope contained the MDAS, the ROHKI, and the OHAQ. The posttest envelope contained the ROHKI and the OHAQ. The envelopes were kept in a locked file cabinet in the office of the education director of each center until they were distributed to the participants.

The nurse/education coordinator of each program distributed the pretest envelopes to class participants. Participants completed the pretest inventories and placed their inventory forms (identified by reference number) in a box. The envelopes addressed by name were destroyed.

The next health education class session, approximately two weeks later consisted of the oral health learning session.

While the plan was to administer the posttests two weeks following the health education class, in both centers the scheduling was such that three weeks elapsed between class and posttest. The participants were asked to complete the posttest inventories. The nurse/education coordinator of each program distributed the posttest envelopes to class participants. Participants completed the posttest inventories and placed their inventory forms (identified by reference number) in a box. The plan was to destroy the envelopes addressed by name. However, many of the women expressed the desire to keep their 
personalized envelopes, so they were allowed to keep them. The remaining envelopes were destroyed.

\section{Oral Health Learning Session Module}

The Oral Health Learning Session Module was developed over a period of several years when I worked as a dentist in the Oregon Department of Corrections, based on the concepts that I felt the inmates did not understand and that seemed essential to communicate to them to change from a pattern of progressive tooth decay and periodontal disease to a state of oral health stability. I had also had experience on the faculty at the Oregon Health and Science University School of Dentistry. Part of my role in clinical teaching was modeling for students how to talk with their patients about oral health topics. Many of the patients who go to the School of Dentistry do so because the fees are lower than those of private-practice dental offices, and many of the patients at the School of Dentistry clinics do not have a history of participation in regular annual dental and dental hygiene visits. I conversed with hundreds of patients and developed a sense of what aspects of oral health knowledge tended to be missing and what attitudes and beliefs interfered with oral health.

When I worked as a dental officer in the Oregon Department of Corrections, I sought a way to do more than try to put a finger in the dike of oral health ignorance. I first presented the learning session around 2001 to women in the Oregon Women's Correctional Center and have modified and fine-tuned it over the years. I took into account the basics of what we in the dental profession hope our patients know-that is, what people need to know to be able to take good care of their mouths. 
The mouth is the only part of the human body that requires daily meticulous care to be healthy. In earlier centuries, when there was less sugar to be had (only honey, only for the wealthy, until the 1700s) and average life expectancies were shorter (less than 50 years in the U.S. in 1900), a person could muddle through life without a toothbrush (Life Expectancy in the USA, 1900-98). With today's longer life expectancies and readily available sugars in the diet, good oral health is essential for systemic health.

I have consulted several health promotion textbooks used in dental education over the decades. The most recent text is 2004's Primary Preventive Dentistry (6th ed.). by Norman Harris and Franklin Garcia-Godoy. The current iteration of the Oral Health Learning Session Module comprises 75 slides. Some are simply titles, and some require a minute or two to elicit responses from participants.

I have kept in mind the principles of the HBM. According to the HBM, a person will take a health-related action if that person

- believes he or she is susceptible to a health problem,

- feels that a negative health condition can be avoided,

- has a positive expectation that by taking a recommended action he/she will avoid a negative health condition, and

- believes that he or she can successfully take a recommended health action.

In addition, the TPB asserts that intentions to perform behaviors of different kinds can be predicted with high accuracy from individuals'

- attitudes toward the behavior,

- subjective norms regarding the behavior, and

- perceived behavioral control (Figure 1).

These intentions, along with actual behavioral control, account for considerable variance in actual behavior (Ajzen, 1991). 
With these two theories in mind - the HBM and the TPB - the learning session module was structured to present oral health, the bacterial diseases that jeopardize the state of health, and the self-care norms encouraged by the dental profession. In addition, the format serves to encourage the participants that prevention of dental diseases is within their capability. The presentation makes the case first that it is possible to keep teeth for a lifetime, that we are all susceptible to dental diseases, and that there are oral hygiene and nutritional actions that are not difficult but can make a powerful difference in the occurrence of dental decay and periodontal diseases.

The Oral Health Learning Session Module is framed by a PowerPoint presentation for ease of facilitation and consistency among presenters. Concepts and best practices were verified using a text used currently for instruction of dental students (Harris \& Garcia-Godoy, 2004) and the American Dental Association website (ADA Center for Evidence-Based Dentistry).

The learning module proposed in this study uses the-small group model, incorporating the concepts and practices advocated by Belenky et al. (1997); Kolb, Boyatzi, and Mainemelis (1999); and Freire (1974), built on constructivist principles and involving various learning experiences. A teaching/learning module for oral health principles that includes collaborative experiences can assist participants in their development along the positions outlined by Belenky et al. (1997) by building trust, demonstrating the immediacy of the principles addressed, and sharing knowledge through dialogue (American Academy of Family Physicians, 1997). 
The Oral Health Learning Session Module studied here incorporates images as well as words and serves as a concise framework to facilitate "covering" of considerable material in a limited time while allowing for spirited dialogue and reflection.

Group methods gleaned from educacion popolar include dinamicas (dynamic interactive exercises), brainstorming, participatory drama, simulation, and games (Freire, 1974; Wiggins, 2010). Burns (2008) similarly advocates a pedagogy she titles "sustainability pedagogy," which emphasizes an experiential, participatory, and multidisciplinary approach to education that acknowledges systemic interrelationships and accentuates the need for personal and cultural transformation through critical reflection on dominant paradigms and unsustainable practices.

The Oral Health Learning Session Module active experimentation aspect incorporates problem solving and small-group dialogue and incorporates physical objects such as toothbrushes and photos of foods. A toothbrush and toothpaste were distributed to all those who attended the oral health session. Small group discussions help provide the action that completes the biological wholeness of learning (Zull, 2002).

The intent is to establish the group's knowledge via questions and dialogue and to use scaffolding to clarify and build on that knowledge. The topics are arranged to flow from consideration of why we need teeth (nutrition, speech, aesthetics, musculoskeletal support), to the role of oral health in overall systemic health, the possibility of keeping teeth lifelong, and what steps are necessary to keep the teeth and mouth healthy. In addition, the items are sequenced in a way to challenge beliefs such as the inevitability of losing teeth and to encourage participants to progress from precontemplation to 
contemplation in the stages of change model (Prochaska, Norcross, \& DiClemente, 1994) or from contemplation to preparation and action.

Questions such as "Why do we need teeth?" are presented visually on PowerPoint slides and repeated orally. The group members are encouraged to contribute to the dialogue in response to questions and to pose questions of their own. I keep a supply of small sample packets of xylitol-containing mints (xylitol is a nonfermentable carbohydrate that does not contribute to tooth decay). Distributing packets of mints to women who offer oral responses to the questions seems to break the ice and foster lively participation in the dialogue.

After oral sharing within the group, the answers suggested by the dental literature appear on the slides, and these concepts are discussed in further detail if there are questions or controversy. Many of the items included in the learning session module relate to the 10 items in the ROHKI. Other questions, which address attitudes and beliefs or provide supplemental information pertinent to the dental decay and periodontal disease topics, include:

- Is it possible to keep your teeth for all your life?

- How can teeth be damaged or lost?

- What causes tooth decay?

- What sources of natural sugar do you have in your diet?

- What sources of added sugar do you have in your diet?

- True or false: Candy will cause tooth decay no matter how well you clean your teeth.

- True or false: Candy or pastries eaten between meals cause more decay than candy or pastries eaten as dessert at a meal.

- Why do we clean our teeth?

- True or false: Bacteria are normally in the saliva and on the teeth and gums.

- Where do germs in your mouth come from?

- How long does it take to thoroughly clean teeth (15 seconds, 1 minute, 2 minutes, 5 minutes)? 
- Why is there fluoride in toothpaste?

- How old should your baby be when you start brushing her teeth?

Many of these items are included in the OHAQ. Additional questions pertain to gingivitis, periodontal disease, flossing, and the effects of medicines, illicit drugs, and tobacco on the mouth.

I have examined a website, http://writingtester.com, to determine reading level of the instruments to ensure that the language used is understandable at or below the sixthgrade reading level. A practice of using a technical term as well as its lay equivalent demonstrates respect for the listener and helps develop the listener's knowledge and understanding.

Because I do have a content "agenda" in my limited time with small groups of learners on the topic of oral health literacy (usually 1 hour), I wrestle with the competing goals of wanting to be inclusive and empowering yet having a traditional transmissive education background and passion for a particular science-based content in oral health issues. My solution has been to structure small-group sessions in a way to engage in dialogue to elicit the learners' knowledge, beliefs, and experience. I encourage them to ask questions as they arise. I use strategies such scaffolding: holding that which is known and building incrementally as I ask and clarify "the facts" in an accessible way, coaching and guiding to build on that knowledge (Windschitl, 1999). We build the case in an interactive setting that encourages learners to reevaluate current beliefs and behaviors. Students are generally able then to draw the conclusions I hope for in the areas of nutrition, oral hygiene, and smoking. I starting with their concrete experience, encourage reflection and abstract conceptualization, and hope for active experimentation to follow 
when they next confront a meal or their toothbrush (Kolb et al., 1999; Zull, 2002).

The participants in the small-group oral health learning experience are not formally generating new ideas in writing, but my goal is that they create their own models of how they will incorporate new information or revise their existing knowledge and beliefs. The study examines the effectiveness of this small-group format for developing knowledge, understanding, motivation, and likelihood of improved oral health practices in at-risk women who participate.

A potential outcome of this study is the establishment of this small-group format as a model for developing knowledge, addressing dental anxiety and other individual concerns, fostering understanding and motivation, and improving oral health practices in at-risk women who participate. Ultimately the results will be used to inform processes in dental student education and public health organizations to address barriers to oral health knowledge and literacy. A related outcome may be support for an increase in an oral health literacy component to chemical dependency treatment programs.

\section{Ethical Issues}

Prior to initiation of the study, approval was obtained from the Human Participants Research Review Committee of the Portland State University Office of Research and Strategic Partnerships. Participants signed an informed consent form prior to participation following explanation of the study.

The two documents that contain subject names are stored in a locked file cabinet. To maintain subject confidentiality, reporting of results will not include participants' names. 


\section{Positionality of the Researcher}

Because I have constructed two of the survey instruments and the contents of the teaching modules, my potential biases, values, and judgments must be brought forth. This might include the extent of my knowledge of dental education, adult development, and learning.

I have been a licensed dentist for 27 years and have worked in private practice, in dental education, and as a dental officer in the Oregon Department of Corrections. In addition, I have a master's degree in counselor education and have served as chair of the Department of Behavioral Sciences at the Oregon Health and Science University School of Dentistry. I have interest and expertise in the recognition and management of dental anxiety and in promoting oral health literacy.

I have worked extensively as a dentist with two populations that exhibit high rates of dental diseases (tooth decay and periodontal diseases) and concomitant low levels of oral health literacy: women incarcerated in the Oregon Department of Corrections and persons served by MTI mobile dental clinics in downtown Portland. This MTI treatment population comprises homeless youth and adults, persons living in residential chemical dependency treatment facilities, and residents of halfway houses in transition from incarceration. I believe, based on my experience, that many members of these populations have lower levels of health knowledge and higher levels of dental anxiety than the typical patients in private dental offices and express attitudes that constitute roadblocks to desired oral health care practices. I believe that health care and education 
provided in either setting provides a potential intervention point for improving health literacy and health behaviors.

Because I have worked closely with low-income populations and have expectations about how participants might react or respond, and because I believe the oral health session will be effective, I have endeavored to address these biases by using standardized, tested instruments or items drawn from such instruments.

\section{Summary of Methods}

This chapter has explained the methods used in this quantitative field-based study of levels of dental anxiety and the effects of an oral health knowledge education intervention. The next chapter presents the results obtained with these methods. 
Chapter Four: Results

This chapter presents the results and statistical analyses of the surveys completed by the participants. These results point to the importance of addressing dental anxiety in chemical dependency treatment and to the utility of small-group educational sessions in changing attitudes as well as knowledge of oral health issues. The chapter begins with the results of the three instruments used and how these results relate to the research questions. The chapter concludes with a brief summary of the findings.

A total of 51 participants in the two residential chemical dependency treatment centers for women completed three pretest instruments. Thirty-eight women attended the oral health information classes: 23 from Center A and 15 from Center B. Twenty-seven women completed the posttest instruments: 16 from Center A and 11 from Center B.

Data were entered in a tabular data file. Data were analyzed using R Statistical Software (R Foundation, 1999). Descriptive statistics, including frequencies and means, were compiled to summarize the data.

Bivariate analysis was used to compare pretest and posttest results and to compare instruments, survey items, and groups. Relationships between pretest and posttest for items in the ROHKI and the OHAQ were examined. On the basis of the categorical or continuous nature of the data, these variables were assessed using inferential methods, including chi-square tests, Fisher's Exact Test, $t$ tests for difference of means, and twoproportion $z$ tests. An alpha level of 0.05 was used to denote statistical significance.

\section{Research Question 1}


Is the level of dental anxiety different from that observed in the general population?

\section{Data}

The MDAS (Humphris, Morrison, \& Lindsay, 1995) was used as a measure of dental anxiety. The five questions in the MDAS are scored from 1 point (not anxious) to 5 points (extremely anxious). The sum of the responses to the five questions yields the raw MDAS score. Raw scores were converted into ordinal categorical values, with scores of 5 to 11 indicating low dental anxiety, 12 to 15 a moderate level of dental anxiety, 16 to 18, high anxiety; and 19 to 25, severe anxiety (Table 5 and Figure 2).

The mean MDAS score for all 51 participants who completed the pretest was 16.06 (SD 6.485), which is in the high-anxiety category. Humphris et al. (1995), in the studies used to validate the MDAS, found the mean MDAS score to be 11.27 (SD 5.07). In a $t$ test with a null hypothesis of a mean score of 11.27 , an observation of 16.06 is significant with $\mathrm{p}<0.0001$.

According to the dental literature, approximately half of Americans experience at least moderate dental anxiety (Corah, 1969; Corah, 1988; McCann, 1989; Ronis, 1994). In the current study, almost three fourths of the participants (73\%) scored in the moderate-to-severe categories (Table 5). Testing the observation of $73 \%$ in the moderateto-severe categories against a null hypothesis of $50 \%$ with a one-proportion $z$ test shows a significant difference in proportions $(p=0.0001)$.

Table 5

MDAS: Anxiety Category Frequency Distribution

\begin{tabular}{|c|c|c|c|c|}
\hline Category & $\begin{array}{c}\text { Low Dental } \\
\text { Anxiety: }\end{array}$ & $\begin{array}{c}\text { Moderate } \\
\text { Dental Anxiety: }\end{array}$ & $\begin{array}{c}\text { High Dental } \\
\text { Anxiety: }\end{array}$ & $\begin{array}{c}\text { Severe Dental } \\
\text { Anxiety: }\end{array}$ \\
\hline
\end{tabular}


ORAL HEALTH KNOWLEDGE, ATTITUDES, BEHAVIORS

\begin{tabular}{|l|c|c|c|c|}
\hline & Scores 5-11 & Scores 12-15 & Scores 16-18 & Scores 19-25 \\
\hline $\begin{array}{l}\text { Number of } \\
\text { participants } \\
\text { (n= 51) }\end{array}$ & 14 & 6 & 12 & 19 \\
\hline $\begin{array}{l}\text { Percentage of } \\
\text { participants } \\
(\mathbf{n = 5 1})\end{array}$ & $27.4 \%$ & $11.7 \%$ & $23.5 \%$ & $37.2 \%$ \\
\hline $\begin{array}{l}\text { Percentage in gen'l } \\
\text { population }\end{array}$ & $51 \%$ & $36 \%^{2}$ & $36 \%^{2}$ & $12-19.5$ \\
\hline
\end{tabular}

1. Hill \& Freeman, 2012. 2. Hill \& Freeman (2012) combine moderate and high dental anxiety in a single category comprising $36 \%$ of the population. Using the range $12 \%$ to $19.5 \%$ for severe anxiety yields a range of $48 \%$ to $55.5 \%$ in the moderate-to-severe categories.

Figure 2 displays the percentages of response categories for the MDAS found in this study. Almost $61 \%$ of participants scored in the high or severe anxiety categories (high, 23.5\%; severe, 37.2\%).

Figure 2

Percentage of Participants in Each MDAS Category

\section{MDAS Anxiety Category Percentages}

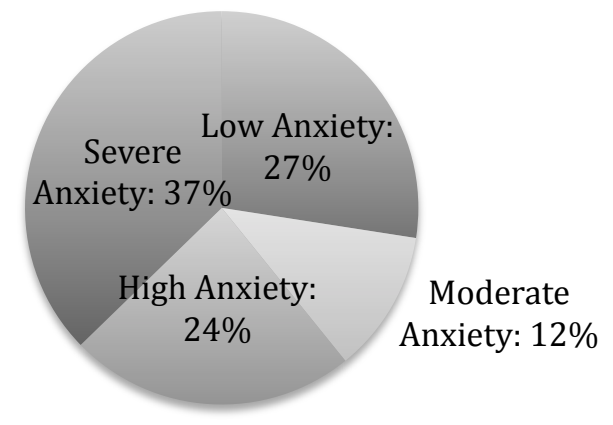

According to the dental literature, $12 \%$ to $19 \%$ of Americans are estimated to fall in the severe category on measures of dental anxiety (Corah, 1988; Hill \& Freeman, 2012; McCann, 1989; Ronis, 1994). Humphris et al. (1995) report that the greatest occurrence of MDAS scores in the severe anxiety category (MDAS totals of 19 to 25) was $19.5 \%$ in the four studies used to validate the MDAS. In our sample, $37.2 \%$ had 
scores of 19 or greater (severe anxiety), almost twice the rate estimated for the general population. Testing the observation of $37.2 \%$ in the severe category against a null hypothesis of $19 \%$ with a one-proportion $z$ test shows a significant difference in proportions $(p=0.0025)$.

Frequencies of responses of the individual MDAS items are shown in Table 6. Scoring 1 point for "not anxious" through 5 points for "extremely anxious" yields the means for individual items. Mean scores for the individual MDAS items ranged from 2.84 for Question 4 (If you were about to have your teeth scaled and polished, how would you feel?) to 3.82 for Question 5 (If you were about to have a local anesthetic injection, how would you feel?). The greatest number of participants indicated "extreme anxiety" to Items 3 and 5, which deal with having a tooth drilled and local anesthetic.

Table 6

MDAS: Item Response Frequencies $(n=51)$

\begin{tabular}{|c|c|c|c|c|c|c|}
\hline Question & $\begin{array}{c}\text { Not } \\
\text { Anxious } \\
1 \text { point } \\
\end{array}$ & $\begin{array}{l}\text { Slightly } \\
\text { Anxious } \\
2 \text { points } \\
\end{array}$ & $\begin{array}{c}\text { Fairly } \\
\text { Anxious } \\
3 \text { points } \\
\end{array}$ & $\begin{array}{c}\text { Very } \\
\text { Anxious } \\
4 \text { points } \\
\end{array}$ & $\begin{array}{l}\text { Extremely } \\
\text { Anxious } \\
5 \text { points } \\
\end{array}$ & $\begin{array}{l}\text { Mean } \\
(\mathrm{SE})^{\mathrm{a}}\end{array}$ \\
\hline $\begin{array}{l}\text { 1. If you went to your } \\
\text { dentist for treatment } \\
\text { tomorrow, how would } \\
\text { you feel? }\end{array}$ & $\begin{array}{c}11 \\
22 \%\end{array}$ & $\begin{array}{c}15 \\
29 \%\end{array}$ & $\begin{array}{c}3 \\
6 \%\end{array}$ & $\begin{array}{c}11 \\
22 \%\end{array}$ & $\begin{array}{c}11 \\
22 \%\end{array}$ & $\begin{array}{l}2.92 \\
(.21)\end{array}$ \\
\hline $\begin{array}{l}2 . \text { If you were sitting } \\
\text { in the waiting room } \\
\text { (waiting for } \\
\text { treatment), how would } \\
\text { you feel? }\end{array}$ & $\begin{array}{c}10 \\
20 \%\end{array}$ & $\begin{array}{c}14 \\
27 \%\end{array}$ & $\begin{array}{c}7 \\
14 \%\end{array}$ & $\begin{array}{c}13 \\
25 \%\end{array}$ & $\begin{array}{c}7 \\
14 \%\end{array}$ & $\begin{array}{l}2.86 \\
(.19)\end{array}$ \\
\hline $\begin{array}{l}3 . \text { If you were about to } \\
\text { have a tooth drilled, } \\
\text { how would you feel? }\end{array}$ & $\begin{array}{c}7 \\
14 \%\end{array}$ & $\begin{array}{c}5 \\
10 \%\end{array}$ & $\begin{array}{c}7 \\
14 \%\end{array}$ & $\begin{array}{c}10 \\
20 \%\end{array}$ & $\begin{array}{c}22 \\
43 \%\end{array}$ & $\begin{array}{l}3.69 \\
(.20)\end{array}$ \\
\hline $\begin{array}{l}\text { 4. If you were about to } \\
\text { have your teeth scaled } \\
\text { and polished, how } \\
\text { would you feel? }\end{array}$ & $\begin{array}{c}13 \\
25 \%\end{array}$ & $\begin{array}{c}10 \\
20 \%\end{array}$ & $\begin{array}{c}11 \\
22 \%\end{array}$ & $\begin{array}{c}6 \\
12 \%\end{array}$ & $\begin{array}{c}11 \\
22 \%\end{array}$ & $\begin{array}{l}2.84 \\
(.21)\end{array}$ \\
\hline $\begin{array}{l}\text { 5. If you were about to } \\
\text { have a local anesthetic } \\
\text { injection in your gum, } \\
\text { above an upper back }\end{array}$ & $\begin{array}{c}6 \\
12 \%\end{array}$ & $\begin{array}{c}5 \\
10 \%\end{array}$ & $\begin{array}{c}7 \\
14 \%\end{array}$ & $\begin{array}{c}6 \\
12 \%\end{array}$ & $\begin{array}{c}27 \\
53 \%\end{array}$ & $\begin{array}{l}3.84 \\
(.20)\end{array}$ \\
\hline
\end{tabular}




\begin{tabular}{|l|l|l|l|l|l|l|}
\hline $\begin{array}{l}\text { tooth, how would you } \\
\text { feel? }\end{array}$ & & & & & & \\
\hline
\end{tabular}

${ }^{\mathrm{a}} \mathrm{SE}=$ standard error of the mean

\section{Research Question 2}

Does the oral health learning session have a measurable effect on the participants' oral health knowledge?

\section{Data}

The ROHKI measured 10 concepts related to oral health conditions and self-care practices. Table 7 shows the numbers and percentages of participants who gave the correct response to each item in the ROHKI.

Table 7

ROHKI: Descriptive data

\begin{tabular}{|c|c|c|c|c|}
\hline Question & $\begin{array}{c}\text { All } \\
\text { Pretest } \\
\text { correct }\end{array}$ & $\begin{array}{l}\text { Attend } \\
\text { Pretest } \\
\text { correct }\end{array}$ & $\begin{array}{l}\text { Attend } \\
\text { Posttest } \\
\text { correct }\end{array}$ & $p$ \\
\hline 1. Sugar contributes to tooth decay because? & $\begin{array}{l}28 / 51 \\
55 \%\end{array}$ & $\begin{array}{l}13 / 27 \\
48 \%\end{array}$ & $\begin{array}{l}19 / 27 \\
70 \%\end{array}$ & $p=0.166$ \\
\hline 2. What is plaque? & $\begin{array}{l}44 / 51 \\
86 \%\end{array}$ & $\begin{array}{l}22 / 27 \\
81.5 \%\end{array}$ & $\begin{array}{l}23 / 27 \\
85 \%\end{array}$ & $p=1.000$ \\
\hline $\begin{array}{l}\text { 3. Does fluoride in toothpaste make any } \\
\text { difference to the health of your teeth? }\end{array}$ & $\begin{array}{l}37 / 51 \\
73 \%\end{array}$ & $\begin{array}{l}16 / 27 \\
59 \%\end{array}$ & $\begin{array}{l}24 / 27 \\
89 \%\end{array}$ & $p=0.028$ \\
\hline 4. What is the truth about flossing? & $\begin{array}{l}45 / 51 \\
88 \%\end{array}$ & $\begin{array}{l}24 / 27 \\
89 \%\end{array}$ & $\begin{array}{l}23 / 27 \\
85 \%\end{array}$ & $p=1.000$ \\
\hline 5. What is gingivitis? & $\begin{array}{l}40 / 51 \\
78 \%\end{array}$ & $\begin{array}{l}23 / 27 \\
85 \%\end{array}$ & $\begin{array}{l}23 / 27 \\
85 \%\end{array}$ & $p=1.000$ \\
\hline $\begin{array}{l}\text { 6. If you do want to enjoy a sugary treat, } \\
\text { when is the most "tooth-friendly" time to } \\
\text { eat it? }\end{array}$ & $\begin{array}{l}9 / 51 \\
18 \%\end{array}$ & $\begin{array}{l}6 / 27 \\
22 \%\end{array}$ & $\begin{array}{l}14 / 27 \\
52 \%\end{array}$ & $p=0.047$ \\
\hline $\begin{array}{l}\text { 7. What is the goal when we brush our } \\
\text { teeth? }\end{array}$ & $\begin{array}{l}48 / 51 \\
94 \%\end{array}$ & $\begin{array}{l}24 / 27 \\
89 \%\end{array}$ & $\begin{array}{l}25 / 27 \\
93 \%\end{array}$ & $p=1.000$ \\
\hline $\begin{array}{l}\text { 8. Research studies have shown a link } \\
\text { between periodontal (gum) disease and } \\
\text { which of the following? }\end{array}$ & $\begin{array}{l}20 / 51 \\
39 \%\end{array}$ & $\begin{array}{l}10 / 27 \\
37 \%\end{array}$ & $\begin{array}{l}20 / 27 \\
74 \%\end{array}$ & $p=0.013$ \\
\hline $\begin{array}{l}\text { 9. What are the two most important dental } \\
\text { health habits? }\end{array}$ & $\begin{array}{l}33 / 51 \\
84 \%\end{array}$ & $\begin{array}{l}18 / 27 \\
67 \%\end{array}$ & $\begin{array}{l}18 / 27 \\
67 \%\end{array}$ & $p=1.000$ \\
\hline $\begin{array}{l}10 . \text { Which of the following statements is/are } \\
\text { true about smoking cigarettes? }\end{array}$ & $\begin{array}{l}43 / 51 \\
84 \%\end{array}$ & $\begin{array}{l}22 / 27 \\
81.5 \%\end{array}$ & $\begin{array}{l}23 / 27 \\
85 \%\end{array}$ & $p=1.000$ \\
\hline
\end{tabular}

Fisher's Exact Test was used rather than the Chi-Square Test for this examination 
of changes between pretest and posttest scores on the individual ROHKI items. It is appropriate for the small sample sizes and computes an exact probability instead of the approximation that the Chi-Square test provides.

Questions 3, 6, and 8 showed significant changes in mean score between pretest and posttest. Several of the questions warrant individual inspection:

ROHKI Item 3. Does fluoride in toothpaste make any difference to the health of your teeth?
A. No, it makes no difference at all, and fluoride is now being phased out because it isn't safe.
B. Fluoride in toothpaste has hugely improved oral health by decreasing cavities.
C. Fluoride isn't dangerous, but toothpaste without fluoride is just as effective at preventing cavities.
D. Nobody really knows because there haven't been many studies in the area.

Option B is the correct response, and the majority of participants gave this response. The increase from 16 correct responses to 24 out of 27 (from $59 \%$ to $89 \%$ ) is significant, with $p=0.028$ (Table 8).

Table 8.

ROHKI Item 3: Does fluoride in toothpaste make any difference to the health of your teeth?

\begin{tabular}{|l|l|l|l|l|}
\hline & A & B $^{\mathrm{a}}$ & C & D \\
\hline All participants ( $=51):$ Pretest & 5 & 37 & 5 & 3 \\
\hline Attendees (n=27): Pretest & 4 & 16 & 3 & 2 \\
\hline Attendees (n=27): Posttest & 0 & 24 & 3 & 0 \\
\hline
\end{tabular}

${ }^{\mathrm{a}} B$ is the correct response.

ROHKI Item 6. If you do want to enjoy a sugary treat, when is the most "toothfriendly" time to eat it?
A. first thing in the morning or last thing at night
B. along with a meal
C. as a snack on its own
D. it doesn't make any difference 
Option B is the correct response. There was significant change from pretest to posttest among women who attended the oral health class $(n=27)$. Six of 27 participants (22.2\%) answered correctly on the pretest; 14 participants (51.9\%) responded with the correct answer on the posttest. The increase from six correct responses to 14 out of 27 ( $22 \%$ to $52 \%)$ is significant, with $p=0.047$. Thirty-six of the larger pretest group $(\mathrm{n}=51$ (70.5\%) answered $D$ (it doesn't make any difference) on the pretest (Table 9).

Table 9

ROHKI Item 6: If you want to enjoy a sugary treat, when is the most "tooth-friendly" time to eat it?

\begin{tabular}{|l|l|l|l|l|}
\hline & A & B $^{\text {a }}$ & C & D \\
\hline All participants (n= 51): Pretest & 2 & 9 & 4 & 36 \\
\hline Attendees (n=27): Pretest ${ }^{\text {b }}$ & 1 & 6 & 3 & 16 \\
\hline Attendees (n=27): Posttest & 2 & 14 & 5 & 6 \\
\hline
\end{tabular}

${ }^{\mathrm{a}} B$ is the correct response. ${ }^{\mathrm{b}}$ One subject left the item unanswered.

ROHKI Item 8. Research studies have shown a link between periodontal (gum) disease and which of the following?
A. low birth weight babies (premature babies)
B. diabetes
C. heart disease and stroke
D. none of the above
E. a, b, and c

Ten of 27 participants (37.0\%) answered correctly (Option E) on the pretest. There were 20 correct responses on the posttest. The increase from 10 correct responses to 20 correct of 27 participants (from $37 \%$ to $74 \%$ ) is significant, with $p=0.013$.

The greatest number of changed responses between pretest and posttest for ROHKI 8 occurred between Response D (none of the above) and Response E ( $a, b$, and c) (Table 10).

Table 10

ROHKI Item 8: Research studies have shown a link between periodontal (gum) disease and which of the following? 


\begin{tabular}{|c|c|c|c|c|c|}
\hline & $\mathbf{A}$ & B & $\mathbf{C}$ & $\mathbf{D}$ & $\mathbf{E}^{a}$ \\
\hline All participants $(\mathrm{n}=51){\text { : } \text { Pretest }^{\mathrm{b}}}^{2}$ & 3 & 8 & 7 & 12 & 20 \\
\hline Attendees $(n=27)$ : Pretest ${ }^{b}$ & 1 & 3 & 3 & 9 & 10 \\
\hline Attendees $(\mathrm{n}=27)$ : Posttest & 1 & 3 & 2 & 1 & 20 \\
\hline
\end{tabular}

${ }^{\mathrm{a}} E$ is the correct response. ${ }^{\mathrm{b}}$ One subject left the item unanswered.

\section{ROHKI Comparison of Mean Cumulative Scores}

Comparison of mean cumulative ROHKI scores between pretest and posttest for the treatment group shows a gain of 1.3 points on the 10-point instrument (pairedsamples $t$ test, $p=0.004$ ) following the one-hour oral health session (Table 11). The increase from a mean of 6.79 correct responses on a 10-point scale to a mean of 8.09 correct responses is significant, with $p=0.004$.

Table 11

Comparison of Mean Cumulative ROHKI Scores

\begin{tabular}{|l|c|c|c|c|c|}
\hline & $\begin{array}{l}\text { Total ROHKI } \\
\text { Pretest } \\
\mathrm{N}=48\end{array}$ & $\begin{array}{l}\text { Total ROHKI } \\
\text { Pretest } \\
\text { Participants N =27 }\end{array}$ & $\begin{array}{l}\text { Total ROHKI } \\
\text { Posttest } \\
\text { Participants N =27 }\end{array}$ & $\begin{array}{l}\text { Change in mean } \\
\text { ROHKI Score } \\
\text { Participants N =27 }\end{array}$ & $P$ \\
\hline Low & 2.5 & 2.5 & 2 & & \\
\hline High & 9.5 & 9 & 10 & & 0.004 \\
\hline Mean & 6.98 & 6.79 & 8.09 & 0.31 & \\
\hline SE & 0.25 & 0.37 & 0.39 & 0.41 & \\
\hline
\end{tabular}

\section{Research Question 3A}

Does participation in the oral health learning session have a measurable effect on the participants' self-reported beliefs and attitudes toward dental health and self-care?

\section{Data}

The OHAQ was used to assess attitudes and behaviors relating to oral health. Questions 1 through 14 measure attitudes. For Items 3, 6, 7, 9, and 11, "agree" is the preferred response from the perspective of the dental community (Harris \& GarciaGodoy, 2004). For these five items, complete agreement with the statement was coded 1 
and partial agreement was coded 2. For questions $1,2,4,5,8,10,12,13$, and 14, "disagree" is the preferred response. For these nine items, complete disagreement was coded 1 and partial disagreement was coded 2 . Table 12 presents the frequencies of responses to the 14 items. In Table 11 responses are summarized: "agree partly" and "agree completely" were combined as "agree," and "disagree partly" and "disagree completely" were combined as "disagree."

The data were coded such that a lower score indicates congruence with the thinking of the dental community. Thus, mean scores for the series of 14 items can be evaluated as a group (Table 11). The instrument range in cumulative scores for Responses 1 through 14 is 14 to 56 . Pretest cumulative scores individual participants for Items 1 through 14 range from 15 to 34 .

Table 12

OHAQ: Frequencies, Items 1-14

\begin{tabular}{|c|c|c|c|c|c|c|c|}
\hline Item & $\begin{array}{l}\text { All } \\
(n=51) \\
\text { Pretest } \\
\text { Agree }\end{array}$ & $\begin{array}{l}\text { All } \\
(\mathrm{n}=51) \\
\text { Pretest } \\
\text { Disagree }\end{array}$ & $\begin{array}{l}\text { Attend } \\
(n=27) \\
\text { Pretest } \\
\text { Agree }\end{array}$ & $\begin{array}{l}\text { Attend } \\
(n=7) \\
\text { Posttest } \\
\text { Agree }\end{array}$ & $\begin{array}{l}\begin{array}{l}\text { Attend } \\
(n=27)\end{array} \\
\text { Pretest } \\
\text { Disagree }\end{array}$ & $\begin{array}{l}\text { Attend } \\
(\mathbf{n}=27) \\
\text { Posttest } \\
\text { Disagree }\end{array}$ & $p$ \\
\hline $\begin{array}{l}\text { 1. I believe } \\
\text { that only the } \\
\text { dentist can } \\
\text { prevent } \\
\text { cavities. }^{\text {b }}\end{array}$ & $\begin{array}{l}4.8 \% \\
7\end{array}$ & $\begin{array}{l}47 \\
92.2 \%\end{array}$ & $\begin{array}{l}2 \\
7.4 \%\end{array}$ & $\begin{array}{l}2 \\
7.4 \%\end{array}$ & $\begin{array}{l}25 \\
92.6 \%\end{array}$ & $\begin{array}{l}25 \\
92.6 \%\end{array}$ & $\begin{array}{l}p= \\
1.000\end{array}$ \\
\hline $\begin{array}{l}\text { 2. I believe } \\
\text { that if my } \\
\text { parents have } \\
\text { bad teeth, } \\
\text { brushing and } \\
\text { flossing will } \\
\text { not help my } \\
\text { teeth. }\end{array}$ & $\begin{array}{l}5 \\
9.8 \%\end{array}$ & $\begin{array}{l}46 \\
90.2 \%\end{array}$ & $\begin{array}{l}3 \\
11.1 \%\end{array}$ & $\begin{array}{l}1 \\
3.7 \%\end{array}$ & $\begin{array}{l}24 \\
88.9 \%\end{array}$ & $\begin{array}{l}26 \\
96.3 \%\end{array}$ & $\begin{array}{l}p= \\
0.610\end{array}$ \\
\hline $\begin{array}{l}\text { 3. I believe } \\
\text { that by } \\
\text { brushing and } \\
\text { flossing my } \\
\text { teeth I am }\end{array}$ & $\begin{array}{l}51 \\
100 \%\end{array}$ & $\begin{array}{l}0 \\
0.0 \%\end{array}$ & $\begin{array}{l}27 \\
100 \%\end{array}$ & $\begin{array}{l}26 \\
96.3 \%\end{array}$ & $\begin{array}{l}0 \\
0.0 \%\end{array}$ & $\begin{array}{l}1 \\
3.7 \%\end{array}$ & $\begin{array}{l}p= \\
1.000\end{array}$ \\
\hline
\end{tabular}


ORAL HEALTH KNOWLEDGE, ATTITUDES, BEHAVIORS

\begin{tabular}{|c|c|c|c|c|c|c|c|}
\hline $\begin{array}{l}\text { less } \\
\text { susceptible to } \\
\text { tooth decay. }\end{array}$ & & & & & & & \\
\hline $\begin{array}{l}\text { 4. I believe } \\
\text { that tooth loss } \\
\text { is a normal } \\
\text { part of } \\
\text { growing old. }\end{array}$ & $\begin{array}{l}26 \\
50.9 \%\end{array}$ & $\begin{array}{l}25 \\
49.0 \%\end{array}$ & $\begin{array}{l}13 \\
48.1 \%\end{array}$ & $\begin{array}{l}4 \\
14.8 \%\end{array}$ & $\begin{array}{l}14 \\
51.9 \%\end{array}$ & $\begin{array}{l}23 \\
85.2 \%\end{array}$ & $\begin{array}{l}p= \\
0.018\end{array}$ \\
\hline $\begin{array}{l}\text { 5. I am likely } \\
\text { to have } \\
\text { gingivitis or } \\
\text { gum disease } \\
\text { in the next } \\
\text { year or two. }\end{array}$ & $\begin{array}{l}33 \\
64.7 \%\end{array}$ & $\begin{array}{l}18 \\
35.2 \%\end{array}$ & $\begin{array}{l}10 \\
37.0 \%\end{array}$ & $\begin{array}{l}5 \\
18.5 \%\end{array}$ & $\begin{array}{l}17 \\
63.0 \%\end{array}$ & $\begin{array}{l}22 \\
81.5 \%\end{array}$ & $\begin{array}{l}p= \\
0.022\end{array}$ \\
\hline $\begin{array}{l}6 . \text { I believe } \\
\text { that I am } \\
\text { responsible } \\
\text { for } \\
\text { preventing } \\
\text { the loss of my } \\
\text { teeth. }\end{array}$ & $\begin{array}{l}49 \\
96.0 \%\end{array}$ & $\begin{array}{l}2 \\
3.9 \%\end{array}$ & $\begin{array}{l}25 \\
92.6 \%\end{array}$ & $\begin{array}{l}26 \\
92.6 \%\end{array}$ & $7.4 \%$ & $\begin{array}{l}1 \\
3.7 \%\end{array}$ & $\begin{array}{l}p= \\
1.000\end{array}$ \\
\hline $\begin{array}{l}\text { 7. I believe } \\
\text { that by } \\
\text { flossing my } \\
\text { teeth I can } \\
\text { prevent } \\
\text { gingivitis. }{ }^{\text {a }}\end{array}$ & $\begin{array}{l}46 \\
90.2 \%\end{array}$ & $\begin{array}{l}5 \\
9.8 \%\end{array}$ & $\begin{array}{l}25 \\
92.6 \%\end{array}$ & $\begin{array}{l}25 \\
92.6 \%\end{array}$ & $\begin{array}{l}2 \\
7.4 \%\end{array}$ & $\begin{array}{l}2 \\
7.4 \%\end{array}$ & $\begin{array}{l}p= \\
1.000\end{array}$ \\
\hline $\begin{array}{l}\text { 8. I believe } \\
\text { dentures are } \\
\text { less trouble } \\
\text { than taking } \\
\text { care of my } \\
\text { natural teeth. }\end{array}$ & $\begin{array}{l}13 \\
25.5 \%\end{array}$ & $\begin{array}{l}37 \\
72.5 \%\end{array}$ & $\begin{array}{l}6 \\
22.2 \%\end{array}$ & $\begin{array}{l}4 \\
14.8 \%\end{array}$ & $\begin{array}{l}27 \\
7.8 \% 1\end{array}$ & $\begin{array}{l}23 \\
85.2 \%\end{array}$ & $\begin{array}{l}p= \\
0.728\end{array}$ \\
\hline $\begin{array}{l}\text { 9. I believe I } \\
\text { know how to } \\
\text { brush my } \\
\text { teeth } \\
\text { correctly. }\end{array}$ & $\begin{array}{l}45 \\
88.2 \%\end{array}$ & $\begin{array}{l}6 \\
11.8 \%\end{array}$ & $\begin{array}{l}26 \\
96.3 \%\end{array}$ & $\begin{array}{l}26 \\
96.3 \%\end{array}$ & $\begin{array}{l}1 \\
3.7 \%\end{array}$ & $\begin{array}{l}1 \\
3.7 \%\end{array}$ & $\begin{array}{l}p= \\
1.000\end{array}$ \\
\hline $\begin{array}{l}\text { 10. If my } \\
\text { gums bleed } \\
\text { when I floss } \\
\text { this usually } \\
\text { means that I } \\
\text { am hurting } \\
\text { my gums and } \\
\text { I should stop }\end{array}$ & $\begin{array}{l}43 \\
84.3 \%\end{array}$ & $\begin{array}{l}7 \\
13.7 \%\end{array}$ & $\begin{array}{l}4 \\
14.8 \%\end{array}$ & $\begin{array}{l}2 \\
7.4 \%\end{array}$ & $\begin{array}{l}23 \\
85.2 \%\end{array}$ & $\begin{array}{l}25 \\
92.6 \%\end{array}$ & $\begin{array}{l}p= \\
0.669\end{array}$ \\
\hline
\end{tabular}


ORAL HEALTH KNOWLEDGE, ATTITUDES, BEHAVIORS

\begin{tabular}{|l|l|l|l|l|l|l|l|}
\hline $\begin{array}{l}\text { flossing my } \\
\text { teeth. }\end{array}$ & & & & & & & \\
\hline $\begin{array}{l}\text { 11. If I knew } \\
\text { the facts } \\
\text { about dental } \\
\text { health I could } \\
\text { help prevent } \\
\text { the loss of my } \\
\text { teeth. }\end{array}$ & $42.4 \%$ & $13.7 \%$ & $96.3 \%$ & $96.3 \%$ & $3.7 \%$ & $3.7 \%$ & 1.000 \\
\hline $\begin{array}{l}\text { 12. I believe } \\
\text { visiting the } \\
\text { dentist is only } \\
\text { necessary } \\
\text { when I am } \\
\text { experiencing } \\
\text { pain. }\end{array}$ & $11.8 \%$ & $88.2 \%$ & $11.1 \%$ & $14.8 \%$ & $88.9 \%$ & $85.2 \%$ & 1.000 \\
\hline $\begin{array}{l}\text { 13. I am } \\
\text { likely to have } \\
\text { tooth decay in } \\
\text { the next year } \\
\text { or two. }\end{array}$ & $52.9 \%$ & $47.0 \%$ & $48.1 \%$ & $22.2 \%$ & $51.9 \%$ & $77.8 \%$ & 0.086 \\
\hline $\begin{array}{l}\text { 14. If my } \\
\text { gums bleed } \\
\text { when I brush } \\
\text { this usually } \\
\text { means that I } \\
\text { am brushing } \\
\text { too hard and I } \\
\text { should stop } \\
\text { brushing my } \\
\text { teeth. }\end{array}$ & $11.8 \%$ & $88.2 \%$ & $11.1 \%$ & $3.7 \%$ & $88.9 \%$ & $96.3 \%$ & 0.610 \\
\hline
\end{tabular}

a "Agree" is the preferred response. ${ }^{b}$ Denotes a response indicating a belief that is a barrier to optimum oral health; "disagree" is the preferred response.

The responses to 11 of the 14 items indicate that the majority of the participants had attitudes that agree with those in the dental profession for these statements. More specifically, more than $90 \%$ of respondents had the preferred response to Items 1, 2, 3, 6, 7, 9, and 11 (Table 12). Between 70\% and 90\% had the preferred response to Items 8,10 , 12 , and 14. There was little change between pretest and posttest for these 11 items. The 
remaining three items, Numbers 4,5 , and 13 , showed greater change between pretest and posttest.

In Fisher's Exact Test, Items 4 and 5 exhibit significant change between pretest and posttest $(p=0.018 ; p=0.022)$.

\section{OHAQ Comparison of Mean Cumulative Scores for Items 1-14}

Comparison of mean cumulative OAHQ scores for Items 1 through 14 shows a decrease of 4 points following the oral health learning session between pretest and posttest for the treatment group (paired-samples $t$ test, $p=0.0001$ ). The data were coded such that a lower score indicates congruence with the thinking of the dental community (Harris \& Garcia-Godoy, 2004).

The changes between pretest and posttest for Items 4 and 4 are significant. In Item 4, 13 participants (48\%) agreed with the statement "I believe that tooth loss is a normal part of growing old" on the pretest. Posttest responses indicate that only 4 participants $(14.8 \%)$ continued to agree. The decrease from 13 "agree" responses to four out of 27 (a decrease of $33.3 \%$ ) is significant with $p=0.018$. This represents a significant shift from external to internal locus of control with respect to the possibility of keeping teeth and an increase in self-efficacy (Wolfe, Stewart, \& Hartz, 1991).

The number who agreed with the Item 5 statement, "I am likely to have gingivitis in the next year or two," fell from $10(37.0 \%)$ to five $(18.5 \%)$ on posttest ( $p=0.022)$, a decrease of $18.5 \%$. Item 13 suggests an encouraging trend in that the number agreeing with the statement, "I am likely to have tooth decay in the next year or two." While the 
results are not statistically significant $(p=0.086)$, the number fell from $13(48.1 \%)$ to six (22.2\%), a decrease of $25.9 \%$.

\section{Research Question 3B}

Are there measurable changes in self-reported oral health-related behaviors following the oral health learning session?

\section{Data}

Items 15 through 20 of the OHAQ address behaviors related to oral health.

Numbers 15 and 16 have to do with frequency of cleaning the teeth with toothbrush and floss. For data entry and analysis purposes, the five categories were coded 1 through 5 , with a lower number indicating greater frequency of tooth brushing or flossing.

Table 13 and Figure 3 display the frequencies of responses to Item 15, "How often do you brush your teeth?" On the pretest, the majority of participants acknowledged brushing their teeth two or more times per day. Among the 51 pretest respondents, eight (16\%) stated they brushed more than twice per day and 20 (39\%) twice per day, for a total of $28(55 \%)$ brushing the two times per day that dentists recommend. Among those who attended the oral health learning session $(n=27), 14(52 \%)$ stated on the pretest and $20(74 \%)$ on the posttest that they brushed two or more times per day.

Table 13

OHAQ Item 15: How often do you brush your teeth?

\begin{tabular}{|l|c|c|c|c|c|c|}
\hline $\begin{array}{l}\text { How often do you } \\
\text { brush your teeth? }\end{array}$ & $\begin{array}{c}>\mathbf{2 x} / \mathbf{d a y} \\
\mathbf{( 1 )}\end{array}$ & $\begin{array}{c}\mathbf{2 x} / \mathbf{d a y} \\
\mathbf{( 2 )}\end{array}$ & $\begin{array}{c}\mathbf{1 x} / \mathbf{d a y} \\
\mathbf{( 3 )}\end{array}$ & $\begin{array}{c}\mathbf{2 - 3 x} / \mathbf{w k} \\
\mathbf{( 4 )}\end{array}$ & $\begin{array}{c}<\mathbf{3} \mathbf{x} / \mathbf{w k} \\
\mathbf{( 5 )}\end{array}$ & $\begin{array}{c}\text { Mean } \\
\mathbf{( S E )}\end{array}$ \\
\hline All participants & 8 & 20 & 17 & 2 & 4 & 2.49 \\
$(\mathrm{n}=51)$ : Pretest & $16 \%$ & $39 \%$ & $33 \%$ & $4 \%$ & $8 \%$ & $(0.15)$ \\
\hline Attendees (n=27): & 5 & 9 & 9 & 2 & 2 & 2.52 \\
Pretest & $19 \%$ & $33 \%$ & $33 \%$ & $7 \%$ & $7 \%$ & $(0.22)$ \\
\hline Attendees (n=27): & 6 & 14 & 5 & 1 & 1 & 2.15 \\
Posttest & $22 \%$ & $52 \%$ & $19 \%$ & $4 \%$ & $4 \%$ & $(0.18)$ \\
\hline
\end{tabular}


Effect size for the mean score in Item 15 is a decrease of 0.37 (SE for pairwise samples $=0.18$, indicating an increase in frequency of brushing. In a paired-samples $t$ test the decrease from a mean of 2.52 to 2.15 is significant, with $p=0.0477$. The scores of 10 of the 27 participants decreased; five participants had reported brushing more than twice a day in the pretest and showed no change in the posttest. Figure 3 displays the increase in frequency of brushing for responses " $>2 \mathrm{x} /$ day" and " $2 \mathrm{x} /$ day" and the decrease in the frequency of the other three responses.

Figure 3

OHAQ Item 15: How often do you brush your teeth?

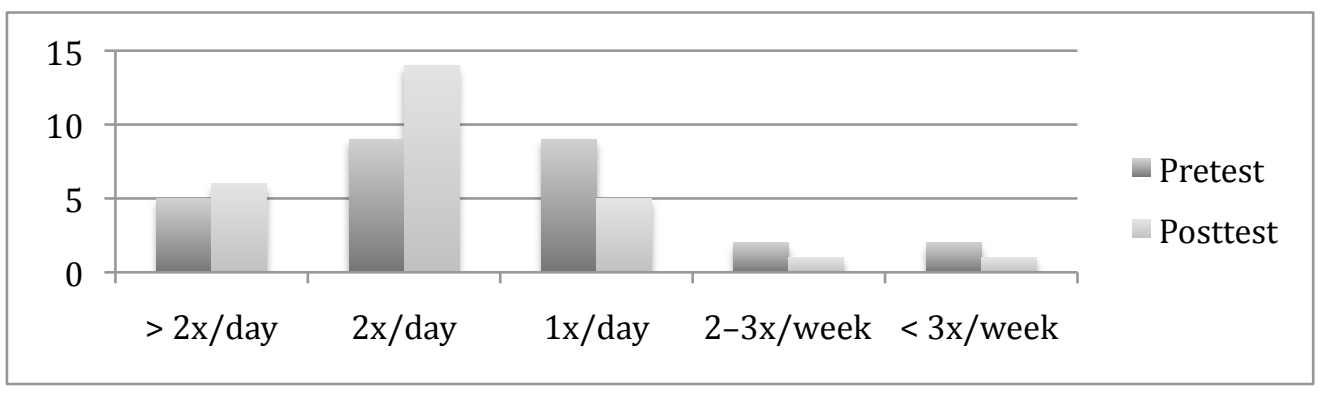

Table 14 shows the responses to OHAQ Item 16, "How often do you clean between your teeth?" On the pretest, $25 \%$ of the 50 participants who responded acknowledged flossing their teeth one or more times per day. Thirty-one percent of attendees on pretest and $42 \%$ on posttest reported flossing one or more times per day. Effect size for the mean score in item 16 is a decrease of 0.54 (SE for pairwise samples $=$ 0.25 ), indicating an increase in the frequency of flossing teeth. In a paired-samples $t$ test, the decrease from a mean of 2.62 to 2.08 is significant, with $p=0.0407$. A lower number indicates increased frequency of flossing. Four of the pretest participants indicated in a written comment by Item 16 that they were either edentulous or had so few remaining teeth that there were no contacts between teeth to floss. Three of these participants 
replied "never" to Question 16; the fourth left it blank.

Table 14

OHAQ Item 16: How often do you clean between your teeth (by dental floss, tooth pick or interdental brush)?

\begin{tabular}{|l|l|l|l|l|l|l|}
\hline $\begin{array}{l}\text { How often do you clean } \\
\text { your between your teeth? }\end{array}$ & $\begin{array}{l}\geq \mathbf{1 x} / \mathbf{d a y} \\
(\mathbf{1})\end{array}$ & $\begin{array}{c}\mathbf{2 - 3 x} / \mathbf{w k} \\
\mathbf{( 2 )}\end{array}$ & $\begin{array}{l}\mathbf{1 x} / \mathbf{w e e k} \\
\mathbf{( 3 )}\end{array}$ & $\begin{array}{c}<\mathbf{1 x} / \mathbf{w k} \\
\mathbf{( 4 )}\end{array}$ & $\begin{array}{c}\text { Never } \\
(\mathbf{5})\end{array}$ & $\begin{array}{l}\text { Mean } \\
(\mathbf{S E})\end{array}$ \\
\hline $\begin{array}{l}\text { All participants: Pretest } \\
(\mathrm{n}=51)\end{array}$ & 13 & 10 & 5 & 16 & 6 & 2.84 \\
\hline $\begin{array}{l}\text { Attendees: Pretest } \\
(\mathrm{n}=26)^{1}\end{array}$ & $25 \%$ & $20 \%$ & $10 \%$ & $31 \%$ & $12 \%$ & $(0.20)$ \\
\hline $\begin{array}{l}\text { Attendees: Posttest } \\
(\mathrm{n}=26)^{1}\end{array}$ & $31 \%$ & 6 & 2 & 8 & 2 & 2.615 \\
& 11 & 9 & $8 \%$ & $31 \%$ & $8 \%$ & $(0.28)$ \\
\hline
\end{tabular}

${ }^{1}$ One participant did not respond to item 16.

OHAQ Items 17 and 18 provide information about the history of the participants' attendance at dental appointments and plans for future dental visits. Data for Item 17 were coded 1 through 6 , with 1 and 2 collapsed into one column indicating one or more visits per year. These data represent participants' histories, with no changes expected between pretest and posttest. There were minor variations, however. Effect size for the mean scores in Item 17 is a decrease of 0.07 (SE for pairwise samples $=0.25$ ). In Fisher's Exact Test, $p=0.5478$, indicating there were not significant changes between pretest and posttest responses (Table 15).

Table 15

OHAQ Item 17: How often do you visit a dentist?

\begin{tabular}{|c|c|c|c|c|c|c|}
\hline $\begin{array}{l}\text { How often do you } \\
\text { visit a dentist? }\end{array}$ & $\geq \begin{array}{c}\geq 1 x / \text { year } \\
(1-2)\end{array}$ & $\begin{array}{r}\text { Every } 2 \\
\text { years (3) }\end{array}$ & $\begin{array}{r}\text { Every } 3 \\
\text { years (4) }\end{array}$ & $\begin{array}{l}<1 x \text { in } 3 \\
\text { years }(5)\end{array}$ & $\begin{array}{c}\text { Never } \\
(6)\end{array}$ & $\begin{array}{c}\text { Mean } \\
(\mathrm{SE})\end{array}$ \\
\hline $\begin{array}{l}\text { All participants: } \\
\text { Pretest }(\mathrm{n}=51)\end{array}$ & 28 & 4 & 2 & 10 & 7 & $\begin{array}{c}2.67 \\
(0.26) \\
\end{array}$ \\
\hline $\begin{array}{l}\text { Attendees: Pretest } \\
(\mathrm{n}=27)\end{array}$ & 16 & 2 & 1 & 5 & 3 & $\begin{array}{c}2.85 \\
(0.35) \\
\end{array}$ \\
\hline $\begin{array}{l}\text { Attendees: } \\
\text { Posttest }(n=27)\end{array}$ & 17 & 0 & 1 & 8 & 1 & $\begin{array}{c}2.78 \\
(0.35)\end{array}$ \\
\hline
\end{tabular}


Responses represented in Item 18 are descriptive, not numeric, and have not been analyzed statistically (Table 16). The responses show a slight decrease in the number who plan to wait until they have a toothache to next attend a dental appointment and a slight increase in those who plan to have a dental exam as their next dental appointment.

Table 16

OHAQ Item 18: I plan to visit the dentist ...

\begin{tabular}{|l|l|l|l|l|l|}
\hline I plan to visit the dentist ... & Toothache & Insurance & $\begin{array}{l}\text { Dental } \\
\text { Exam }\end{array}$ & $\begin{array}{l}\text { Dental } \\
\text { hygiene }\end{array}$ & $\begin{array}{l}\text { I don't } \\
\text { know }\end{array}$ \\
\hline All participants: Pretest $(\mathrm{n}=51)$ & 7 & 14 & 11 & 8 & 11 \\
\hline Attendees: Pretest $(\mathrm{n}=27)$ & 3 & 4 & 7 & 6 & 7 \\
\hline Attendees: Posttest $(\mathrm{n}=27)$ & 1 & 6 & 10 & 6 & 4 \\
\hline
\end{tabular}

OHAQ Item 19 was "Do you smoke cigarettes or use another form of tobacco?" Twenty-five of the 27 treatment group participants reported on the pretest that they smoked; 22 reported smoking on the posttest (Table 17). The decrease from $92.6 \%$ to $81.5 \%$ is not significant (paired samples $t$ test, $p=0.111$ ). While the effects of smoking on the health of the mouth were discussed in the oral health learning session, smoking cessation was not a major objective of the session. The modest decrease is more likely attributed to the chemical dependency treatment program.

A total of $92.6 \%$ of the women who attended the oral health learning session acknowledged smoking, which is almost five times the $19.3 \%$ of adults in the United States who currently smoke cigarettes (Smoking and Tobacco Use, 2012). Testing the observation of $92.6 \%$ in the study participants against a null hypothesis of $19.3 \%$ with a one-proportion $z$ test shows a significant difference in proportions $(p<0.0001)$.

Table 17

OHAQ Item 19: Do you smoke cigarettes or use another form of tobacco?

Do you smoke cigarettes or use another form of tobacco?
Yes

No 


\begin{tabular}{|l|c|c|}
\hline All participants: Pretest & 43 & 8 \\
$(\mathrm{n}=51)$ & $84.3 \%$ & $15.7 \%$ \\
\hline Attendees: Pretest & 25 & 2 \\
$(\mathrm{n}=27)$ & $92.6 \%$ & $7.4 \%$ \\
\hline Attendees: Posttest & 22 & 5 \\
$(\mathrm{n}=27)$ & $81.5 \%$ & $18.5 \%$ \\
\hline
\end{tabular}

OHAQ Item 20 was "Have you ever used alcohol or other drugs to calm you to help you go to a dental appointment?" Almost 55\% of the respondents acknowledged that they had used alcohol or other drugs to self-premedicate dental anxiety in order to attend a dental appointment (Table 18). Comparing the mean of cumulative scores on the MDAS with the dichotomous responses on OHAQ Item 20 using a $t$-test $(\mathrm{n}=51)$, there does not exist a significant difference in mean MDAS total scores based on OAHQ 20 ( $p$ $=0.1376)$. Thus the MDAS dental anxiety score was not a significant predictor of selfpremedication. People with low dental anxiety were as likely to premedicate as those with high dental anxiety.

Table 18

OHAQ Item 20: Have you ever used alcohol or other drugs to calm you to help you go to a dental appointment?

\begin{tabular}{|l|c|c|}
\hline $\begin{array}{l}\text { Have you ever used alcohol or other drugs to calm } \\
\text { you to help you go to a dental appointment? }\end{array}$ & Yes & No \\
\hline All participants: Pretest $(\mathrm{n}=51)$ & 28 & 23 \\
& $54.9 \%$ & $45.0 \%$ \\
\hline
\end{tabular}

\section{Research Question 4}

Is there discussion about oral health topics among the study population following the oral health learning session?

\section{Data}

OHAQ Item 21 was added for the posttest as a result of my experience working with incarcerated women. It seemed that the oral health information that was shared with 
one woman in the clinic was known by others when they appeared for appointments. Item 21 indicates that the majority of women $(59.25 \%)$ did converse with others about the content of the oral health learning session (Table 19).

Table 19

OHAQ Item 21: Much learning occurs outside the classroom. Please indicate which statement best fits your experience.

\begin{tabular}{|c|c|}
\hline Attended, talked with other women & Attended, did not talk with other women \\
\hline $16(59.25 \%)$ & $11(40.74 \%)$ \\
\hline
\end{tabular}

\section{Summary of Results}

Research Question 1 was, "Is the level of dental anxiety different from that observed in the general population?" The results of the MDAS indicate that levels of dental anxiety did indeed differ from that observed in the general population. The mean MDAS cumulative score is significantly higher than that found in other populations. The results of the MDAS are notable and significant in the high percentage of women in the two treatment centers who evidence high levels of dental anxiety.

Research Question 2 was, "Does the oral health learning session have a measurable effect on the participants' oral health knowledge?" Results of the ROHKI indicate that the oral health learning session does have a measurable effect on the participants' oral health knowledge. This answers Research Question 2. Mean scores on the ROHKI increased significantly on posttest. The results of the ROHKI are encouraging both in the general level of preexisting knowledge and in the positive changes in responses to a number of specific items on posttest. Specific items in the ROHKI that showed significant gains involve the role of fluoride in toothpaste, the timing of sugary treat consumption, and the association between periodontal disease and 
systemic diseases.

Research Question 3A was, "Does participation in the oral health learning session have a measurable effect on the participants' self-reported beliefs and attitudes toward dental health and self-care?" The results of the OHAQ indicate that participation in the oral health learning session does result in measurable changes in the participants' selfreported beliefs and attitudes toward dental health.

Research Question 3B was, “Are there measurable changes in self-reported oral health-related behaviors following the oral health learning session?" The results of the OHAQ indicate that participation in the oral health learning session does result in measurable changes in the participants' self-reported health-related behaviors.

The results of the OHAQ (Research Questions 3A and 3B) are encouraging both in the general level of positive attitudes that many of the participants demonstrated in the pretest and in the positive changes in responses to specific items on the posttest. Mean scores on the OHAQ improved on the posttest. Items in the OHAQ that showed significant changes are the belief that tooth loss is not a normal part of growing old and individuals' belief in the likelihood of incurring disease or tooth decay in the next year.

Research Question 4 was, "Is there discussion about oral health topics among the study population following the oral health learning session?" Results of this OHAQ item, present on the posttest only, indicate that more than half the participants continued to discuss oral health topics following the oral health learning session.

The results of these analyses provide statistical support for the utility of the oral health education intervention. In addition, the existence of large numbers of women with 
high levels of dental anxiety provides important information that should be considered in chemical dependency treatment.

Chapter 5 presents discussion of the findings and their practical significance, with implications for further research and practice. The final chapter also addresses the limitations of the study and offers suggestions for further research. 
Chapter Five: Discussion

This study has examined attitudes and knowledge regarding oral health and measured dental anxiety among women in two residential treatment centers for chemical dependency. Three instruments, the MDAS, ROHKI, OHAQ), were employed in this study.

Four key findings emerge from this study:

1. The levels of dental anxiety in the study population are far higher than those of the general population, and they warrant specific attention in treatment programs for chemical dependency in women.

2. Levels of oral health knowledge can be improved with a one-hour education intervention.

3. Attitudes toward oral health and oral health behaviors can be favorably changed with a one-hour education intervention.

4. The majority of women in these residential chemical dependency treatment centers do discuss the health information with other residents following the oral health session.

\section{Dental Anxiety as a Significant Contributing Factor}

The results of the MDAS, administered as part of the pretest only, indicate that, among this population of low-income women in treatment for chemical dependencies, a greater proportion experiences high-to-severe levels of dental anxiety than what is found in the general population. Historically, dental anxiety has been attributed primarily to traumatic or embarrassing situations in the dental chair. Traumatic experiences outside the dental office, such as histories of physical and sexual abuse, are beginning to be recognized in the dental literature (Hays \& Stanley, 1997; Heines, 2005; Stalker et al., 2005). The facts that $61 \%$ of the women scored in the high-to-severe categories of dental anxiety and $95 \%$ to $100 \%$ of the women have experienced physical and sexual trauma hightlight the influence of such trauma histories on dental anxiety. 
More than half the women (54.9\%) acknowledged having used alcohol or other drugs as premedication to manage the stress of dental appointments. Given the high level of dental anxiety in the group and the fact that women with both low and high levels of dental anxiety self-premedicated for dental appointments, adding treatment components to address dental anxiety needs to be part of chemical dependency treatment for lowincome women.

There is evidence that measuring and discussing dental anxiety help decrease the anxiety. I recommend the use of an instrument such as the MDAS and a combination of group discussion and individual counseling to help women develop alternative strategies for managing their dental anxiety (Humphris, Clarke, \& Freeman, 2006).

Significant changes in knowledge and attitudes are recorded in the responses to items in the ROHKI and OHAQ.

\section{Oral Health Knowledge Improvement}

The existing levels of knowledge of oral health principles among these lowincome women in treatment for chemical dependency are encouraging, as evidenced by high percentages of correct pretest responses to five items:

- What is plaque?

- What is the truth about flossing?

- What is gingivitis?

- What is the goal when we brush our teeth?

- Which of the following statements is/are true about smoking cigarettes?

Pretest scores ranged from $81 \%$ to $89 \%$ correct for these five items (Table 7) among those who attended the oral health education class. This indicates that there is a general basic understanding of dental plaque and gingivitis, the goals of the oral hygiene practices of tooth brushing and flossing, and of some of the effects of tobacco on oral 
health. Posttest scores were modestly higher, from $85 \%$ to $94 \%$ correct, although these changes were not statistically significant (Table 7).

The items on the ROHKI that did show significant gains represent fundamentally important concepts in oral health promotion, prevention of oral diseases, and an appreciation of the interconnectedness of oral and systemic health. There is great potential for application of this knowledge to improve the oral and systemic health of the participants and their children.

The question of whether fluoride in toothpaste makes a difference in the health of teeth showed significant gains between pretest and posttest (Table 7). Fifty-nine percent of attendees gave pretest responses to this question that indicated a sound knowledge of the role of fluoride in toothpaste; $89 \%$ gave the correct response on the posttest. Fluoridation of toothpaste began in the United States in 1955, yet misinformation and controversy still surround its use. This is reflected in the responses that indicate the beliefs that fluoride does not increase the effectiveness of toothpaste, that it is not safe, and that there have not been studies (Table 8). The posttest responses indicate the influence of the dialogue during the oral health session of the role of fluoride in toothpaste, its action in the tooth surface, and the existence of sound research to support the safety and effectiveness of fluoride's presence in toothpaste.

The benefits of fluoridated toothpaste depend, of course, on the regular daily use in tooth brushing. Posttest results from the OHAQ, to be discussed later, indicate that the number of individuals who brush the desired two times per day increased significantly. 
One ROHKI item deals with the optimal timing of sugar consumption. Options were: as a snack on its own, first thing in the morning or last thing at night, along with a meal, or that it doesn't make any difference when sugars are consumed. "Along with a meal" is the preferred response. Twenty-two percent of the participants gave that response on the pretest, and more than half responded correctly on the posttest, a significant change (Table 8).

Sugar causes less harm when consumed during a meal, because saliva flow is greater and the sugars are diluted and swallowed rather than remaining on the teeth to be fermented by bacteria. I learned from prison inmates that many used food as a nighttime comfort, going to sleep with a chocolate bar in their mouth or after eating dry sugarsweetened cereal (and not brushing their teeth). Bedtime is the worst time to consume sugars, as the saliva flow decreases during the night and sugar and bacteria combine to produce acid over a number of hours, leading to tooth decay.

This awareness of the effect of sugar consumption timing on dental caries has the potential to decrease the tooth decay rate significantly. The oral health class addresses the amount of sugar in the diet, consistency (stickiness in particular) of sugary foods, frequency of consumption of sugary foods, and the timing - that is, eating sugars during meals (or as dessert) rather than as snacks.

One final ROHKI item produced significant results. This involved systemic conditions associated with periodontal diseases. Options included preterm low-birthweight babies (premature babies), diabetes, and cardiovascular diseases (including heart disease and stroke). The greatest number of changed responses between the pretest and 
posttest for this item occurred between the response "none of the above" and the response that included all three systemic conditions (Table 10). This is important because it indicates a new awareness of the interrelatedness between the health of the mouth and systemic health. Periodontal diseases do not predict or directly cause systemic pathology; the research demonstrates a complementary relationship, possibly related to underlying factors such as elevated levels of C-reactive proteins in the blood.

Two additional items are worthy of comment, although their changes between pretest and posttest scores were not significant. The first represents a general increase in the appreciation that the interaction between sugars in the diet and bacteria in the mouth is responsible for tooth decay. The item asks how sugar contributes to tooth decay: does it directly attack enamel, mechanically abrade and roughen tooth surfaces, combine with proteins in saliva to create a hardened layer of film on teeth, or is it converted by bacteria into acid which attacks tooth surfaces?

Correct responses to this item regarding sugar and tooth decay rose from $48 \%$ in the pretest to $70 \%$ posttest ( $p=0.166$, Table 7 ). The concept that it is possible to prevent tooth decay by decreasing sugars in the diet and bacteria in the mouth was a recurring theme in the oral health learning session. The significance of this is evident in the change in attitude: "I am likely to have tooth decay in the next year or two" (Table 12). While not statistically significant $(p=0.086)$, a $26 \%$ drop in the number who believe they will experience tooth decay is encouraging. It indicates an increase in a sense of agency and a belief that tooth decay is not something that simply occurs, but something that can be prevented by personal action. 
ROHKI Item 10 deals with the effects on oral health of smoking cigarettes. A surprising $81.5 \%$ of the participants correctly answered on the pretest that smoking is related to oral diseases, including half of all cases of periodontal disease and three fourths of all cancers of the mouth (Table 12). This is surprising in that, in my years of conducting small-group oral health group sessions, the only response any participant has given to the question of how tobacco harms the mouth is, "It stains your teeth."

Mean total scores on the ROHKI increased from 6.79 to 8.09 on a 10-point scale for the treatment group following the one-hour oral health session (Table 11). This significant improvement underscores the utility of the session.

\section{Improvement in Oral Health Attitudes and Behaviors}

As a whole, the responses are encouraging for OHAQ Items 1 through 14 regarding beliefs and attitudes toward oral health. Informal discussions with dentists indicate that many dentists believe the majority of low-income patients think, for example, that dentures are the solution to dental problems (OHAQ Item 8). In this study, 21 of 27 participants disagreed with this statement regarding dentures on the pretest.

Items 1 through 14 on the OHAQ deal with beliefs and attitudes toward oral health and oral hygiene practices. While only two of the individual items showed significant changes between pretest and posttest, the mean scores for this section (Items 1 through 14) as a whole improved significantly. The individual items have implications for internal versus external locus of control, beliefs that interfere with oral health, and self-efficacy (Wolfe, Stewart, \& Hartz, 1991). Thus, movement along continua represented by the Likert scale responses to these items is indicative of individuals' 
shifting toward increased self-efficacy and toward beliefs and attitudes more consistent with dental research and dental practice.

Changes in OHAQ Item 13, while not significant, are worth noting in that there was a general shift from what I consider a fatalistic stance that decay and gingivitis are inevitable to a more optimistic and empowered position that, with care, these conditions can be prevented. The number who disagreed with the statement in Item 5, "I am likely to have gingivitis in the next year or two," rose from $62.9 \%$ to $81.4 \%$ on posttest. The number who disagreed with the statement in Item 13, "I am likely to have tooth decay in the next year or two" also rose, from $51.8 \%$ to $77.8 \%$. It is interesting to consider the responses to Items 5 (gingivitis in the next year) and 13 (tooth decay in the next year) along with those of Item 11, "If I knew the facts about dental health I could help prevent the loss of my teeth." More than $96 \%$ of participants agreed on both the pretest and the posttest with this statement. Considering the changes in Items 5 and 11, which indicate increased confidence in the individuals' ability to prevent decay and gingivitis, it can be concluded that the respondents now consider that they know more of "the facts" about dental health as a result of the educational intervention.

Items 15 through 20 deal with behaviors related to oral health. There was a trend toward increased frequency of tooth brushing and flossing (OHAQ Items 15 and 16, Tables 13 and 14). The significant increase from approximately half brushing twice per day to almost three quarters has important systemic health implications as well as benefits for oral health. (de Oliveira, Watt, \& Hamer, 2010) reported that individuals who brushed their teeth less frequently than once a day were $70 \%$ more likely to have a heart 
attack or other cardiovascular disease event than those who brushed twice a day, even after controlling for many other factors. Brushing once rather than twice a day was associated with a $30 \%$ increase in the risk of these cardiovascular events.

According to the TPB, intentions to perform behaviors can be predicted accurately from attitudes toward the behavior, subjective norms, and perceived behavioral control (Ajzen, 1991). Ajzen (1991) concludes that intentions do correlate highly with actual behaviors, and that it is from the level of beliefs that differences in behavior occur. I maintain that all of the TPB determinants are addressed in the oral health learning session: challenging the belief that tooth loss is inevitable, convincing the participants that tooth decay and gingivitis can be prevented, presenting the norm of daily oral hygiene practices, and fostering self-efficacy by teaching that the self-care necessary to maintain teeth is within the individual's ability and control. Study results indicate a shift from anticipating the next dental visit at a time of acute infection to plans for routine dental exam and dental hygiene appointments, which is a more proactive stance.

Item 19 asked whether the participant smokes cigarettes or uses other forms of tobacco. Nearly $93 \%$ of the women acknowledged smoking, which is almost five times the $19.3 \%$ of adults in the United States who currently smoke cigarettes (Smoking and Tobacco Use, 2012). The oral health session does address the oral and systemic harmful effects of smoking. Given the prevalence of tobacco use in this population, more emphasis could placed on this component of the session.

\section{Lasting Benefits of Oral Health Education}


Women discuss health information with other women. Item 21 was framed by the acknowledgement that much learning occurs outside the classroom. The majority of participants acknowledged that they had continued to discuss the oral health topics following the oral health learning session. This study confirms the concept that providing health information in an engaging way to women who are making other health-related changes in their lives while in treatment for chemical dependencies is an effective way to improve the health of these women and their children and families.

\section{Efficacy of Small-Group Oral Health Appointments and Oral Health Education}

It is rare for oral health topics to be presented in a group setting for adults. This section presents the history and rationale for small-group consideration of medical topics, with the recommendation that small-group appointments or other group settings do provide an effective way for disadvantaged women to challenge beliefs and norms, provide health information in a way that encourages reflection and action, and foster empowerment.

While oral diseases and oral health literacy have not been studied or reported in the group medical appointment literature, these chronic conditions fit the criteria: oral diseases are common, costly to repair, and responsive to lifestyle changes. The understanding of etiology and management of oral plaque-related diseases and the dietary and other behavioral issues involved with oral diseases are similar to those issues that have proven successful in the small group format in the medical office context. Because periodontal diseases and caries (cavities) are chronic bacterially mediated diseases and the inflammation of periodontal diseases has been associated with systemic issues such as 
diabetes and cardiovascular disease, improved oral health can have broader health effects in mitigating systemic disease progress. In addition, for dialogue regarding oral health knowledge, the group provides something like the "therapeutic container" of counseling: a safe place, away from the dental chair and its potential anxiety triggers.

The study reported in this dissertation is based in part on the concept that group medical appointments can be used in dentistry as well as in medicine for a systems approach to oral health knowledge and attitudes - to foster understanding of the multiple etiologies and self-care strategies necessary to bring about health promotion self-care behaviors. In a learner-centered small-group medical setting, a person who has not had an orientation to health promotion behaviors in any aspect of her life (nutrition, exercise, birth control, oral hygiene practices, etc.) is more likely to develop an understanding of the interrelationships among these practices and her well-being (Jaret, 2001). She may become motivated to put the recommendations into practice as she develops confidence that she can be successful. These are profound developmental changes representing cognitive, attitudinal, and motivational metamorphoses (Cunningham \& Blaser, 2004; Lippman, 2000; Masley et al., 2000; Noffsinger, 2001; Ajzen, 1991; Ajzen, 2006).

Several authors cited in this dissertation address the need for providing contextstime, space, focus - for individuals to identify areas in which change is desirable and the factors that contribute to them (Freire, 1974; Parks, 2005; Stake, 1986). Once the individuals in a group have taken ownership of the issues, they can then develop plans to resolve these issues (Freire, 1974; Parks, 2005; Stake, 1986; Wiggins, 2010).

Taking ownership of a problem or situation is in itself empowering. The oral 
health learning session fosters this by presenting the issues involved in oral health in a systematic and cohesive way, encouraging individuals to consider their own oral health in ways that are frequently novel for that individual. The Socratic question and exploration format, allowing nonjudgmental consideration of all opinions expressed, encourages participation in the group process. (The reward of xylitol mints for offering opinions also helps encourage participation!)

Experiencing the process of reflection and intuitive generation, realizing that one has valid ideas and can reach reasonable conclusions, experiencing validation and encouragement in the group process - all of these contribute to women's adult development and empowerment (Belenky et al., 1997; Windschitl, 1999). The change process is complex, involving interrelated processes of new experience, reflection, and intuitive generation of conclusions (Kolb et al., 1999; Zull, 2002). Realization that there are options to choose from contributes to the conviction that action is required and to the motivation and confidence to take that action (Ajzen, 1991; Stake, 1986).

\section{Limitations of the Study}

This is a small and short-term study of a single educational intervention. The nonprobability sample, small sample size, and specific nature of the setting-women's chemical dependency treatment centers - preclude generalizability to other groups or settings. The sample was limited to English-speaking women. Reliance on self-reported data is a potential study limitation.

Participation in the research study was voluntary. All residents in Center A and all residents in Center B who were in the first three months of treatment attended the oral 
health session, exceptions being those who were ill or had medical appointments that day. A small subset of the total participants self-selected to attend the oral health session, that is, those in the final three months of the six-month treatment program at Center B.

The instruments themselves will have an effect on participants; administration of the ROHKI, for example, may raise awareness or clarify knowledge among the participants independent of the experience of the small group learning session. I speculate that the multiple choice format contributed to the relatively high number of correct responses to Item 8 in the ROHKI regarding the effects of tobacco on oral health.

The OHAQ lacks questions about sugar intake, and the addition of an item addressing consumption of soda would be valuable in future iterations of the OHAQ as a gauge of dietary sugars.

Four of the pretest participants indicated in a written comment by Question 16 that they were either edentulous or had so few remaining teeth that there were no contacts between teeth to floss. Three of these participants replied "never" to Question 16; the fourth left it blank. The OHAQ could be improved by the addition of an item regarding missing teeth or presence of dentures.

\section{Recommendations for Further Research}

Similar studies in larger diverse populations will allow more thorough analysis of the potential interconnectedness among dental anxiety and oral health knowledge, attitudes, and behaviors. Surveying additional residents of centers for treatment of chemical dependency would provide more robust data to build on the current study and allow for more detailed analysis of associations and trends. Surveys of other identified 
groups of people with low income, such as parents of children in Head Start, clinics for low-income pregnant women (Hom, Lee, Divaris, Baker, \& Vann, 2012), and prison inmates, would provide information that might support incorporating similar group oral health educational interventions for these groups.

Surveys of populations with varying levels of education and income and populations without chemical dependency (or having the $15 \%$ incidence estimated in the general population [Office on Disability]) would provide data as to whether dental anxiety impacts oral health knowledge, attitudes, and behaviors independent of education level. Patients attending clinics in dental schools are one such population. Studying the levels of oral health knowledge and potentially related dental anxiety for this population will provide a basis for refinement of the dental school oral health promotion curriculum and of communication practices among dental students, dental professionals, and the patients in their practices.

My impression from previewing the instruments among college-educated coworkers is that groups with more general education would achieve higher scores on the ROHKI and OHAQ, but these instruments have not been formally evaluated in groups with higher levels of education than were represented in the research reported here. There is concern within professional dental associations that physicians and nurses should be able to provide oral health guidance to patients. Surveying medical and nursing students early in their education would provide baseline information to allow assessment of and enhancement of oral health curriculum in medical and nursing professional education. 
Surveys of U.S. dental schools would provide information as to what exposure dental students have to assessing and managing dental anxiety and to providing oral health information to patients.

Specific key topics to focus on in the oral health learning sessions and oral health learning strategies can be refined and improved by further analysis. Further research can provide insight into the long-term effects of the oral health learning session on oral health behaviors.

Questions to be added in future iterations of the OHAQ will provide further information to assist in analysis: (a) education level; (b) sugar consumption, including sugar-sweetened beverages such as soda, Kool-Aid, and sports beverages; and (c) whether the subject is edentulous or has partial or complete removable dentures.

\section{Further Implications and Recommendations}

The prevalence of high-to-severe dental anxiety in this population undergoing treatment for chemical dependency underscores the imperative to assess and address dental anxiety as part of chemical dependency treatment programs. Professional education for counselors in the corrections setting and in chemical dependency treatment programs in the community will provide awareness and strategies for gaining competency in assessing and addressing dental anxiety in these settings.

Organizations that provide health care for participants or residents can help improve overall health as well as oral health for participants by improving oral health knowledge. Existing groups such as parents of children in Head Start, clinics for lowincome pregnant women, and corrections facilities provide a context for small-group 
learner-centered oral health intervention. Other community-based settings include public health clinics and dental school clinics.

Education of dental students can be improved by including principles of education and communication around oral health topics, which can be presented in the context of learning to facilitate a small-group learner-centered oral health intervention such as that presented in this study. Administration and assessment of a dental anxiety instrument such as the MDAS, as well as strategies for proportionate intervention, must be part of the dental curriculum for dentists to provide dental care and oral health instruction to all potential patients (Newton, Asimakopoulou, Daly, Scambler, \& Scott, 2012).

Continuing education for dental professionals also will benefit from courses that include administration and assessment of a dental anxiety instrument such as the MDAS as well as strategies for proportionate intervention in addressing dental anxiety (Newton et al., 2012). Many dentists, dental hygienists, and dental assistants volunteer to provide dental treatment in contexts such as the MTI mobile dental clinics. Orientation for volunteers provides a context for inclusion of information on administration and assessment of a dental anxiety instrument, strategies for helping patients manage dental anxiety, and ways of effectively communicating oral health information targeted for lowincome, at-risk individuals.

School nurses constitute an important nexus for disseminating general health and oral health information and for screening children for dental treatment in free mobile dental clinics. I met with representatives of the Parkrose Educational District near Portland, Oregon, who determined that the Oral Health Learning Session Module is 
appropriate for students in Grades 7 through 12, and recommended that grant funds be obtained to translate the module into Spanish and Russian and for funding substitute nurses so that school nurses might attend continuing education around facilitating the learner-centered oral health educational sessions.

\section{Conclusions}

As described in the TPB, the behavior changes reported in the posttest are evidence of modifications of attitudes toward tooth brushing and flossing frequency, of the normative beliefs toward oral self-care, and strengthening of perceived behavioral control (Ajzen, 1991). Combined, these lead to intentions, and, optimally, to new or improved behaviors. The interactive small-group format has been demonstrated in this study to have modest but significant impact on the processes of TPB and positive change in health behaviors.

Healthy People 2010 (Institute of Medicine, 2000), which features a goal of eliminating health disparities, provides public health professionals with a clear rationale for research, practice, and advocacy in the area of alternative programs and policies. Because the health effects of poverty operate through multiple pathways, no single strategy will reverse these adverse health effects (Mann et al., 1999). Chemical dependency treatment provides a structured, focused format for fostering positive health behavior choices and changes. The programs I have visited all have weekly health education sessions conducted by nurses. The programs have not had formal oral health components, and they welcomed the oral health presentations and participation in the present study. 
The people who attend low-income nonprofit chemical dependency treatment programs represent a microcosm of public or community health. Changes that may be hoped for in the community public health setting will involve improving general health literacy and oral health knowledge. Because these people have generally been less likely to attend to health in preventive medical or dental appointments, a plan and structure to meet in small groups in already-existing community settings is necessary to help manage chronic diseases including dental decay and periodontal diseases. For dental health and oral health literacy to be improved, factors that are major challenges include existing beliefs, knowledge, and health behaviors and dental anxiety that impede access to care.

\section{Summary}

There were three main areas of findings in this study. The first, the observation of the high incidence of high-to-severe dental anxiety in this population, is significant in its binocular view of dental anxiety and chemical dependency in women, with implications for the addition of dental anxiety management strategies in such chemical dependency treatment programs.

The second area of findings deals with the oral health learner-centered educational intervention. Results of this study indicate that knowledge and attitudes regarding oral health as well as oral health self-care behaviors can be strengthened with a single one-hour educational intervention. According to the TPB, beliefs highly influence behavior. The oral health learning session succeeded in addressing the tenets of the TPB, challenging the belief that tooth loss is inevitable; convincing the participants that tooth decay and gingivitis can be prevented; presenting the norm of daily oral hygiene 
practices; and fostering a sense of self-efficacy, that the self-care necessary to maintain teeth is within the individuals' ability and control. My hope is that other dental professionals and nurses will be able to use the Oral Health Learning Session Module in community settings to improve the oral health knowledge, beliefs, norms, attitudes, and behaviors related to the participants' oral health.

The third finding is that when information is presented in an engaging learnercentered way in small groups of women, participants continue the conversation around this information, further strengthening the effect of the educational intervention.

Acknowledging, challenging, and changing the values, norms, assumptions, and beliefs that determine the responses of an individual or a group to health recommendations can break the perpetuation of organizational inequalities and inequities pertaining to gender, race, class, and sexuality (Brookfield, 1995; Creedon, 1993). The oral health learning session has demonstrated utility in the limited context of this study. If, indeed, cultural capital includes attitudes toward health, then bringing to awareness such culture-related factors as normative beliefs and knowledge within the educational intervention affects the cultural capital, providing a positive influence on the health chances and choices of the women and their families. 


\section{References}

Abrahamsson, K. L., Berggren, U., Hakeberg, M., \& Carlsson, S. G. (2001). Phobic avoidance and regular dental care in fearful dental patients: A comparative study. Acta Odontologica Scandinavica, 59, 273-279.

ADA Center for Evidence-Based Dentistry. (n.d.). Retrieved March 9, 2011, from http://ebd.ada.org

Airasian, P., \& Walsh, M. (1997). Constructivist cautions. Phi Delta Kappan, 78, 444449.

American Academy of Family Physicians. (1997). Group visits (shared medical appointments): Introduction. Retrieved from http://www.aafp.org/online/en/home/practicemgt/quality/ditools/pracredesign/jan uary05.html

American Dental Association. (2008). Key dental facts. Chicago, IL: American Dental Association.

American Dental Association Council on Access, Prevention, and Interprofessional Relations. (2010). Health literacy in dentistry action plan 2010-2015. Chicago, IL: American Dental Association.

Aro, A. R., \& Absetz, P. (2009). Guidance for professionals in health promotion: Keeping it simple - but not too simple. Psychology and Health, 24, 125-129.

Ayers, W. (2005). Psychology and Dentistry: Mental Health Aspects of Patient Care. Binghampton, NY: The Haworth Press.

Ajzen, I. (1991). The theory of planned behavior. Organizational Behavior and Human Decision Processes, 50, 179-211.

Ajzen, I. (2006). TPB diagram. Retrieved from http://people.umass.edu/aizen/tpb.diag.html

Bandura, A. (1989). Social cognitive theory. In R. Vasta (Ed.), Annals of child development (Vol. 6, pp. 1-60). Greenwich, CT: Jai Press.

Bartholomew, L. K., \& Mullen, P. D. (2011). Five roles for using theory and evidence in the design and testing of behavior change interventions. Journal of Public Health Dentistry, 70(S), 20-33.

Becker, M. (1974). The health belief model and personal health behavior. Health Education Monographs, 2, 324-473.

Beegle, D. (2003). Overcoming the silence of generational poverty: Invisible literacies. Retrieved from Communication Across Barriers website: http://www.combarriers.com/TP0151Overcoming.pdf

Belenky, M. F., Clinchy, B. M., Goldberger, N. R., \& Tarule, J. M. (1997). Women's ways of knowing: The development of self, voice and mind (10th ed.). New York, NY: Basic Books.

Berry, J. (2005, November 7). New ADA president outlines priorities. American Dental Association News, p. 29.

Bertness, J., \& Holt, K. (2004). Oral health and health in women: A two-way relationship. Retrieved from http://www.ask.hrsa.gov/detail.cfm?id=MCH00123 
Blomster, B. (1997). Patients still want the human touch. California Dental Association Journal, 25(4), 186-187.

Bolton, J., Cox, B., Clara, I., \& Sareen. (2006). Use of alcohol and drugs to self-medicate aniety disorders in a nationally representative smple. Journal of Nervous and Mental Disease, 194(11), 818-825.

Braithwaite, R., Treadwell, H., \& Arriola, K. (2005). Health disparities and incarcerated women: A population ignored. American Journal of Public Health, 95(10), 16791681.

Brookfield, S. (1995). Becoming a critically reflective teacher. San Francisco, CA: Jossey-Bass.

Bruner, J. (1996). Constructivist theory. Learning theories. Retrieved from http://www.educationau.edu.au/archives/cp/04c.htm

Bullock, K. (1999). Dental care of patients with substance abuse. Dental Clinics of North America, 43(3), 513-526.

Burns, H. (2008). Teaching and learning sustainability: Using action research to test the burns model of sustainability pedagogy in two university courses. Portland, OR: Portland State University.

Corah, N. (1969). Development of a dental anxiety scale. Journal of Dental Research, 48, 596.

Corah, N. L. (1988). Dental anxiety: assessment, reduction and increasing patient satisfaction. Dental Clinics of North America, 32, 779-790.

Creedon, P. (1993). Acknowledging the infrasystem: A critical feminist analysis of systems theory. Public Relations Review, 19(2), 157-166.

Crossley, H. (1996). Management of the active or recovering chemically dependent dental patient. Maryland State Dental Association, 39(2), 85-86.

Cunningham, C., \& Blaser, J. (2004). Group visits can save time, but are they right for you? Retrieved from

http://www.acponline.org/clinical_information/journals_publications/acp_internis t/apr04/group.htm

Curtis, E. (2003). Heavy drinking, drug abuse present health complications for dental treatment. Retrieved from http://www .agd.org/media/2003/dec/abuse.html

Davey, G. (1989). Dental phobias and anxieties: Evidence for conditioning processes in the acquisition and modulation of a learned fear. Behavior Research and Therapy, 27, 51-58.

Davis, T. C., Long, S. W., Jackson, R. H., Mayeaux, E. J., George, R. B., Murphy, P. W., et al. (1993). Rapid estimate of adult literacy in medicine: A shortened screening instrument. Family Medicine, 25, 391-395.

DePaola, D. (1998, October). Beyond the university: Leadership for the common good. Paper presented at American Association of Dental Schools 75th Summit Conference, Washington, D.C. (pp. 1-9).

Doerr, P., Lang, W., Nyquist, L., \& Ronis, D. (1998). Factors associated with dental anxiety. Journal of the American Dental Association, 129, 1111-1119. 
Dube, S., Felitti, V. J., Dong, M., Chapman, D. P., Giles, W. H., \& Anda, R. F. (2003). Childhood abuse, neglect, and household dysfunction and the risk of illicit drug use: The Adverse Childhood Experiences (ACE) study. Pediatrics, 111, 564-572.

Duin, S. (2004, January 11). College education for a captive audience. The Oregonian. Retrieved from http://www.oregonian.com

Empey, G., \& Bradley, K. J. (2007). Oregon smile survey. Retrieved from http://www.oregon.gov/DHS/ph/oralhealth/docs/smile 2007.pdf

Engstrom, C. M., \& Tinto, V. (2008). Learning better together: The impact of learning communities on the persistence of low-income students. Retrieved from http://www.sdbor.edu/services/studentaffairs/documents/LearningBetterTogether_ Engstrom-Tinto-2008.pdf

Ennis, C. D. (1992). Reconceptualizing learning as a dynamic system. Journal of Curriculum and Supervision, 7(2), 115-130.

Feldman, M., \& Christensen, J. (1997). Behavioral Medicine in Primary Care. Stamford, CT: Appleton \& Lange.

Festinger, L. (1964). Conflict, decision, and dissonance. Oxford, England: Stanford University Press.

Filewich, R. J., Jackson, E., \& Shore, H. (1981). Effects of dental fear on efficiency of routine dental procedures. Journal of Dental Research, 60(A), Abstract \#895.

Freire, P. (1974). Pedagogy of the oppressed. (M. B. Ramos, trans.) New York, NY: Seabury.

Freudenberg, N. (2002). Adverse effects of US jail and prison policies on the health and well-being of women of color. American Journal of Public Health, 92, 18951899.

Friedlander, A. H., Friedlander, I., \& Marder, S. (2004). Posttraumatic stress disorder: Psychopathology, medical management, and dental implications. Oral Surgery, Oral Medicine, Oral Pathology, Oral Radiology, Endodontics, 97(1), 5-11.

Friedlander, A. H., Marder, S. R., Pisegna, J. R., \& Yagiela, J. A. (2003). Alcohol abuse and dependence: Psychopathology, medical management and dental implications. Journal of the American Dental Association, 134, 731-740.

Gibson-Howell, J. (1996). Domestic violence identification and referral. Journal of Dental Hygiene, 79(2), 74-79.

Glick, M. (2009). Utilization and access: Different concepts for different interests? Journal of the American Dental Association, 140(4), 396-98.

Gong, M. A., Lee, J. Y., Rozier, R. G., Pahel, B. T., Richman, J. A., \& Vann, W. F. (2007). Development and testing of the Test of Functional Health Literacy in Dentistry (TOFHLiD). American Association of Public Health Dentistry, 67(2), $105-112$.

Harris, N., \& Garcia-Godoy, F. (2004). Primary Preventive Dentistry (6th ed.). Upper Saddle River, NJ: Pearson Prentice Hall.

Harrison, J. (2004). Paradigm shift: From quality to systems excellence. CorrectCare, $18(1), 3$.

Hays, K., \& Stanley, S. F. (1997). The impact of childhood sexual abuse on women's dental experiences. Journal of Child Sexual Abuse, 5(4), 65-74. 
Heines, V. (2005). Speaking out - to improve the health of inmates. American Journal of Public Health, 95, 1685-1688.

Hill, K., \& Freeman, R. (2012). British adults: Self reported oral health, dental attendance and anxiety. Retrieved from IADR website: http://iadr.confex.com/iadr/2012rio/webprogram/paper162535.html

Holt, V., \& McHugh, K. (1997). Factors influencing patient loyalty to dentist and dental practice. British Dental Journal, 183(11), 365-370.

Hom, J. M., Lee, J. Y., Divaris, K., Baker, A. D., \& Vann, W. F. (2012). Oral health literacy and knowledge among patients who are pregnant for the first time. Journal of the American Dental Association, 143, 972-980.

Horowitz, A., \& Kleinman, D. V. (2008). Oral Health Literacy: The New Impreative to Better Oral Health. Dental Clinics of North America, 52(2), 333-344.

Humphris, G., Clarke, H., \& Freeman, R. (2006). Does completing a dental anxiety questionnaire increase anxiety? A randomised controlled trial with adults in general dental practice. British Dental Journal, 201(1), 33-35.

Humphris, G., Freeman, R., Campbell, J., Tuuti, H., \& D’Souza, V . (2000). Further evidence for the reliability and validity of the Modified Dental Anxiety Scale. International Dental Journal, 50(6), 367-370.

Humphris, G. M., \& Hull, P. (2007). Do dental anxiety questionnaires raise anxiety in dentally anxious adult patients? A two-wave panel study. Primary Dental Care, 14(1), 7-11.

Humphris, G., Morrison, T., \& Lindsay, S. (1995). The Modified Dental Anxiety Scale: Validation and United Kingdom norms. Community Dental Health, 12(3), 143150.

Institute of Medicine. (2000). Healthy people 2010. Retrieved from http://www.cdc.gov/nchs/healthy_people/hp2000.htm

Institute of Medicine. (2002). Unequal treatment: Confronting racial and ethnic disparities in health care. Washington, DC: National Academy Press.

Iyengar, S. (2010). The art of choosing. New York, NY: Hachette Book Group.

Jaret, P. (2001). Ten ways to improve patient compliance: The doctor-patient relationship is key. Retrieved from

http://www.hippocrates.com/FebruaryMarch2001/02features/02feat_compliance.h tml

Jones, E. M., Knutson, D., \& Haines, D. (2003). Common problems in patients recovering from chemical dependency. American Family Physician, 68, 19711978.

Jones, Colwyn M., McCann, Mary, \& Nugent, Zoann. (2002). Scottish prisons' dental health survey. Retrieved from www.scotland.gov.uk/library5/health/spdhm-04.asp

Keenan, J. (2004). Health literacy: The challenges and opportunities. CorrectCare, 18(2), 3.

Kim, J., Prince, M., Kim, S., Yang, S., Shin, I., \& Yoon, J. (2007). Dental health, nutritional status and recent-onset dementia in a Korean community population. International Journal of Geriatric Psychiatry, 22, 850-855. 
Kneckt, M. (2000). Psychological features characterizing oral health behavior, diabetes self-care health status among IDDM patients. Oulu, Finland: Faculty of Medicine, University of Oulu.

Kneckt, M., Syrjaia, A., Laukkanen, P., \& Knuuttila, M. (1999). Self-efficacy as a common variable in oral health behavior and diabetes adherence. European Journal of Oral Science, 107, 89-96.

Kolb, D. A. (1984). Experiential learning: Experience as the source of learning and development. Englewood Cliffs, NJ: Prentice-Hall.

Kolb, D. A., Boyatzi, R. E., \& Mainemelis, C. (1999). Experiential learning theory: Previous research and new directions. Retrieved from www.d.umn.edu/ kgilbert/educ5165-731/Readings/experiential-learningtheory.pdf

Kronenfeld, J. J., \& Glik, D. C. (1991). Perceptions of risk: Its applicability in medical sociological research. Research in the Sociology of Health Care, 9, 307-334.

Lewis, C. (2006). Treating Incarcerated Women: Gender Matters. Psychiatric Clinics of North America, 29(3), 773-789.

Life Expectancy in the USA, 1900-98. (n.d.). Retrieved from Department of Demography, UC Berkeley website: http://demog.berkeley.edu/ andrew/1918/figure2.html

Lippman, H. (2000). Making group visits work. Retrieved from Hippocrates 14(7): http://www.hippocrates.com/archive/July2000/07features/07feat_GroupVisits.htm 1

Logan, H. L. (2011). A new paradigm for behavior change. Journal of Public Health Dentistry, 70(S), 34.

Maiman, L., \& Becker, M. (1974). The health belief model: Origins and correlates in psychological theory. Health Education Monographs, 2, 336-353.

Mann, J., Gruskin, S., Grodin, M., \& Annas, G. (eds.). (1999). Health and human rights reader. New York, NY: Routledge.

Martino, S. (2011). Oral health behavioral and social intervention research concepts and methods. Journal of Public Health Dentistry, 71(S), 2-6.

Masley, S., Sokoloff, J., \& Hawes, C. (2000). Planning group visits for high-risk patients. Retrieved from http://www .aafp.org/fpm/20000600/33plan.html

McCann, D. (1989). Phobia: conquering fear with trust. Journal of the American Dental Association, 119, 593-598.

Milne, D. B. (1989). Too much soda pop may take some fizz out of your bones. Retrieved from www.ars.usda.gov/News/docs.htm?docid=10884

Moisey, S. (1984). How “open” is open learning? Innovation in Higher Education, 9(1), $5-18$

Mokdad, A. H., Ford, E. S., Bowman, B. A., Dietz, W. H., Vinicor, F., Bales, V. S., et al. (2003). Prevalence of obesity, diabetes, and obesity-related health risk factors, 2001. Journal of the American Medical Association, 289(1), reprint.

Moore, R., \& Brodsgaard, I. (2001). Dentists' perceived stress and its relation to perceptions about anxiour patients. Community Dentistry and Oral Epidemiology, 29(1), 73-80. 
National Center for Education Statistics. (2003). The health literacy of America's adults: Results from the 2003 National Assessment of Adult Literacy. Retrieved from http://nces.ed.gov/NAAL/health.asp

National Center for Education Studies. (2012). Public high school graduation rates (Indicator 32-2012). Retrieved from nces.ed.gov/programs/coe/indicator_scr.asp

Newman, C., \& Bolton, L. (2003). Substance abuse and the dental patient . . . what's the connection? Dental Assisting, 72(1), 14-19.

Newton, J. T., \& Buck, D. J. (2000). Anxiety and pain measures in dentistry: A guide to their quality and application. Journal of the American Dental Association, 13, 1449-1457.

Newton, K., Asimakopoulou, B., Daly, B., Scambler, S., \& Scott, S. (2012). The management of dental anxiety: Time for a sense of proportion? British Dental Journal, 213, 271-274.

NHS Health Development Agency-UK. (1997). Effectiveness of oral health promotion: Health promotion effectiveness reviews summary bulletin. Retrieved from www.nice.org.uk/nicemedia/documents/effectivenessoralhealth.pdf

National Institute of Dental and Craniofacial Research. (2000). Oral health in America: A report of the surgeon general. Retrieved from http://www2.nidcr.nih.gov/sgr/sgrohweb/welcome.htm

National Institute of Dental and Craniofacial Research. (2009). Strategic plan 2009-2013 (U.S. Department of Health and Human Services National Institute of Health). Bethesda, MD: NIDCR.

NIDCR. (2011). National Institute of Dental and Craniofacial Research. Retrieved from www.nidcr.nih.gov/datastatistics/finddatabytopic

Noddings, N. (1984). Caring. Berkeley: University of California Press.

Noffsinger, E. (2001). Enhance satisfaction with drop-in group visits. Retrieved from Hippocrates 15(2) website: http://www.Hippocrates.com/FebruaryMarch2001/02features/02feat_digma.html

Office of Women's Health Research. (1999). Agenda for research on women'shHealth for the 21st century: A report of the task force on the NIH Women's Health Research Agenda for the 21 st Century. Bethesda, MD: National Institute of Health.

Office on Disability. (n.d.). Retrieved from U.S. Department of Health \& Human Services website: http://www.hhs.gov/od/about/fact_sheets/substanceabuse.html

Parks, S. D. (2005). Leadership can be taught. Boston, MA: Harvard Business School.

Patton, L., Strauss, R., McKaig, R., Porter, D., \& Eron, J. (2003). Perceived oral health status, unmet needs, and barriers to dental care among HIV/AIDS patients in a North Carolina cohort: Impacts of race. Journal of Public Health Dentistry, 63(2), 86-91.

Perry, William. (1968). Forms of intellectual and ethical development in the college year: A scheme. New York, NY: Reinhart and Winston.

Prochaska, J., Norcross, J., \& DiClemente, C. (1994). Changing for Good. New York, NY: HarperCollins. 
R Foundation. (1999). R: A language and environment for statistical computing. Vienna, Austria. Retrieved from http://www.R-project.org

Robertson, D. L. (1996). Facilitating transformative learning: Attending to the dynamics of the educational helping relationship. Adult Education Quarterly, 47(1), 41.

Robertson, D. L. (1988). Self-Directed growth. Muncie, IN: Accelerated Development.

Ronis, D. (1994). Updating a measure of dental anxiety: Reliability, validity, and norms. Journal of Dental Hygiene, 68, 228-233.

Rosenstock, I. M. (1974). The Health Belief Model and preventive health behavior. Health Education Monographs, 2, 354-386.

Sainsbury, D. (1999). Drug addiction and dental care. New Zealand Dental Journal, 95 (420), 58-61.

Seligman, M. (1992). Helplessness. New York, NY: Freeman.

Settineri, S., Tati, F., \& Fanara, G. (2005). Gender differences in dental anxiety: Is the chair position important? Journal of Contemporary Dental Practice, 6(1), 115122.

Sgan-Cohen, H., \& Mann, J. (2007). Health, oral health, and poverty. Journal of the American Dental Association, 138, 1437-1442.

Shimkus, J. (2004). One size does not fit all at Indiana Women's Prison. CorrectCare, $18(2), 8$.

Smith, J. (1989). The nature of social and educational inquiry: Empiricism versus interpretation. Norrwood, NJ: Ablex.

Stake, R. (1986). New directions in educational evaluation. (E. R. House, ed.) London, UK: Falmer.

Stalker, C. A., Russell, B. D., Teram, E., \& Schacter, C. L. (2005). Providing dental care to survivors of childhood sexual abuse: Treatment considerations for the practitioner. Journal of the American Dental Association, 136(9), 1277-1281.

Stockinger-Moore, V. (1997). Making the connection: The exceptional new patient interview. California Dental Association Journal, 25(4), 305-311.

Stone, T. (2002). Take care when using prisoners as research subjects. Retrieved from http://www.ncchc.org/pubs/CC/research.html

Tanner, L. (2012, March 11). Emergency room supplants dentist's chair. The Oregonian, p. A4.

Todd, J., \& Lader, D. (1991). Adult dental health 1988. London, UK: Her Majesty's Stationery Office.

Toepell, A. (2003). The health belief model and safer sex: Implications for women's health. Women's Health and Urban Life: An International and Interdisciplinary Journal, 2(1), 22-41.

Treadwell, H., \& Formicola, A. (2005). Improving the oral health of prisoners to improve overall health and well-being. American Journal of Public Health, 95, 16771678.

U.S. Department of Health and Human Services. (2000). Oral Health in America: A Report of the Surgeon General. Rockville, MD: National Institutes of Health.

Von Fraunhofer, J., \& Rogers, M. (2004). Dissolution of dental enamel in soft drinks. General Dentistry, 309-312. 
Walker, E., Milgrom, P., Weinstein, P., Getz, T., \& Richardson, R. (1996). Assessing abuse and neglect and dental fear in women. Journal of the American Dental Association, 127, 485-490.

Wallston, B. S., Wallston, K. A., Kaplan, G. D., \& Maides, S. A. (1976). Development and validation of the health locus of control (HLC) scale. Journal of the Consulting Clinical Physchologist, 44, 580-585.

Wayne, B., Trajtenberg, C., \& Hyman, D. (2001). Tooth and periodontal disease: A review for the primary care physician. Southern Medical Journal, 94, 925-932.

Weiss, B. D., Mays, M. Z., Martz, W., Castro, K. M., DeWalt, D. A., Pignone, M. P., et al. (2004). Quick assessment of literacy in primary care: The newest vital sign. Annals of Family Medicine, 3, 544-422.

Wheatley, M. (1992). Leadership and the new science: Learning about organization from an orderly universe. San Francisco, CA: Berrett-Koehler.

Wiggins, N. (2010). La palabra es salud: A comparitive study of the effectiveness of popular education vs. traditional education for enhancing health knowledge and skills and increasing empowerment among paris-based community health workers $(\mathrm{CHWs})$. Portland, OR: Portland State University.

Windschitl, M. (1999). The challenges of sustaining a constructivist classroom culture. Phi Delta Kappan, 751-755.

Wolfe, G. R., Stewart, J. E., \& Hartz, G. W. (1991). Relationship of dental coping beliefs and oral hygiene. Community Dentistry and Oral Epidemiology, 19(2), 112-115.

Zlotnick, C. (1997). Posttraumatic stress disorder (PTSD), PTSD comorbitity, and childhood abuse among incarcerated women. Journal of Nervous and Mental Disease, 185, 761-763.

Zull, J. E. (2002). The art of changing the brain: Enriching the practice of teaching by exploring the biology of learning. Sterling, VA: Stylus. 


\section{Appendix A: Modified Dental Anxiety Scale (MDAS)}

Please indicate by inserting " $\mathrm{x}$ " in the appropriate box

1. If you went to your dentist for treatment tomorrow, how would you feel?
Not Anxious
Slightly Anxious
$\square$ Fairly Anxious
$\square$ Very Anxious
$\square$ Extremely Anxious

2. If you were sitting in the waiting room (waiting for treatment), how would you feel?
$\square$ Not Anxious
Slightly Anxious
$\square$ Fairly Anxious
$\square$ Very Anxious
$\square$ Extremely Anxious

3. If you were about to have a tooth drilled, how would you feel?

$\square$ Not Anxious

Slightly Anxious

$\square$ Fairly Anxious

$\square$ Very Anxious

$\square$ Extremely Anxious

4. If you were about to have your teeth scaled and polished, how would you feel?
$\square$ Not Anxious
Slightly Anxious
$\square$ Fairly Anxious
$\square$ Very Anxious
$\square$ Extremely Anxious

5. If you were about to have a local anesthetic injection in your gum, above an upper back tooth, how would you feel?
Not Anxious
Slightly Anxious
$\square$ Fairly Anxious
Very Anxious
$\square$ Extremely Anxious

Scoring the MDAS [this information is not printed on the form that patients see]

$\mathrm{a}=1, \mathrm{~b}=2, \mathrm{c}=3, \mathrm{~d}=4, \mathrm{e}=5 \quad$ Total possible $=25$

Anxiety rating:

- $12-15=$ moderate anxiety but have specific stressors that should be discussed and managed

- $16-18=$ high anxiety

- $19-25$ = severe anxiety (phobia). Might be manageable with the Dental Concerns Assessment but might require the help of a mental health therapist. 
Appendix B: Rustvold Oral Health Knowledge Inventory

\section{Sugar contributes to tooth decay because?}

a) Sugar directly harms tooth enamel

b) Sugar combines with proteins in saliva to create a hard layer on teeth.

c) Sugar is changed by bacteria into acid that harms tooth surfaces

\section{What is plaque?}

a) the protective coat that naturally occurs on teeth

b) a harmless substance that can be removed completely with brushing

c) a germ-containing substance that collects on the surface of teeth

d) a whitening substance that makes your teeth shine

\section{Does fluoride in toothpaste make any difference to the health of your teeth?}

a) No, it makes no difference at all, and fluoride is now being phased out because it isn't safe

b) Fluoride in toothpaste has hugely improved oral health by decreasing cavities

c) It isn't dangerous, but toothpaste without fluoride is just as effective at preventing cavities.

d) Nobody really knows because there haven't been many studies in the area

\section{What is the truth about flossing?}

a) flossing is bad for your teeth

b) it is OK to floss, but you should stop immediately if your gums start bleeding

c) flossing is fine if it makes your mouth feel fresher but it doesn't improve the health of your mouth

d) regular flossing is an important part of your dental health routine and you shouldn't worry if your gums bleed a bit at first

\section{What is gingivitis?}

a) poor support of the bone that supports the teeth

b) a condition where the teeth stain

c) inflammation of the gums that involves swelling and bleeding

d) the name given to germs that inhabit the mouth

e) a name made up by advertising agencies to scare consumers into buying their products

f) another name for having several cavities at the same time 
Appendix B: Rustvold Oral Health Knowledge Inventory, continued

\section{If you do want to enjoy a sugary treat, when is the most "tooth-friendly" time to eat it?}
a) first thing in the morning or last thing at night
b) along with a meal
c) as a snack on its own
d) it doesn't make any difference

\section{What is the goal when we brush our teeth?}

a) To remove germs (bacteria) from all tooth surfaces

b) To remove food from tooth surfaces

c) neither a nor b (some other reason than to remove germs or food)

d) both a and $b$ (to remove germs, to remove food)

\section{Research studies have shown a link between periodontal (gum) disease and which of the following?}
a) Low Birth Weight Babies (premature babies)
b) Diabetes
c) Heart Disease and Stroke
d) none of the above
e) a, b, and c

\section{What are the two most important dental health habits?}

a) Brushing twice daily and rinsing with mouthwash after each brushing

b) Brushing after every meal and using a water-pick device daily

c) Brushing twice daily and flossing once a day

d) Flossing every day and rinsing with mouthwash after each flossing

10. Which of the following statements is/are true about smoking cigarettes?

a) Half of all cases of periodontal disease (destructive disease of the bone and gums that support the teeth) are due to cigarette smoking.

b) Three-fourths of all cancers of the mouth are due to tobacco smoking.

c) Smoking can cause lung cancer, but doesn't harm the mouth.

d) both a and b: $1 / 2$ of periodontal disease cases; $3 / 4$ of all cancers of the mouth 


\section{Appendix C: Oral Health Attitudes Questionnaire}

1. I believe that only the dentist can prevent cavities.

$\square$ I agree completely $\square$ I agree partly $\square$ I disagree partly $\square$ I disagree completely

2. I believe that if my parents have bad teeth, brushing and flossing will not help my teeth.

$\square$ I agree completely $\square$ I agree partly $\square$ I disagree partly $\quad \square$ I disagree completely

3. I believe that by brushing and flossing my teeth I am less susceptible to tooth decay.

$\square$ I agree completely $\square$ I agree partly $\square$ I disagree partly $\quad \square$ I disagree completely

4. I believe that tooth loss is a normal part of growing old.

$\square$ I agree completely $\quad \square$ I agree partly $\quad \square$ I disagree partly $\quad \square$ I disagree completely

5. I am likely to have gingivitis or gum disease in the next year or two.

$\square$ I agree completely $\square$ I agree partly $\square$ I disagree partly $\quad \square$ I disagree completely

6. I believe that I am responsible for preventing the loss of my teeth.

$\square$ I agree completely $\square$ I agree partly $\square$ I disagree partly $\square$ I disagree completely

7. I believe that by flossing my teeth I can prevent gingivitis.

$\square$ I agree completely $\square$ I agree partly $\square$ I disagree partly $\quad \square$ I disagree completely

8. I believe dentures are less trouble than taking care of my natural teeth.

$\square$ I agree completely $\quad \square$ I agree partly $\quad \square$ I disagree partly $\quad \square$ I disagree completely

9. I believe I know how to brush my teeth correctly

$\square$ I agree completely $\quad \square$ I agree partly $\quad \boldsymbol{I}_{\text {I disagree partly }} \quad \boldsymbol{\square}$ I disagree completely

10. If my gums bleed when I floss this usually means that I am hurting my gums and I should stop flossing my teeth

$\square$ I agree completely $\quad \square$ I agree partly $\quad \square$ I disagree partly $\quad \square$ I disagree completely

11. If I knew the facts a out dental health I could help prevent the loss of my teeth

$\square$ I agree completely $\square$ I agree partly $\square$ I disagree partly $\quad \square$ I disagree completely

12. I believe visiting the dentist is only necessary when I am experiencing pain

$\square$ I agree completely $\square$ I agree partly $\quad \square$ I disagree partly $\quad \square$ I disagree completely

13. I am likely to have tooth decay in the next year or two.

$\square$ I agree completely $\quad \square$ I agree partly $\square$ I disagree partly $\quad \square$ I disagree completely 


\section{Appendix C: Oral Health Attitudes Questionnaire, continued}

14. If my gums bleed when I brush this usually means that I am brushing too hard and I should stop brushing my teeth

$\square$ I agree completely $\square$ I agree partly $\square$ I disagree partly $\quad \square$ I disagree completely

15. How often do you brush your teeth?

$\square$ more than twice a day

$\square$ twice a day

$\square$ once a day

2-3 times a week

$\square$ less frequently

16. How often do you clean your between your teeth (by dental floss, tooth pick or interdental brush)?

$\square$ once a day or more
$\square$ 2-3 times a week
$\square$ once a week
$\square$ less frequently
$\square$ never

17. How often do you visit a dentist?

$\square$ more than once a year

$\square$ once a year

$\square$ every two years

$\square$ every three years

$\square$ less frequently

$\square$ Never

18. I plan to visit the dentist

$\square$ when I have a toothache

$\square$ when I have dental insurance

$\square$ to have a routine exam within the next year

$\square$ to have my teeth cleaned within the next year

$\square$ I don't know when

19. Do you smoke cigarettes or use another form of tobacco? $\square$ Yes $\quad \square$ No

20 . Have you ever used alcohol or other drugs to calm you to help you go to a dental appointment?

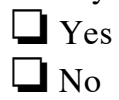

21. [Posttest only] Much learning occurs outside the classroom. Please indicate which statement best fits your experience:

I attended the dental health class and have talked with other women about what we learned.

$\square$ I attended the dental health class and have NOT talked with other women about what we learned. 
Appendix D: Oral Health Learning Session Module
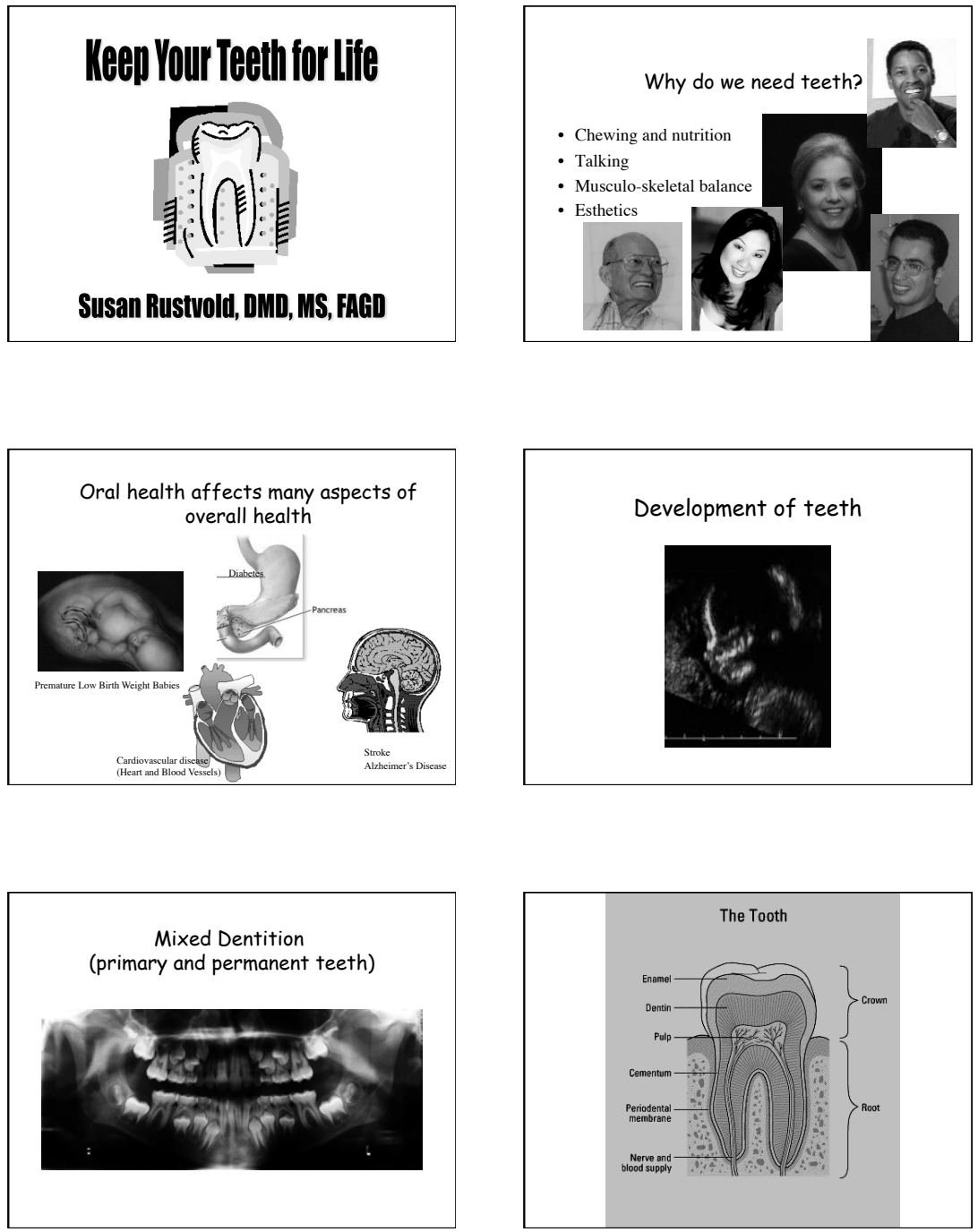
ORAL HEALTH KNOWLEDGE, ATTITUDES, BEHAVIORS

Appendix D: Oral Health Learning Session Module, continued
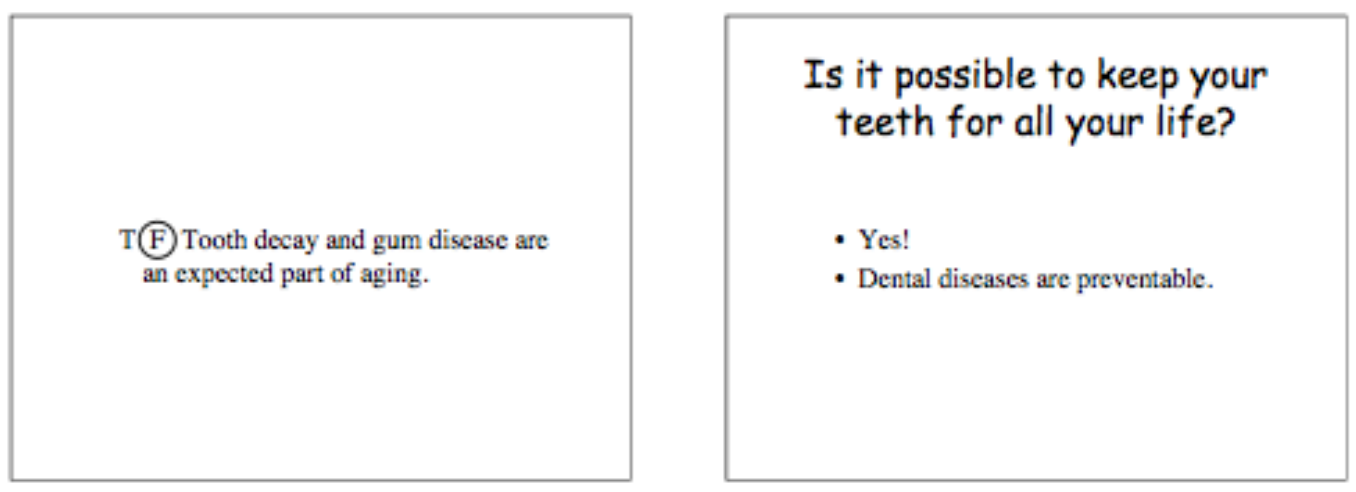

How can teeth be damaged or lost?

- Diseases: Decay and Gum disease

- Trauma

- Abrasion: friction, wearing

- Erosion: acid dissolving
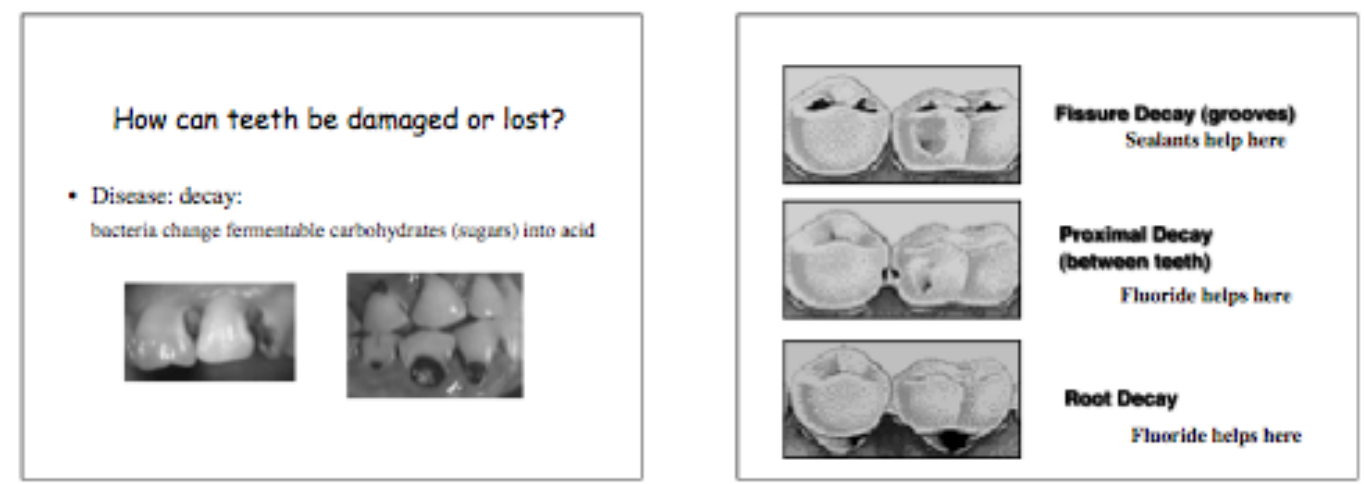
ORAL HEALTH KNOWLEDGE, ATTITUDES, BEHAVIORS

Appendix D: Oral Health Learning Session Module, continued
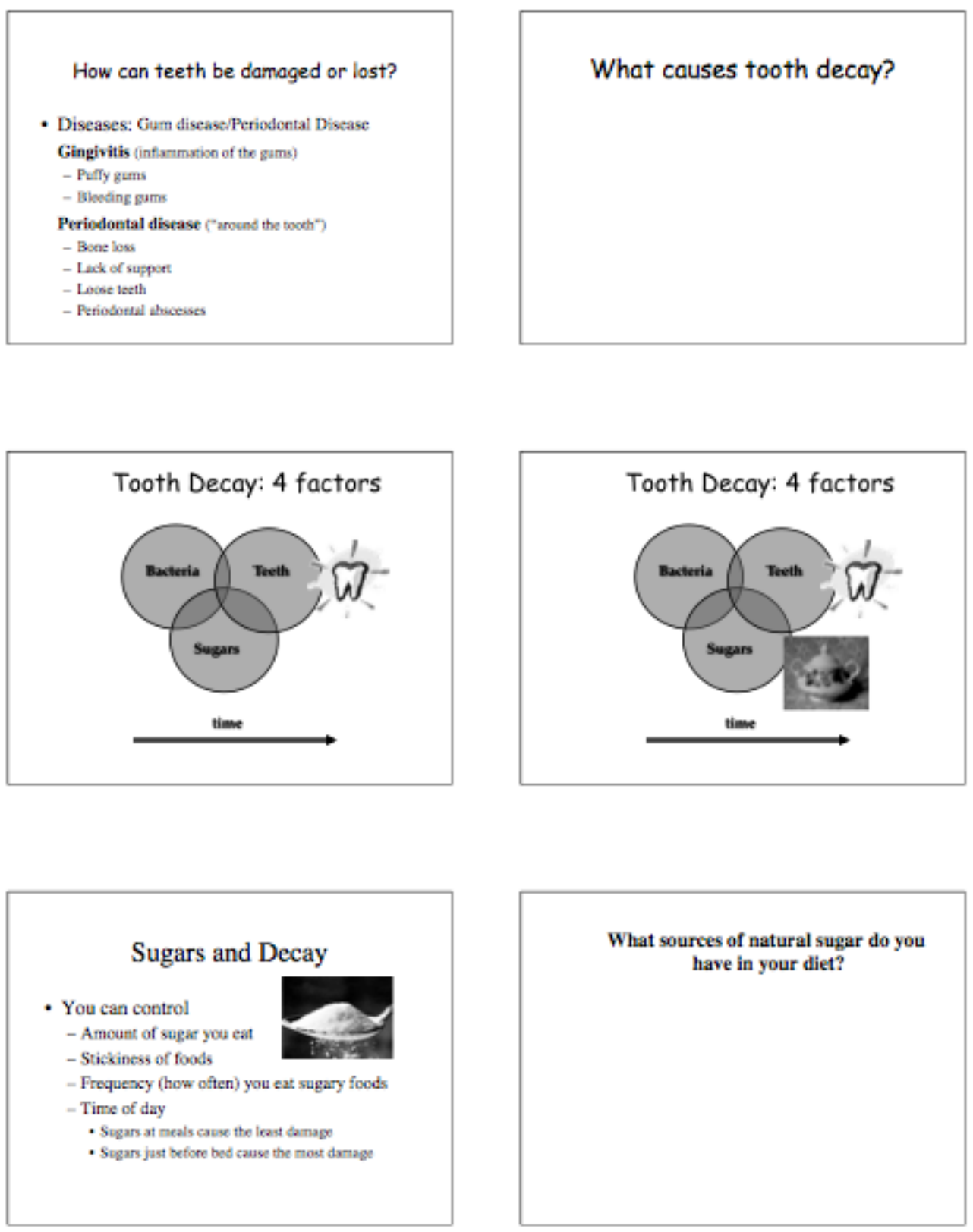
ORAL HEALTH KNOWLEDGE, ATTITUDES, BEHAVIORS

Appendix D: Oral Health Learning Session Module, continued
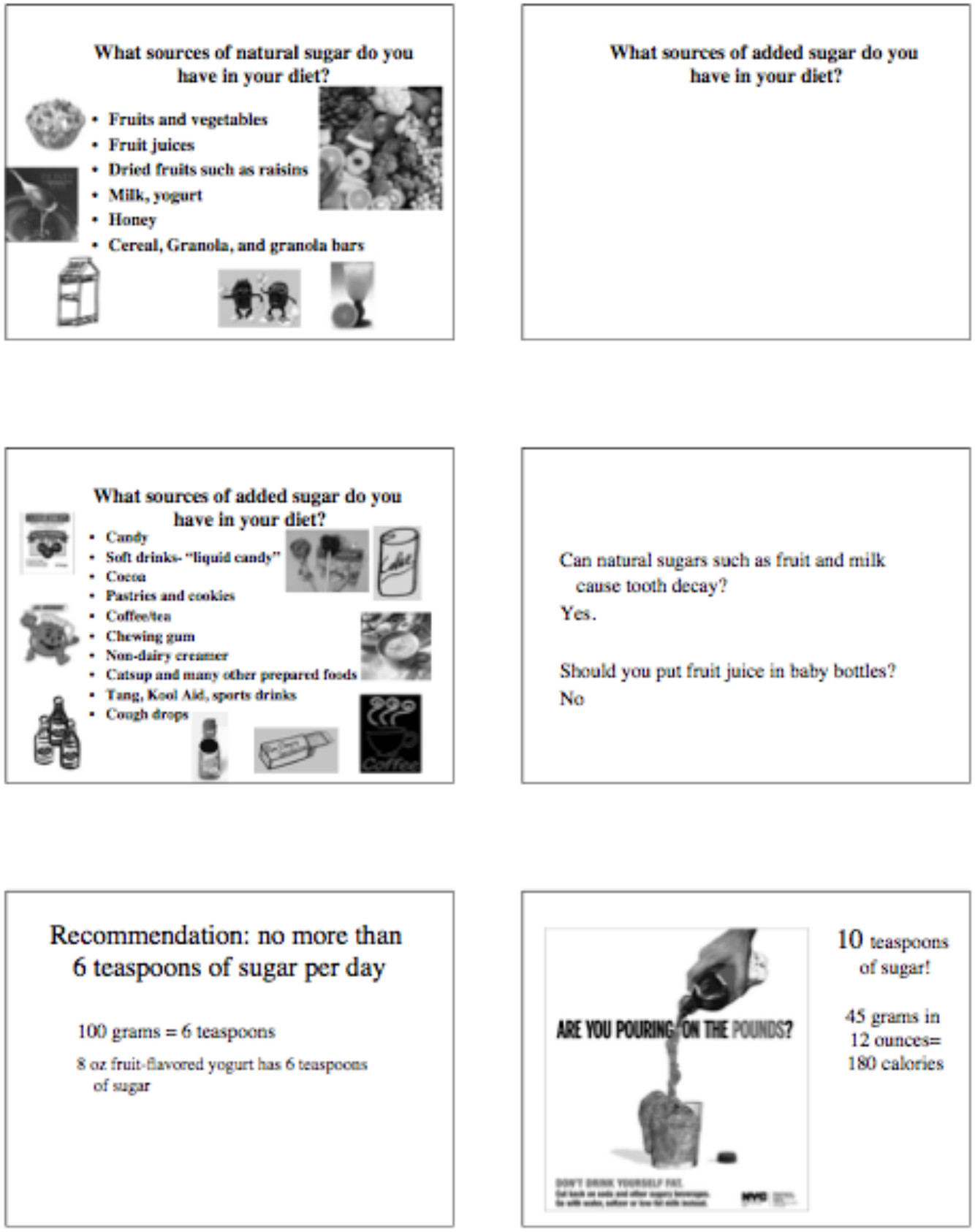
ORAL HEALTH KNOWLEDGE, ATTITUDES, BEHAVIORS

Appendix D: Oral Health Learning Session Module, continued
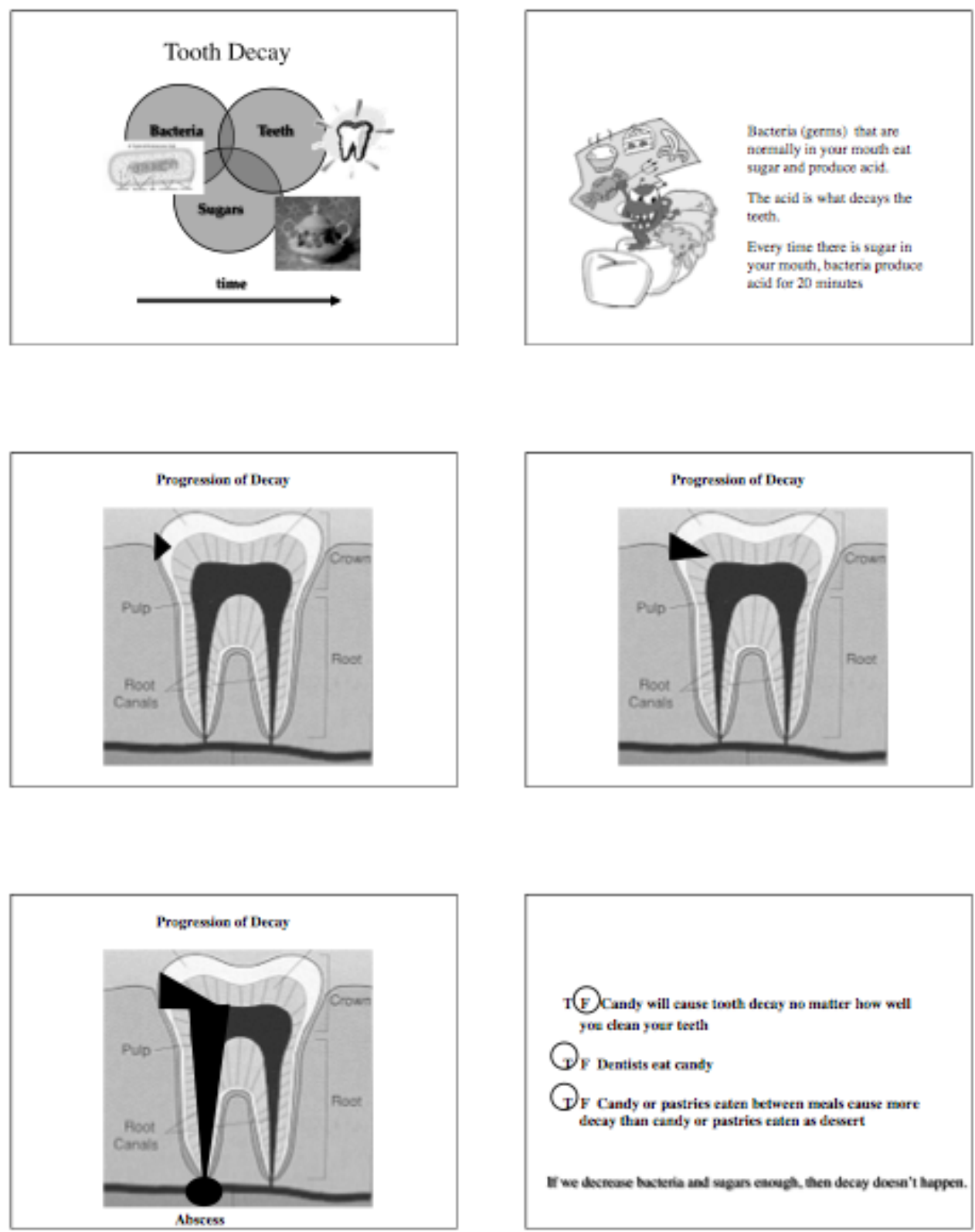
ORAL HEALTH KNOWLEDGE, ATTITUDES, BEHAVIORS

Appendix D: Oral Health Learning Session Module, continued
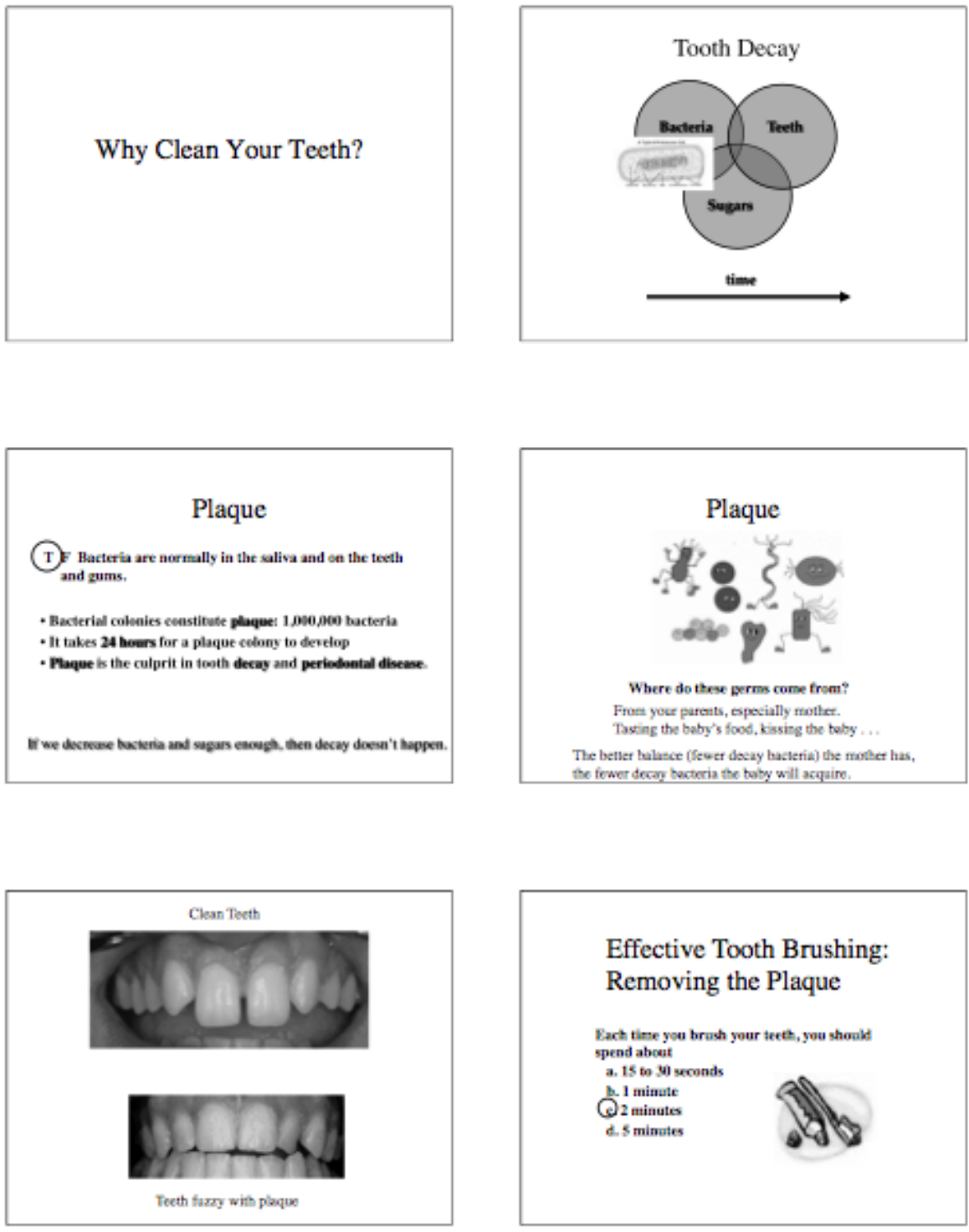
ORAL HEALTH KNOWLEDGE, ATTITUDES, BEHAVIORS

Appendix D: Oral Health Learning Session Module, continued
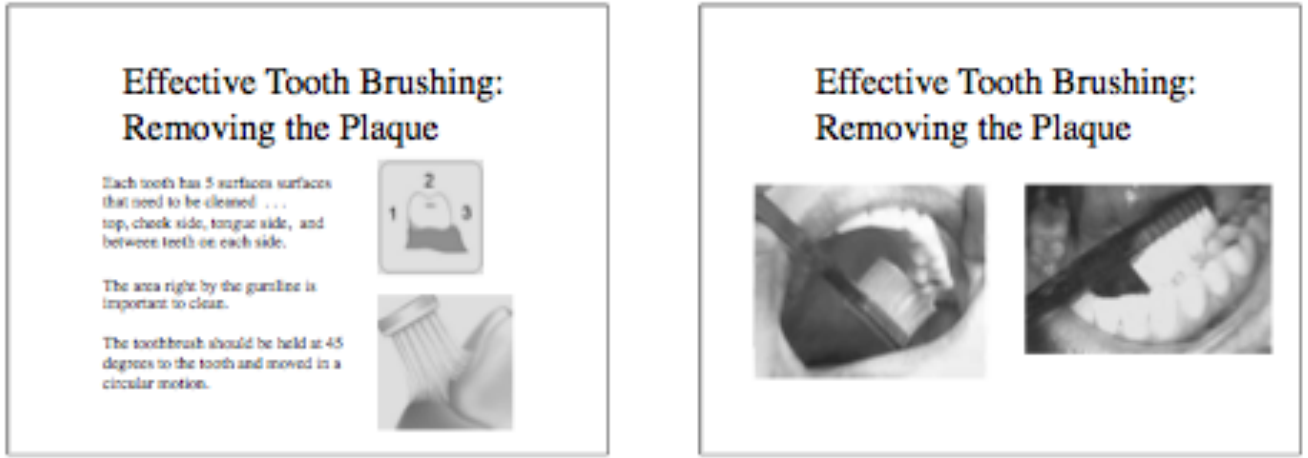

Effective Tooth Brushing:

Removing the Plaque
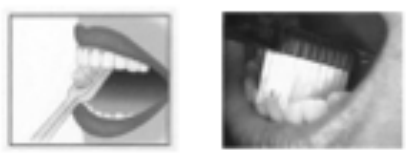

Tengue side of from teeth: use the trush vertically (up and dows) tallet than sideways.

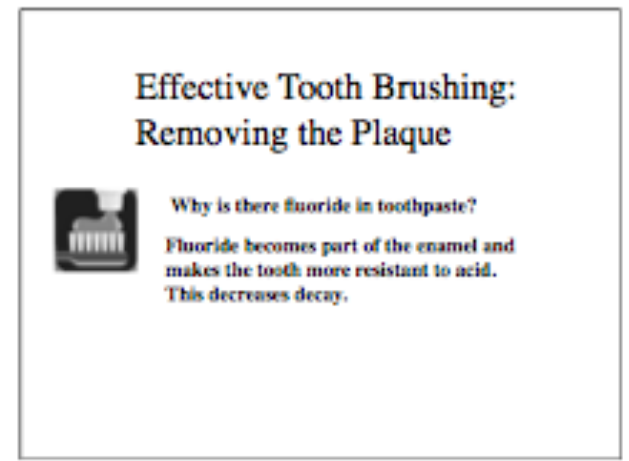

Your Baby's Teeth

How old should your baby be when you start brabhing her teeth?

As soon as there are teeth.

You can use a wablebet or finger bresh

What aze should the first dental

appointment be?

One year

Xylitol chewing gum and mints

- Xylitol is a natural healthy sweetener found in birch trees, com, strawberries, plums, and the human body, since we generate a few grams of xylitol daily during normal metabolism.

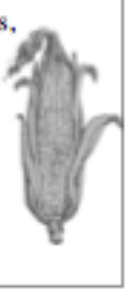


ORAL HEALTH KNOWLEDGE, ATTITUDES, BEHAVIORS

Appendix D: Oral Health Learning Session Module, continued

\section{Xylitol chewing gum and mints}

- Xylitol reduces the numbers of placue bacteria

- Xylitol prevents bacteria from sticking to teeth

- Xylitol is not fermented by bacteria and does not form acid that decays teeth
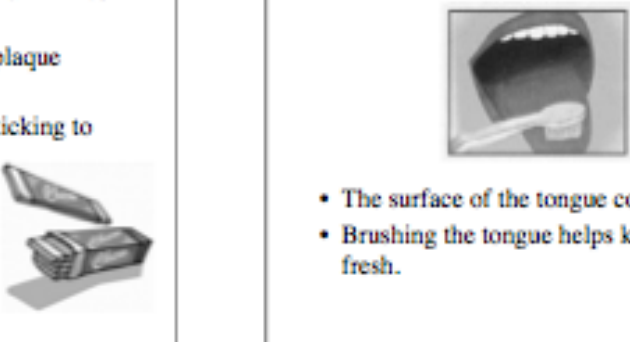

- The sufface of the tongue collects bacteria.

- Brushing the tongue helps keep the breath fresh.
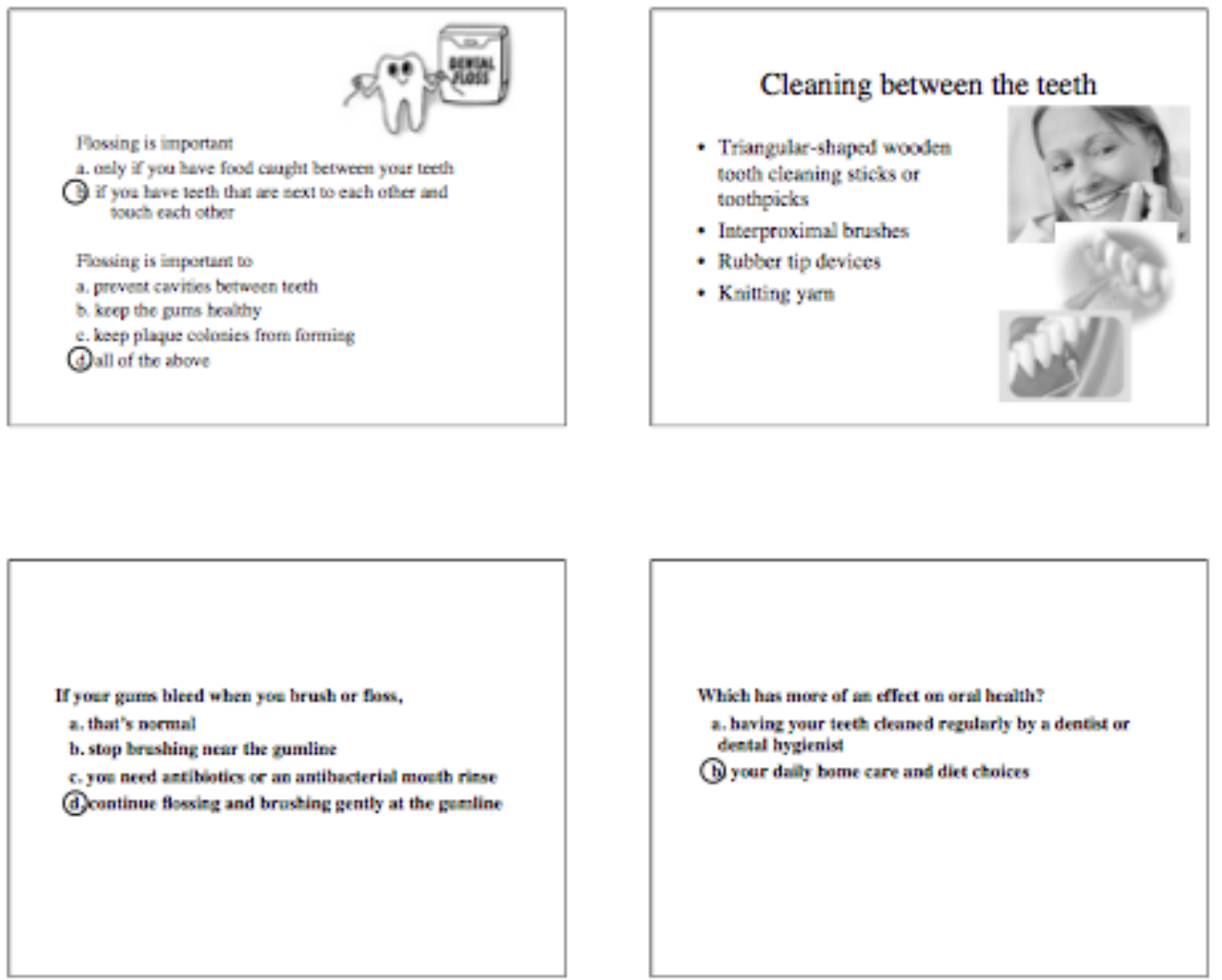
ORAL HEALTH KNOWLEDGE, ATTITUDES, BEHAVIORS

Appendix D: Oral Health Learning Session Module, continued
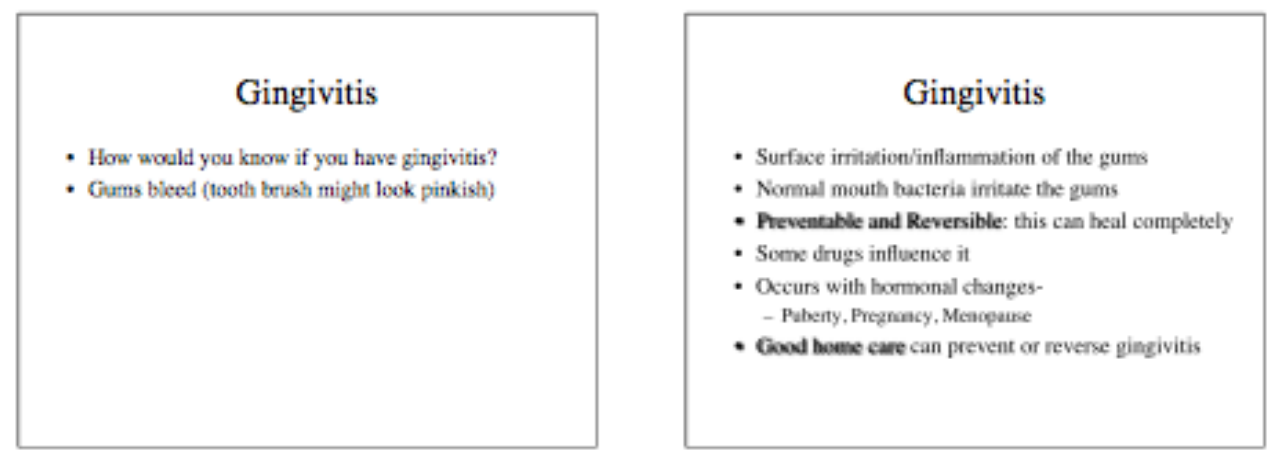

Hormones affect health of gums
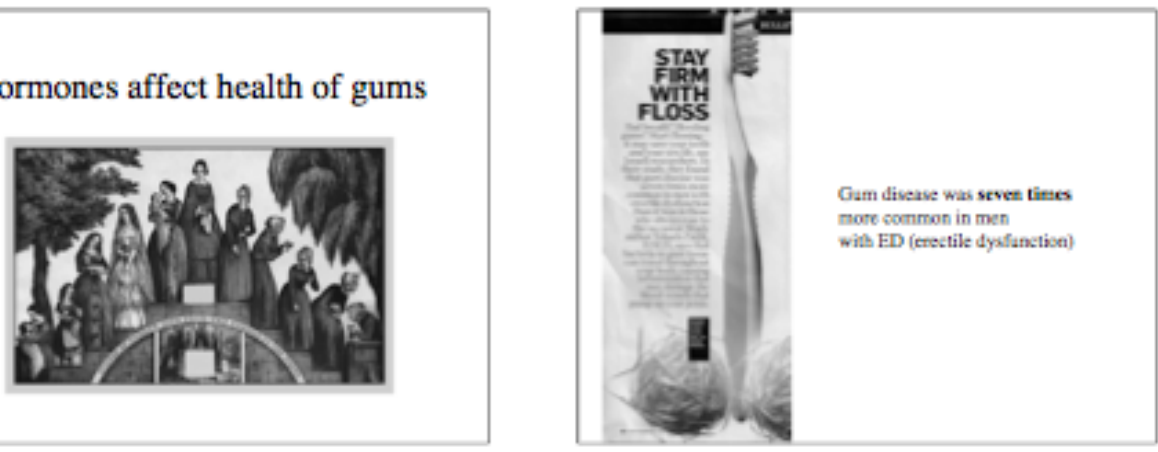

\section{Periodontal Disease}

- More serious than gingivitis: involves gums and the bone support

- Preventable bet not reversible: when bone is lost, it doesn't grow back

- Normal mouth bacteria irritate the gums

- Both the bacteria themselves and the body's response to them damage the bone

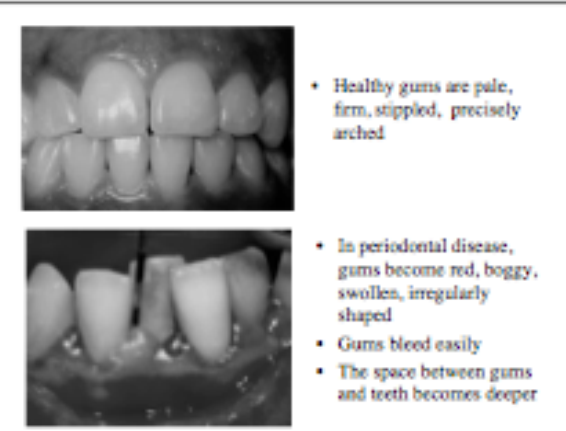


ORAL HEALTH KNOWLEDGE, ATTITUDES, BEHAVIORS

Appendix D: Oral Health Learning Session Module, continued

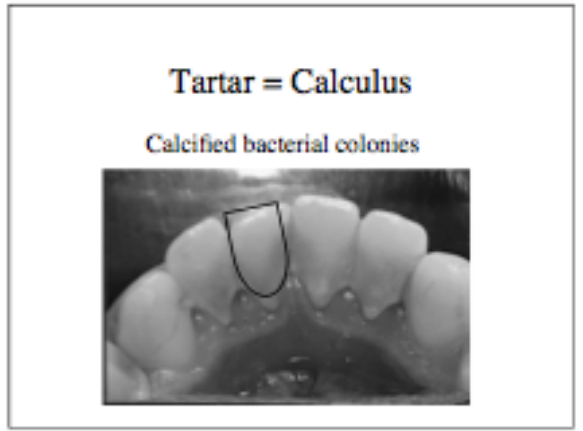

\section{Medicines and Oral Health}

- Saliva is necessary to:

- Dilute the acid that the germs make

- Provide cakium to re-mineralize the teeth

- Keep the gums and mucosa healthy

- Many prescription medicines change the saliva: it becomes thicker, there's less of it

- High blood pressure medications

- Antidepressiens.

What do you think?

How do methamphetamine and heroin and other drugs hurt your mouth?

\section{Drugs and Oral Health}

- Methamphetamine and coeaine and heroin and other drugs change the saliva: is becomes thicker. there's less of it

- People using drugs ofien neglect tooth brushing and flossing

- People using dnaes often don't reach for water

when their mouth is dry

- Seft drinks, ebocolate milk

- Cheving gams with sagar

- Drugs cause clenching and grinding of teeth

- Teeth become deeayed and braken.

What do you think?

How do cigarettes or othet forms of tobacco hurt your mouth?

Drugs and Oral Health

Tobaceo

- Periodontal disease

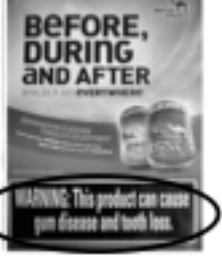


ORAL HEALTH KNOWLEDGE, ATTITUDES, BEHAVIORS

Appendix D: Oral Health Learning Session Module, continued
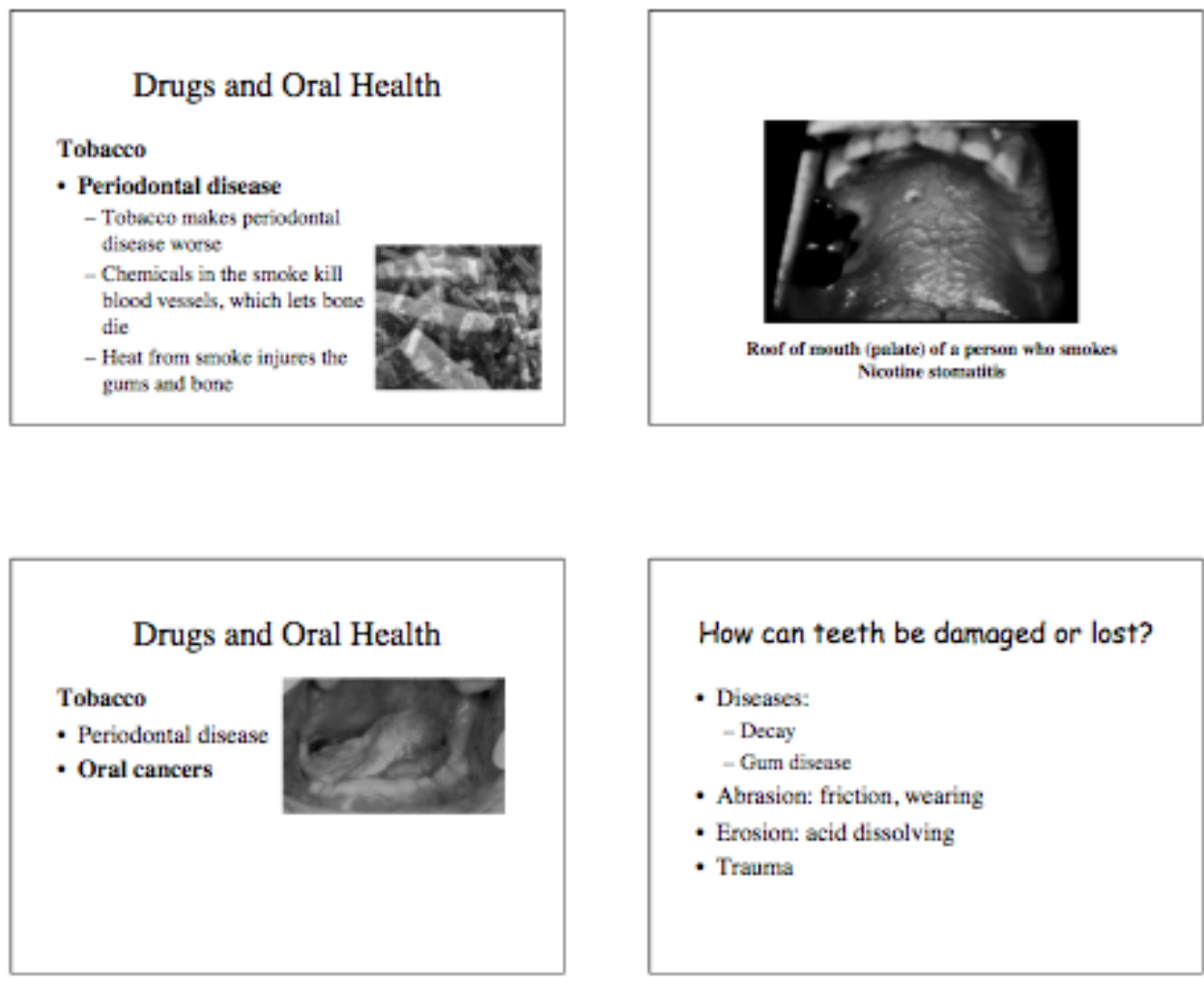

How can teeth be damaged or lost?

- Diseases:

- Decay

- Gum disease

- Abrasion: friction, wearing

- Erosion: acid dissolving

- Trauma

How can teeth be damaged or lost?

Eresion: acidic chemical processes

- Dietary:

- Lemons

- Seet drinks

Seet drinks

- Stumach acid

- Gastric reflus

- Bulimia
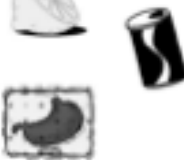

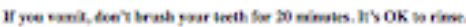

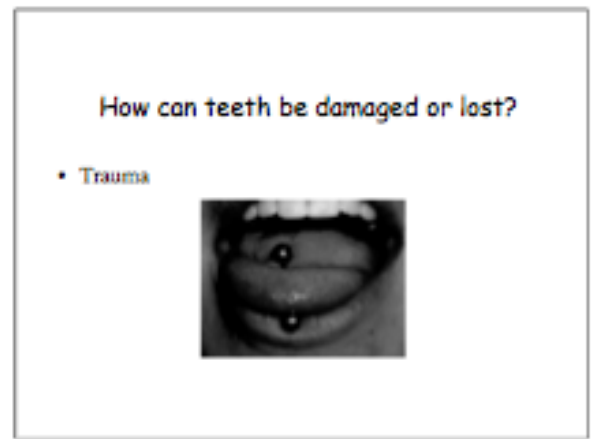


ORAL HEALTH KNOWLEDGE, ATTITUDES, BEHAVIORS

Appendix D: Oral Health Learning Session Module, continued
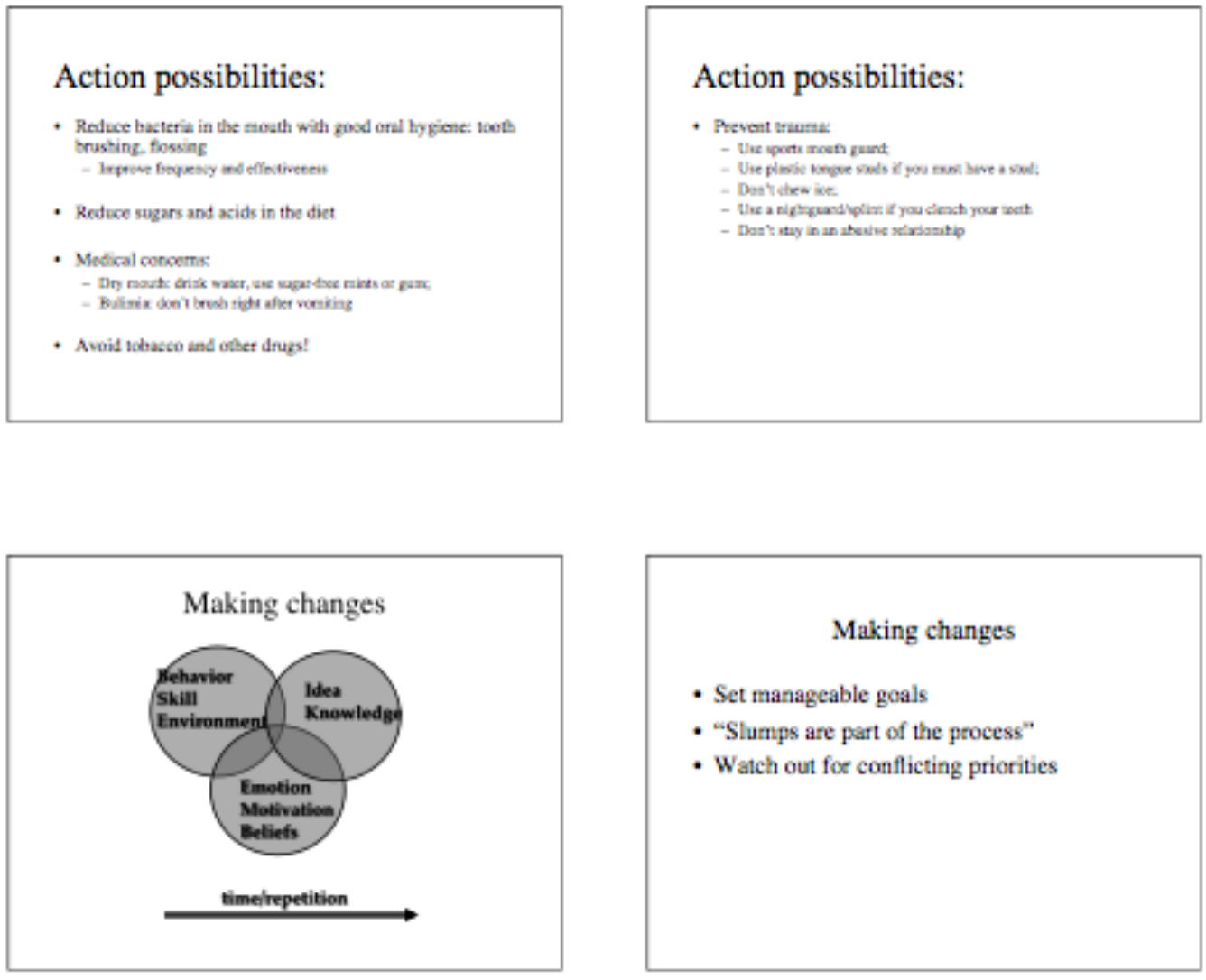

- What, if anything, did you learn here that you plan to do differently?

- If there's more than one strategy you plan to use, which one will you start with?

\section{Thanks for your participation!}

- Slides I've removed follow 
Appendix E: Informed Consent Form—Dental Anxiety and Oral Health Knowledge

You are invited to be part of a research study conducted by Susan Rustvold, a dentist, from the Graduate School of Education, Portland State University. Dr. Rustvold hopes to learn whether the dental health class is an effective way to help people learn about the health of the mouth.

All clients of the *** treatment center will attend a one-hour dental health class on how to best take care of your teeth and gums. Everyone who attends the class will answer some written questions about dental health.

If you decide to be part of the study, your responses to the questionnaires will be included in the study. If you choose not to participate, then your answers will not be counted. You will not be paid for participating in the study, but the study may help to create better programs for you and other clients in the future. While attendance at the class is required, the research I am inviting you to participate in is voluntary.

Any information that is obtained in connection with this study and that can be linked to you or identify you will be kept confidential. Your name will not be on the questionnaires. A random number will represent you instead of your name on the pages so your answers can be counted without identifying you. If you are part of the study the overall results of the group might be used in a published article, but they will not have your name or any identifying characteristics attached to them. No one will be able to tell that you were in the study. Your answers to the questionnaires will be kept in a locked file in Dr Rustvold's office or on a locked computer file in her computer during the study and for three years afterwards. Nobody will have access to your answers except Dr Rustvold and other people working on this study (for example, Dr Rustvold's advisor at Portland State University).

You do not have to participate in this study, and if you choose not to participate it will not affect your participation in the health learning session. You may also withdraw from this study at any time, even if you agree now to be in it, without affecting your progress in the $* * *$ program.

If you have concerns or problems about your participation in this study or your rights as a research subject, please contact the Office of Research and Sponsored Projects, Market Center Building, $6^{\text {th }}$ floor, $1600 \mathrm{SW} 4^{\text {th }}$ Avenue, Portland Oregon, 97201. If you have questions about the study itself, contact me through $* * *$ of your treatment center. 


\section{Appendix E: Informed Consent Form—Dental Anxiety and Oral Health Knowledge, continued}

Your signature indicates that you have read and understand the above information and agree or decline to take part in this study.

Please understand that you may withdraw your consent at any time without penalty, and that, by signing, you are not waiving any legal claims, rights, or remedies. You can keep an extra copy of this form for your own records.

I want to participate in the study.

Signature

Date

Printed name 